\title{
Effect of vitamin E on glutathione-dependent enzymes
}

Citation for published version (APA):

van Haaften, R. I. M. (2003). Effect of vitamin E on glutathione-dependent enzymes. [Doctoral Thesis, Maastricht University]. Datawyse / Universitaire Pers Maastricht. https://doi.org/10.26481/dis.20030625rh

Document status and date:

Published: 01/01/2003

DOI:

10.26481/dis.20030625rh

Document Version:

Publisher's PDF, also known as Version of record

\section{Please check the document version of this publication:}

- A submitted manuscript is the version of the article upon submission and before peer-review. There can be important differences between the submitted version and the official published version of record.

People interested in the research are advised to contact the author for the final version of the publication, or visit the DOI to the publisher's website.

- The final author version and the galley proof are versions of the publication after peer review.

- The final published version features the final layout of the paper including the volume, issue and page numbers.

Link to publication

\footnotetext{
General rights rights.

- You may freely distribute the URL identifying the publication in the public portal. please follow below link for the End User Agreement:

www.umlib.nl/taverne-license

Take down policy

If you believe that this document breaches copyright please contact us at:

repository@maastrichtuniversity.nl

providing details and we will investigate your claim.
}

Copyright and moral rights for the publications made accessible in the public portal are retained by the authors and/or other copyright owners and it is a condition of accessing publications that users recognise and abide by the legal requirements associated with these

- Users may download and print one copy of any publication from the public portal for the purpose of private study or research.

- You may not further distribute the material or use it for any profit-making activity or commercial gain

If the publication is distributed under the terms of Article $25 \mathrm{fa}$ of the Dutch Copyright Act, indicated by the "Taverne" license above, 
Effect of vitamin $E$ on glutathione-dependent enzymes 
Rachel I.M. van Haaften, Maastricht 2003

ISBN 90-5278-379-9

Production: Datawyse | Universitaire Pers Maastricht Lay-out: Harriet Kierkels

The study presented in this thesis was performed at the Nutrition and Toxicology Research Institute Maastricht (NUTRIM) which participates in the Graduate School VLAG (Food Technology, Agrobiotechnology, Nutrition and Health Sciences), accredited by the Royal Netherlands Academy of Arts and Sciences.

\section{atifin}

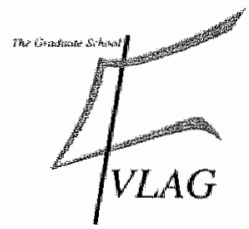

Financial support for printing of this thesis has kindly been provided by DSM Research, Technomed Europe and the Dr. Ir. Van de Laar Stichting. 


\title{
Effect of vitamin $E$ on glutathione-dependent enzymes
}

\author{
PROEFSCHRIFT \\ ter verkrijging van de graad van doctor \\ aan de Universiteit Maastricht, \\ op gezag van de Rector Magnificus, \\ Prof. dr. A.C. Nieuwenhuijzen Kruseman, \\ volgens het besluit van het College van Decanen, \\ in het openbaar te verdedigen op \\ woensdlag 25 juni 2003 om 16.00 uur \\ door \\ Rachel I.M. van Haaften \\ Geboren op 10 augustus 1976 te Geleen
}

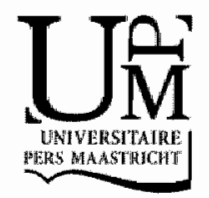




\section{Promotor:}

Prof. dr. A. Bast

\section{Co-promotores:}

Dr. Ir. C.T.A. Evelo

Dr. G.R.M.M. Haenen

\section{Beoordelingscommissie:}

Prof. dr. F.J. van Schooten (voorzitter)

Prof. dr. T.W.A. de Bruin

Prof. dr. M.P. van Dieijen -Visser

Prof. dr. D.C.M. Leysen

Prof. dr. G.J. Mulder (Universiteit Leiden) 
Voor pap, mam en Marc 


\section{Contents}




\section{Contents}

Abbreviations

Chapter 1

General Introduction and outline of the thesis

\section{Chapter 2}

Effect of vitamin $\mathrm{E}$ on glutathione-dependent enzymes

\section{Chapter 3}

No reduction of $\alpha$-tocopherol quinone by glutathione in rat liver microsomes

\section{Chapter 4}

$\alpha$-Tocopherol inhibits human glutathione S-transferase P1-1

\section{Chapter 5}

Inhibition of human glutathione S-transferase P1-1

by tocopherols and $\alpha$-tocopherol derivates

\section{Chapter 6}

Tocotrienols inhibit human glutathione S-transferase P1-1

\section{Chapter 7}

Inhibition of various glutathione S-transferase isoenzymes

by RRR-a-tocoplierol.

\section{Chapter 8}

Hypochlorous acid is a potent inhibitor of GST P1-1

\section{Chapter 9}

Summary and General discussion

Samenvatting

Dankwoord 


\section{Abbreviations}




\section{Abbreviations}

\begin{tabular}{|c|c|}
\hline$\alpha-\Pi P$ & $\alpha$-tocopherol transfer protein \\
\hline${ }^{10}$ & singlet oxygen \\
\hline AP1 & activator protein 1 \\
\hline$A p o B$ & apolipoprotein B \\
\hline ARE & antioxidant response element \\
\hline AVED & ataxia with vitamin $\mathbf{E}$ deficiency \\
\hline CONB & 1-chloro-2,4-dinitrobenzene \\
\hline CEHC & carboxyethyl hydroxychroman \\
\hline CGST & cytosolic glutathione S-transferase \\
\hline CYP & cytochrome $\mathrm{P} 450$ \\
\hline CYP-450 & cytochrome $\mathrm{P} 450$ \\
\hline Cys & cysteine \\
\hline FIVE & familial isolated vitamin $\mathrm{E}$ \\
\hline FRR & free radical reductase \\
\hline $\mathrm{GCS}$ & glutamylcysteine synthetase \\
\hline GGT & gamma-glutamyl transpeptidase \\
\hline Glu & glutamic acid \\
\hline Gly & glycine \\
\hline GPX & glutathione peroxidase \\
\hline GRD & glutathione reductase \\
\hline GS* & thiyl radical \\
\hline GSH & reduced glutathione \\
\hline G-site & glutathione binding site \\
\hline 6556 & oxidised glutathione \\
\hline $65 T$ & glutathione S-transferase \\
\hline $\mathrm{H}_{2} \mathrm{O}_{2}$ & hydrogen peroxide \\
\hline HDL & high-density lipoprotein \\
\hline$H M G-C O A$ & 3-hydroxy-3-methylglutaryl coenzyme A \\
\hline $\mathrm{HOCl}$ & hypochlorous acid (=hypochlorite) \\
\hline H-site & hydrophobic binding site \\
\hline LDL & low-density lipoprotein \\
\hline MAPEG & $\begin{array}{l}\text { membrane-associated proteins in eicosanoid } \\
\text { and glutathione metabolism }\end{array}$ \\
\hline MDA & malondialdehyde \\
\hline MGST & microsomal glutathione S-transferase \\
\hline MRP & multidrug resistance-associated protein \\
\hline NEM & N-ethylmaleimide \\
\hline NFKB & nuclear factor $\mathrm{kB}$ \\
\hline
\end{tabular}




$\begin{array}{ll}\text { NO* } & \text { nitric oxide } \\ 0^{*-} & \text { superoxide anion } \\ \text { OH }^{*} & \text { hydroxyl radical } \\ \text { PIP } & \text { peroxidation inhibiting protein } \\ \text { PKC } & \text { protein kinase C } \\ \text { PLHG-PX } & \text { phospholipid hydroperoxide glutathione peroxidase } \\ \text { PP2A } & \text { protein phosphatase 2A } \\ \text { PUFA } & \text { polyunsaturated fatty acid } \\ \text { RNS } & \text { reactive nitrogen species } \\ \text { RO* } & \text { alloxyl radical } \\ \text { ROO* } & \text { peroxyl radical } \\ \text { ROOH } & \text { phospholid hydroperoxide } \\ \text { ROS } & \text { reactive oxygen species } \\ \text { TAP } & \text { tocopherol-associated protein } \\ \text { TBA } & \text { thiobarbituric acid } \\ \text { VLDL } & \text { very-low-density lipoprotein }\end{array}$




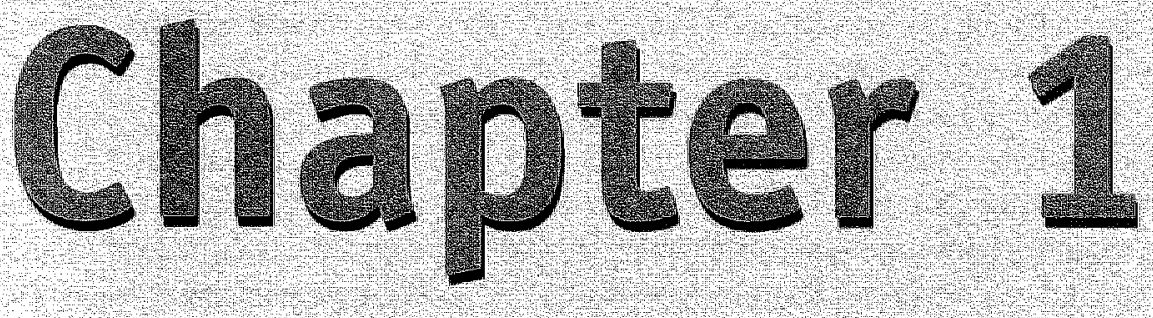

\section{General introduction and outline of the thesis}




\subsection{General introduction}

Reactive oxygen species and various electrophiles are involved in the ethiology of diseases varying from cancer to cardiovascular and pulmonary disorders. The human body is protected against damaging effects of these compounds by a wide variety of systems. An important line of defence is formed by the antioxidants. Vitamin $E$ (consisting of various forms of tocopherols and tocotrienols) is an important fatsoluble, chain-breaking antioxidant. Besides working as an antioxidant this compound possesses multiple other functions with possible physiological relevance. The glutathione-dependent enzymes form another line of defence. Two important enzymes in this class are the free radical reductase and glutathione S-transferases (GSTs). GSTs are a familly of phase II detoxification enzymes. They can catalyse glutathione conjugation with various electrophiles in most cases the electrophiles are detoxified by this conjugation, but in some cases the electrophiles are activated. Antioxidants do not act in isolation but form an intricate network. It is for instance known that vitamin $E$, together with glutathione and a membrane-bound enzyme (free radical reductase) can prevent against damaging effects of reactive oxygen species on polyunsaturated fatty acids in biomembranes (lipid peroxidation).

The aim of this thesis is to study the interaction between the two defence systems, vitamin $E$ and glutathione-dependent enzymes. The simplest expectation would be that antioxidants like vitamin $E$ can have protective effects on glutathione-dependent enzymes; we will see that reality is a bit more complicated.

\subsection{Outline of this thesis}

This thesis focuses on the multiple effects of different forms of vitamin $E$ on glutathione-dependent enzymes. Especially the interplay of vitamin $E$ or a-tocopherol quinone, a metabolite of vitamin $E$, and free radical reductase, the reduction of $\alpha$ tocopherol quinone by glutathione and the effect of different forms of vitamin $E$ on glutathione S-transferase activity are explored. Possible implications of these effects are discussed. 
- Chapter 2 reviews old and recent data of vitamin $E$ and glutathione-dependent enzymes. Also the interplay between vitamin E and glutathione-dependent enzymes is discussed.

- Chapter 3 reports the interplay of $\alpha$-tocopherol and $\alpha$-tocopherol quinone with glutathione in the process of lipid peroxidation. The possible reduction of $\alpha-$ tocopherol quinone by glutathione is described.

- The effect of $\alpha$-tocopherol on the activity of GST P1-1 and the kinetics of the change in activity are explored in Chapter 4. Possible implications for the change in activity are outlined.

- Chapter 5 focuses on the effects of different forms of tocopherol and tocopherol derivatives (used as supplements or as additive in e.g., cosmetic products) on the activity of GST P1-1. A risk assessment for application of tocopherol ester containing products on the skin is reported.

- The effect of tocotrienols on GST P1-1 activity is described and a possible tocopherol/tocotrienol binding site in the three dimensional structure of GST P1-1 is examined in Chapter 6.

- In Chapter 7 the effect of $\alpha$-tocopherol on the activity of various GST isoenzymes is compared. The purified forms of isoenzymes mu, alpha and pi and human homogenates in which these isoenzymes are present are used. A possible role of vita$\min E$ in chemotherapy is discussed.

- The effect of hypochlorous acid on the activity of GST P1-1 is presented in Chapter 8. A pivotal role of hypochlorous acid in (patho)-physiology is suggested. 


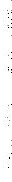



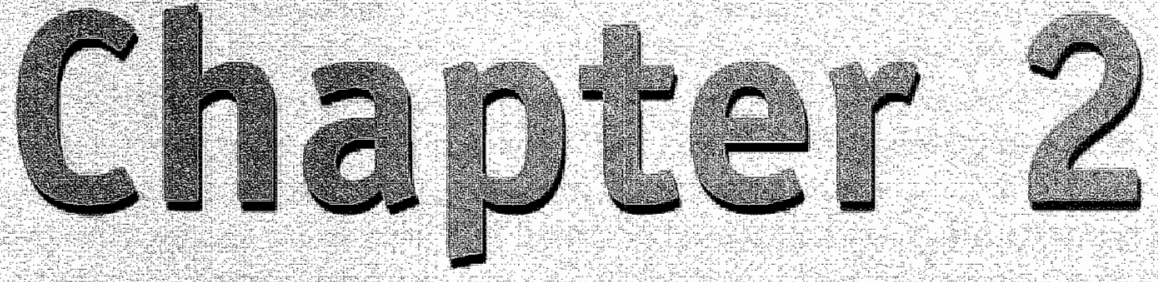

\title{
Effect of vitamin $E$ on glutathione-dependent enzymes
}

\author{
Rachel I.M. van Haaften \\ Guido R.M.M. Haenen \\ Chris T.A. Evelo \\ and Aalt Bast
}

Drug Metabolism Reviews submitted 


\subsection{Free radicals and related 'reactive species'}

The human body is expiosed to a huge number of compounds. By themselves most of these compounds are not harmful, but upon metabolic activation some can become toxic. Oxygen is such a compound. During metabolism of oxygen, most of it is bound to hydrogen during oxidative phosphorylation, forming water. However, $4-5 \%$ of the consumed oxygen is not completely reduced to water ${ }_{,}$but forms hydrogen peroxide or free radicals. A free radical is defined as any species capable of independent existence that contains one or more unpaired electrons. Due to the unpaired electron(s) these molecules can be very reactive.

The partly reduced forms of oxygen formed are called Reactive 0xygen Species (ROS). This is a collective term not only for oxygen radicals but also for some nonradical reactive derivatives of oxygen. Besides ROS also Reactive Nitrogen Species (RNS) exist. Important ROS/RNS are the superoxide radical, hydroxyl radical, hydrogen peroxide, hypochlorous acid, singlet oxygen and peroxynitrite. These compounds do not all have the same reactivity. The hydroxyl radical is the most reactive compound; it has a high oxidising capacity. Although hydrogen peroxide is a powerful oxidant, it is relatively unreactive towards most biological substrates unless it is present in unphysiologically high concentrations. A list of reactive oxygen and nitrogen species is given in table 1 . ROS and RNS are also called oxidants or prooxidants due to the capability of oxidising biomolecules.

Table 1. Reactive oxygen and reactive nitrogen species:

\section{Reactive oxygen species (ROS)}

Radicals

\begin{tabular}{ll}
\hline Superoxide & $\left(\mathrm{O}_{z}^{-}\right)$ \\
Hydroxyl & $\left(\mathrm{OH}^{*}\right)$ \\
Peroxyl & $\left(\mathrm{RO}_{z}^{*}\right)$ \\
Alloxyl & $\left(\mathrm{RO}^{*}\right)$ \\
Hydroperoxyl & $\left(\mathrm{HO}_{2}^{*}\right)$
\end{tabular}

Non radicals

$\begin{array}{ll}\text { Hydrogen peroxide } & \left(\mathrm{H}_{2} \mathrm{O}_{2}\right) \\ \text { Hypochlorous acid } & (\mathrm{HOCl}) \\ \text { Hypobromous acid } & (\mathrm{HOBr}) \\ \text { Ozone } & \left(\mathrm{O}_{3}\right) \\ \text { Singlet oxygen } & \left(\mathrm{O}_{2}\right)\end{array}$

\section{Reactive nitrogen species (RNS)}

Radicals

Nitric oxide

Nitrogen dioxide

$\left(\mathrm{NO}^{*}\right)$

$\left(\mathrm{NO}_{z}^{*}\right)$
Non radicals

$\begin{array}{ll}\text { Nitrous acid } & \left(\mathrm{HNO}_{z}\right) \\ \text { Nitrosyl cation } & \left(\mathrm{NO}^{+}\right) \\ \text {Nitroxyl anion } & \left(\mathrm{NO}^{-}\right) \\ \text {Peroxynitrite } & \left(\mathrm{NNO}^{-}\right) \\ \text {Peroxynitrous acid } & (\mathrm{ONOOH}) \\ \text { Alkyl peroxynitrite } & (\mathrm{ROONO})\end{array}$


The human body itself produces certain ROS and RNS and these reactive species fulfil several pivotal physiological functions. The reactivity of oxygen is for instance utilised by the cytochrome $\mathrm{P} 450$ enzyme system for hydroxylation of relatively inert endogenous compounds and xenobiotics. Various phagocytic cells are able to produce hypochlorous acid ( $\mathrm{HOCl}$ ) which plays an important role in their bactericidal action. $\mathrm{NO}^{-}$and $\mathrm{O}_{2}^{--}$also play an important role in the regulation of the contraction tone of the smooth muscle of blood vessels $[1,2]$.

Beside their physiological functions, ROS and RNS can damage practically all compounds occurring in living organisms, including DNA, proteins, carbohydrates and lipids. Damage to these major biomolecules may contribute to the development of multiple diseases such as cancer, cardiovascular and neurological diseases, emphysema or ageing.

The polyunsaturated fatty acids (PUFAs) in the cell membrane are important targets for the reactive species. Radicals may initiate peroxidation of the PUFAs. In this process of lipid peroxidation the attacking free radical abstracts a hydrogen atom from a PUFA. The formed lipid radical can be delocalised over various structures and is in this way resonance stabilised. The lipid radical reacts rapidly with oxygen, producing a peroxyl radical. Subsequently, the lipid peroxyl radical abstracts a hydrogen atom from a second PUFA and a lipid hydroperoxide and a new lipid radical are formed. This new lipid radical reacts again with axygen, is transformed into another lipid hydroperoxide and generates a third lipid radical. This propagation or chain reaction is interrupted when two unpaired electrons meet and form a pair (termination) or when a relatively unreactive radical is formed. Products, which are formed during this process, include 2-alkenals, 4-hydroxy-2-alkenals and malondialdehyde. These products can be toxic; malondialdehyde (MDA) can react with DNA bases and introduce mutagenic lesions resulting in different types of diseases, and 4-hydroxy2-nonenal (a form of 4-hydroxy-2-alkenal) can inhibit cell growth, and display genotoxic activity.

The lipid hydroperoxide can also be cleaved to form radicals that start a new radical chain reaction. This process is called 'lipid-hydroperoxide-dependent' lipid peroxidation. When the chain reaction is induced by radicals not originating from lipid hydroperoxides the process is called lipid-hydroperoxide-independent" lipid peroxidation. 


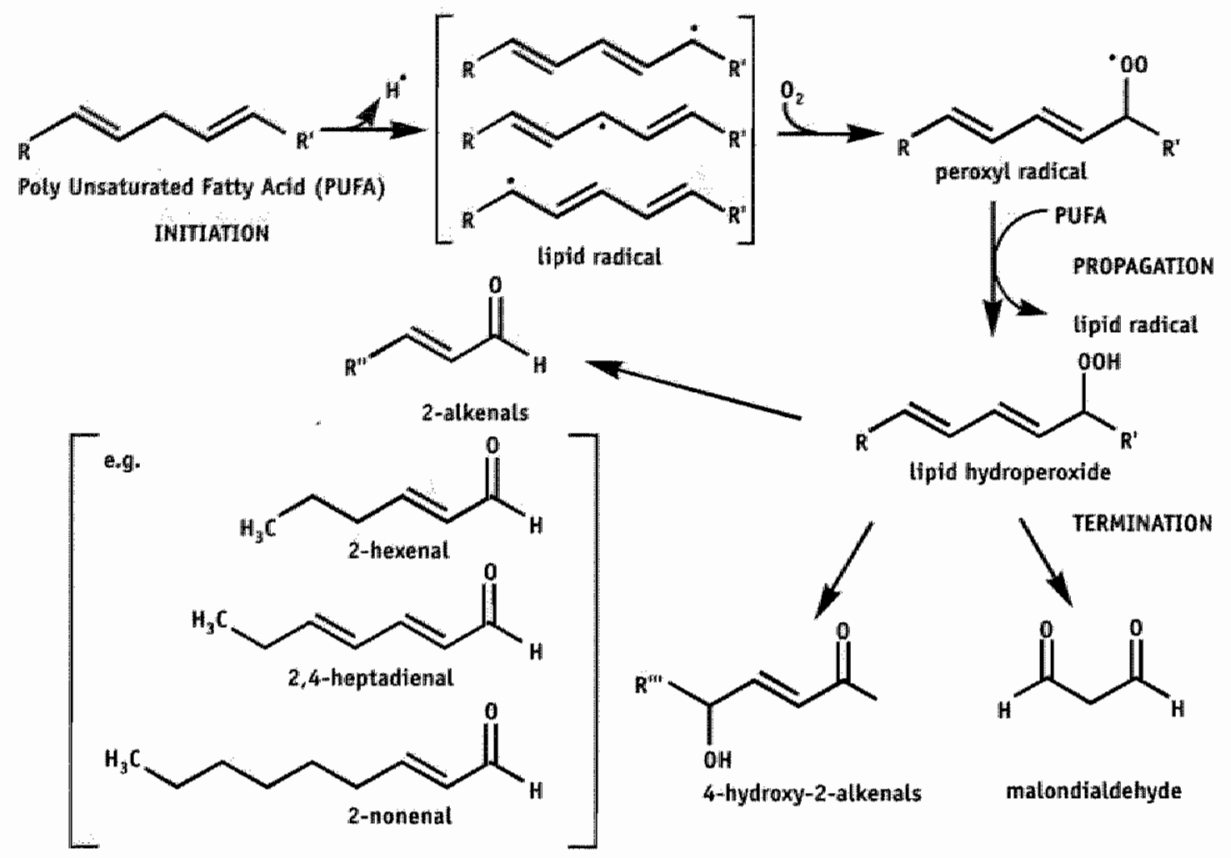

Figure 1. Process of lipid peroxidation and formation of toxic substances.

\subsection{Antioxidant defence}

To protect against the damaging actions of ROS and RNS, the human body contains an intricate network of antioxidants. The term antioxidant has been defined as "any substance that, when present at low concentrations compared with those of an oxidisable substrate, significantly delays or prevents oxidation of that substrate' [3]. Antioxidants can be classified by function in categories [4-7]. The first category is formed by the enzymatic antioxidants. This category of antioxidants is designed by nature to cope with superoxide and hydroperoxides (hydrogen peroxide). Superoxide is degraded by superoxide dismutase (SOD) into hydrogen peroxide and oxygen. Catalase is able to degrade hydrogen peroxide and glutathione peroxidase (GPX) degrades hydrogen peroxide and organic hydroperoxides.

The second category is formed by the non-enzymatic antioxidants and is composed of low molecular weight antioxidants which can be divided into hydrophilic (e.g. vitamin C, glutathione and flavonoids) and hydrophobic antioxidants (e.g. caro-

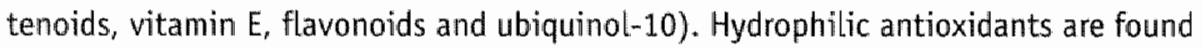
in cytosolic, mitochondrial and nuclear aqueous compartments of the cells, while hydrophobic antioxidants are present in lipoproteins and membranes. The reaction kinetics of the non-enzymatic antioxidants is very fast, much faster than reactions of ROS/RNS with other biological targets. 
A third category of antioxidant defence is formed by compounds able to sequester transition metals. Traces of transition metal ions such as iron and copper can transform hydrogen peroxide into a hydroxyl radical, which is a highly oxidising compound. This reaction is called the Fenton reaction and proceeds as follows:

$$
\mathrm{Fe}^{2+}+\mathrm{H}_{2} \mathrm{O}_{2} \rightarrow \mathrm{Fe}^{3+}+\mathrm{OH}^{*}+\mathrm{OH}^{-}
$$

Proteins such as transferrin, ferritin and ceruloplasmin prevent the formation of hydroxyl radicals by sequestering of transition metals.

The overall function of antioxidants is acting as a co-ordinated and balanced network to protect tissues and body fluids from damage by ROS and RNS. Disturbance of the balance between oxidants and antioxidants in favour of the oxidants is called oxidative stress [4]. This will promote damage to important cellular compounds. When this damage occurs at relatively low level, the human body is able to repair or replace the attacked substrates with the help of several kinds of repair enzymes [6].

Table 2. Antioxidant defence.

\section{Enzymatic antioxidants}

Enzyme

Reaction

Superoxide dismutase (SOD)

$2 \mathrm{O}_{2}^{*-}+2 \mathrm{H}^{+} \rightarrow \mathrm{H}_{2} \mathrm{O}_{2}+\mathrm{O}_{2}$

Glutathione peroxidase (GPX)

$2 \mathrm{GSH}+\mathrm{H}_{2} \mathrm{O}_{2} \rightarrow \mathrm{GSSG}+\mathrm{H}_{2} \mathrm{O}$

$2 \mathrm{GSH}+\mathrm{ROOH} \rightarrow \mathrm{GSSG}+\mathrm{ROH}+\mathrm{H}_{2} \mathrm{O}$

Catalase

$2 \mathrm{H}_{2} \mathrm{O}_{3} \rightarrow \mathrm{O}_{3}+2 \mathrm{H}_{2} \mathrm{O}$

Non-enzymatic antioxidants (low molecular weight antioxidants)

Hydrophilic

Vitamin C

Hydrophobic

Glutathione

Carotenoids

Flavonoids

Vitamin $\mathrm{E}$

Flavonoids

Ubiquinol-10

\section{Sequestration of transition metal ions}

Protein

Metal ion

Transferrin

$\mathrm{Fe}$

Ferritin

$\mathrm{Fe}$

Ceruloplasmin

$\mathrm{Cu}$

\section{Repair systems}

Excision repair and replacement of damaged bases in DNA

Increased turnover of damaged proteins 


\subsection{Vitamin $\mathrm{E}$}

\subsubsection{Introduction}

Vitamin E was discovered in 1922 by Evans and Bishop to be an essential factor in the reproduction [8]. Absence of this dietary factor caused fetal death and resorption in laboratory rats. Mason showed that vitamin $E$ is essential for spermatogenic activity [9]. Because of this function vitamin $\mathrm{E}$ was first designated as the antisterility vitamin. In 1936 Evans and Emerson isolated a smail amount of pure vitamin $E$ from wheat germ oil and named it tocopherol [10]. Fernholz elucidated in 1938 the chemical structure of tocopherol [11].

Vitamin $E$ is the term used for two groups of closely related, fat-soluble compounds, the tocopherols and the tocotrienols. Both tocopherols and tocotrienols consist of a chroman head (with two rings: one heterocyclic and one phenolic) and a carbon tail attached at the 2-position of the head. The difference between tocopherols and tocotrienols is formed in the carbon-tail; tocopherols contain a saturated phytyl tail and tocotrienols contain three isolated double bounds in their isoprenoid tail. The names tocopherol and tocotrienol are derived from the Greek words tokos (childbirth), pherein (to bring forth) and trien (three unsaturated bonds); the -ol ending is added to indicate the hydroxyl substituent of the molecules. Both groups consist of four different analogs called $\alpha-, \beta-, \gamma$ - and $\delta$-vitamer. These vitamers differ in the number and position of the methyl substituents attached to the chomanol ring. Due to the three chiral centra present at positions 2 in the chroman ring and $4^{\prime}$ and $8^{\prime}$ in the phytyl tail of tocopherol there are eight stereoisomers possible of each tocopherol vitamer.<smiles></smiles><smiles>[R1]c1c(C)c2c(c([R2])c1O)CC[C@@](C)(CC/C=C(/C)CC/C=C(\C)CCC=C(C)C)O2</smiles>

\begin{tabular}{|c|cc|}
\hline & $\mathrm{R}_{1}$ & $\mathrm{R}_{2}$ \\
\hline$\alpha$ & $\mathrm{CH}_{3}$ & $\mathrm{CH}_{3}$ \\
$\beta$ & $\mathrm{CH}_{3}$ & $\mathrm{H}$ \\
$\gamma$ & $\mathrm{H}$ & $\mathrm{CH}_{3}$ \\
$\delta$ & $\mathrm{H}$ & $\mathrm{H}$ \\
\hline
\end{tabular}

Figure 2. Molecular structures of tocopherols and tocotrienols. The naturally occurring vitamers $\alpha, \beta$, $\gamma$ and $\delta$ have methylation patterns as indicoted. 
All natural occurring tocopherols $(\alpha-, \beta-, \gamma$ and $\delta$-) have the RRR-configuration. The synthetic form of $\alpha$-tocopherol, all-rac- $\alpha$-tocopherol, is normally an equimolar mixture of the eight different stereoisomers $[12,13]$.

Tocotrienols only have one chiral centre at position 2 , so there are only 2 stereoisomers. The presence of the double bonds at positions $3^{\prime}$ and $7^{\prime}$ in the tail allows however for the existence of four cis/trans geometrical isomers per tocotrienol [12].

\subsubsection{Uptake and metabolism}

Since vitamin $E$ is a vitamin, it has to be acquired from foods or supplements. The main sources of vitamin $E$ are vegetables and seed oils, whereas animal products are generally pour sources of this vitamin. The natural sources of tocopherol mainly consist of nuts and common vegetable oils (i.e., wheat germ and sunflower).

Tocotrienols have a relative high abundance in cereal grains (i.e., oat, barley and rye) and certain vegetable oils (i.e., palm oil and rice bran oil) [14]. There exists a strong correlation between the amount of unsaturated fatty acids in plant oils and its tocopherol content [15]. Of all forms of vitamin $E_{*} \gamma$-tocopherol and $\alpha$-tocopherol are the vitamers present in the highest amounts in the human diet. When vitamin $E$ is provided as supplement or is added to a product, e.g. a cosmetic product, the hydroxyl group in the phenolic ring of the chroman head has frequently been blacked. Sequestration of this group ( $\mathrm{e.g.,}$ by esterification with acetate or succinate) renders the molecule less vulnerable to oxidation. In vivo, the ester is saponified by an esterase, e.g. in the gut Lumen, revealing the hydroxyl group [16, 17].

Dietary vitamin $E$ is absorbed in the small intestine, in the unesterified form, where it is incorporated into chylomicrons. These are transported via the lymph and released into the circulation. The chylomicrons also contain triacylglycerols, which are hydrolysed by the endothelial-bound lipoprotein lipase. Consequently, the chylomicron remnant, with the incorporated vitamin $E$, is formed. These chylomicron remnants reach the liver. The liver contains a protein, $\alpha$-tocopherol transfer protein ( $\alpha$ uTP), which is able to selectively sort out RRR- $\alpha$-tocopherol from all incoming tocopherols $[18$, 19]. The other forms of vitamin $\mathbb{E}$ have lower affinities for this protein.

Relative affinity compared to RRR- $\alpha$-tocopherol are: $\beta$-tocopherol, $38 \%$; $\gamma$-tocopherol, $9 \%$; $\delta$-tocopheroL, $2 \%$; SRR- $\alpha$-tocopherol, $11 \%$; $\alpha$-tocotrienol, $12 \%$; and an esterified form of the vitamin, $\alpha$-tocopherol-acetate, $2 \%$ [20].

Due to its lipophilic character, vitamin $E$ is very poorly soluble in the hydrophilic milieu of blood plasma, cytosol and extracellular fluids. Therefore, vitamin $\mathrm{E}$ is (like other lipophilic vitamins) bound to specific proteins or lipoproteins during absorption, tramsport and distribution. The sorted RRR- $\alpha$-tocopherol is incorporated into very-Low-density lipoproteins (VLDL). The other forms of vitamin $E$ with the lower 
affinity for the $\alpha$-TTP are metabolised and finally excreted via the bile or the urine. Vitamin $E$ bound to the VLDL is secreted form the parenchymal cells and metabolised by lipoprotein lipase. Some of the vitamin E associated with chylomicrons and VLDL is transferred to peripheral cells and high-density lipoproteins (HDL) during lipolysils. Vitamin E in VLDL ends up in low-density lipoproteins (LDL) due to metabolism of VLDL. This LDL-associated vitamin $E$ is taken up by receptor-mediated uptake of LDL in peripheral cells $[17,21-23]$. In the plasma, vitamin $E$ is transported via binding to lipoproteins. The intracellular transport of vitamin $E$, e.g., between membrane compartments, is facilitated by tocopherol-associated proteins (TAPs). TAP may also act as a molecular chaperone that protects tocopherol from tocopherolmetabolising enzymes, and may be involved in the alpha-tocopherol mediated cell signalling [24]. TAPs have as the TTP the highest affinity for RRR- $\alpha$-tocopherol compared to the other forms of vitamin $E[25]$.

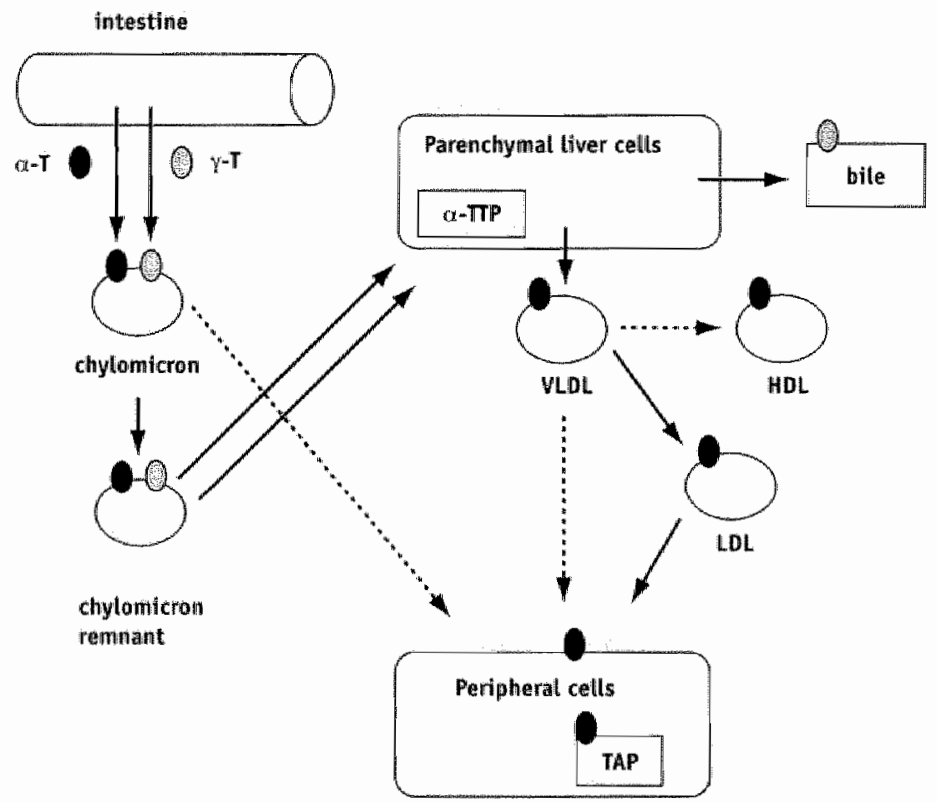

Figure 3. Trowsport of vitamin $E$ between different tissiches. Black bullet represents $R R R$ - $\alpha$-tocopherol and grey bullet means $\gamma$ tocopherol.

The normal plasma level of vitamin $\mathbb{E}$ is between $23 \mu \mathrm{M}$ and $35 \mu \mathrm{M}[26,27]$. Genetic defects in $\alpha$-TTP can lead to plasma vitamin $E$ levels as low as $1 \%$ of the normal concentrations. People with this genetic defect have neurological abnormalities that are characterised by dying of the axons of the sensory neurons, resulting in ataxia, 
muscle inclusions and retinal degeneration [28-31]. This characteristic syndrome is called ataxia with vitamin E deficiency (AVED), previously called familial isolated vitamin $E$ (FIVE) $[22,32]$. When people with this disorder are supplemented with $\alpha$-tocopherol, the plasma concentrations will reach normal levels within hours, but declines fast when supplementation is stopped. The temporarily increase in plasma concentration due to the supplementation is caused by non-specific redistribution of $\alpha$-tocopherol to peripheral cells from chylomicrons (dotted arrow on the left in Figure 3.) [33].

The forms of vitamin $E$ that are not taken up by the liver are finally excreted (as described above) by the bile or via the urine. Bilary transport mechanisms of vitamin $E$ are not known. Before urinary excretion vitamin $E$ is extensively metabolised. Tocopherols and tocotrienols are metabolised by side-chain degradation via $\omega$ hydroxylation and $\beta$-oxidation. The initial step, the $\omega$-hydroxylation of the sidechain is performed by CYP4F2, a cytochrome P450 (CYP)-dependent hydroxylase. This hydroxylase also catalyses $\omega$-hydroxylation of leukotriene $B_{4}$ and arachidonic acid [34]. The $\omega$-hydroxylation is followed by five $\beta$-oxidation cycles [35-38]. Final products, carboxyethyl hydroxychromans (CEHCs), are excreted via the urine [39]. Enzymes involved in the degradation of unsaturated fatty acids (2,4-dienoyl-COA reductase and 3,2-enoyl-CoA isomerase) are needed for the degradation of the unsaturated side chain of tocotrienols [40]. However, irrespective of the difference in side chain between tocopherols and tocotrienols, the final products of the metabolism are CEHCs [41]. 


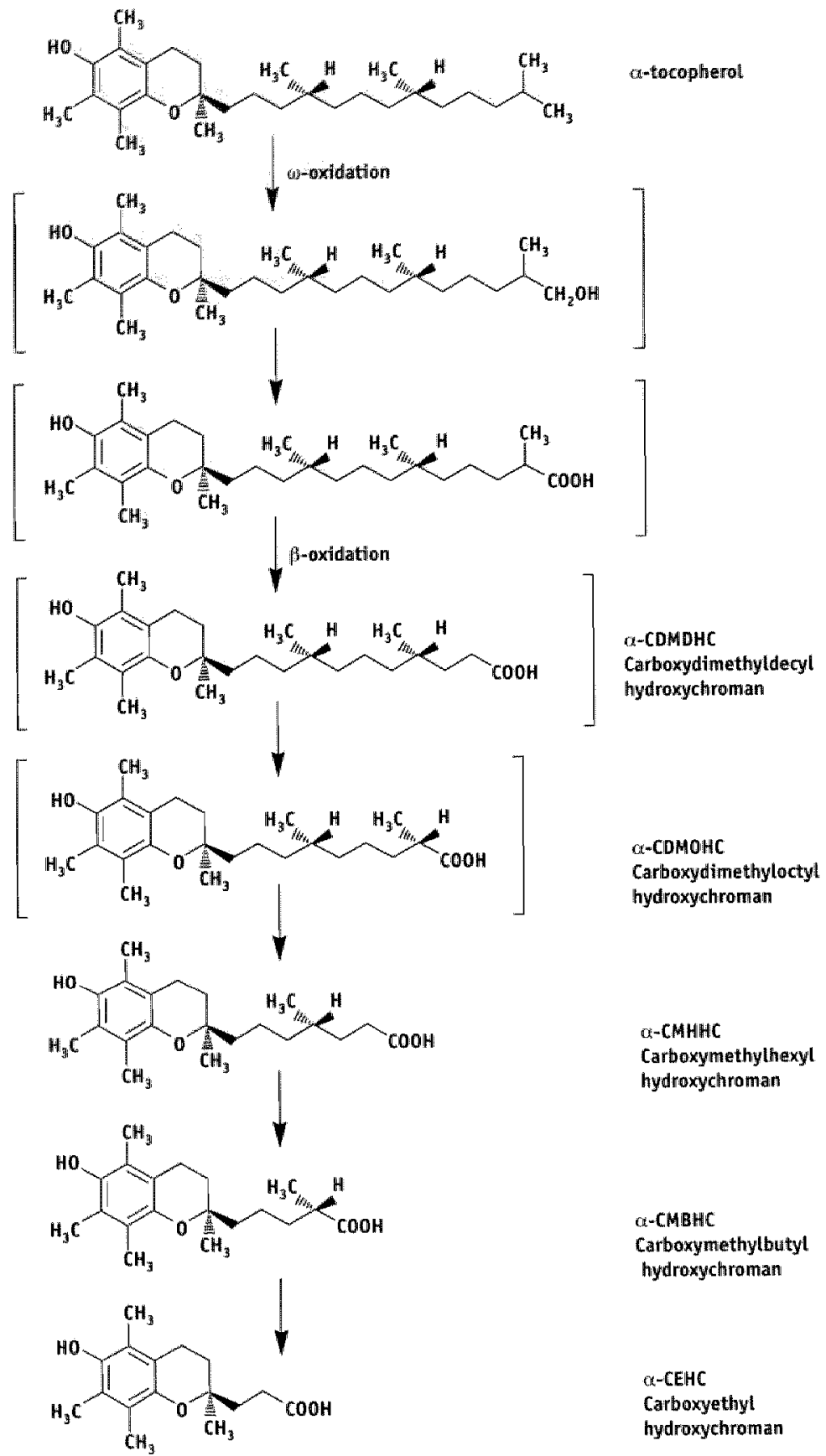

Figure 4. Mechanism of tocopherol side-chain degradation ( $\alpha$-tocopherol is shown as an example). Side-chain degradation starts with (1)-oxidation, followed by five $\beta$-oxidation cycles. 


\subsubsection{Functions of vitamin $E$}

\subsubsection{Antioxidant function}

Both tocopherols and tocotrienols are well recognised for their antioxidative effects. Because $\alpha$-tocopherol is the form of vitamin $E$ mostly present in the human body, its antioxidant effect is the most important in the defence against reactive oxygen species of all vitamin $E$ vitamers. The best-known antioxidant function of $\alpha$ tocopherol is scavenging of peroxyl radicals that propagate chains in the nonenzymatic lipid peroxidation (Figure 1.). Tocopherol (1) functions as a chain-breaking antioxidant by reacting of the hydroxyl group with a peroxyl radical ( $\left(\mathrm{OO} 0^{\circ}\right)$ either by hydrogen transfer or by sequential electron, then proton transfer to form a lipid hydroperoxide and the tocopheroxyl radical (2).
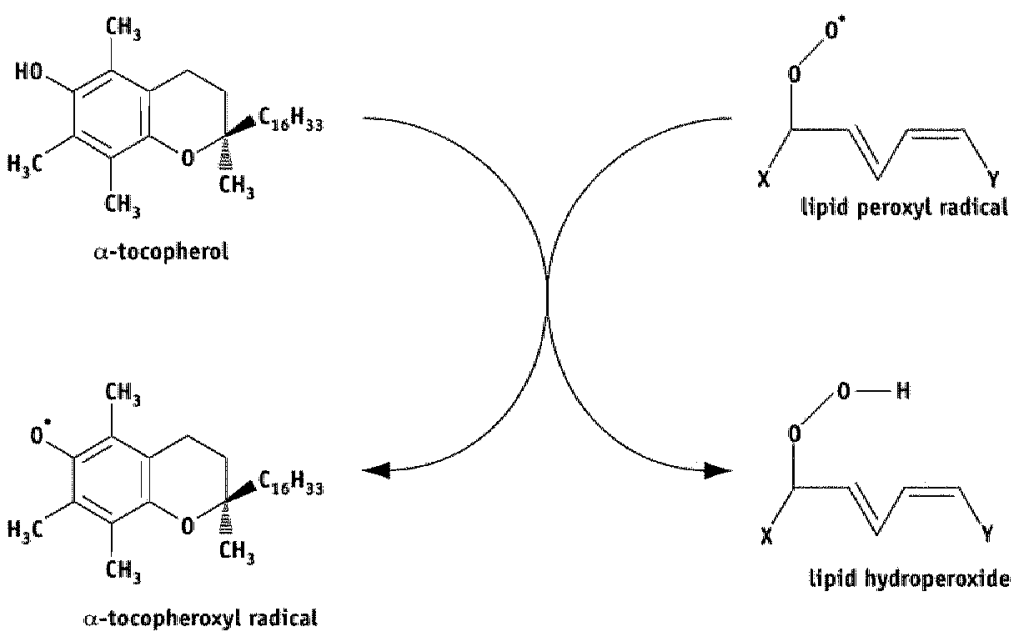

Figure 5. Antioxidant function of vitanin E: scavenger of peroxyl rodicals.

This radical is a resonance stabilised radical due to delocalisation of the unpaired electron over the choman head of the molecule, rendering the radical relatively unreactive. Reaction of the tocopheroxyl radical with a peroxyl radical can lead to two groups of products. The first are $8 \alpha$-substituted tocopherones (3), which contain a hydroxyl group or a peroxyl radical-derived adduct in the chroman head. These products lead to the formation of $\alpha$-tocopherol quinone (4).

The second group of products is the epoxy- $8 \alpha$-hydroperoxytocopherones (5), which have an epoxide in the chroman head. These compounds hydrolyse and rearrange to epoxy- $\alpha$-tocopherol quinones (6). $\alpha$-Tocopherol quinone can be reduced, by a two electron reduction, to $\alpha$-tocopherollhydroquinone $(7)$ in cell-free and cellular systems

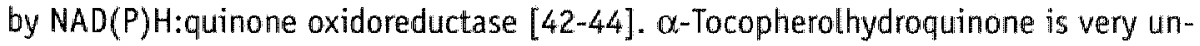
stable and easily autoxidises to $\alpha$-tocopherol quinone when exposed to aerobic con- 
ditions $[42,45]$. This autoxidation yields $\alpha$-tocopherol quinone as major product, but also some epoxy-o-tocopherol quinones are formed as minor products $[46,47]$. It has been demonstrated that $\alpha$-tocopherol quinone can be recycled to the parent compound $\alpha$-tocopherol in man [48].

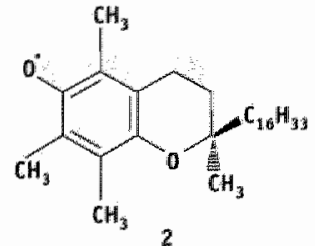<smiles>CCCCCCCC[C@]1(C)CCC2=C(C)C(=O)C(C)=C(C)C2(O)O1</smiles>

3<smiles>C[14CH3]</smiles>

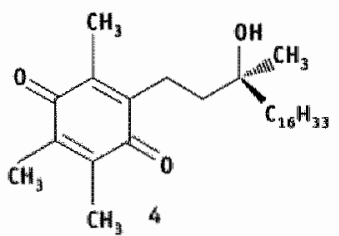

$2 \mathrm{e}^{*} \cdot 2 \mathrm{H}^{+} \downarrow$<smiles>CCCCCCCC[C@@](C)(O)CCc1c(C)c(O)c(C)c(C)c1O</smiles>

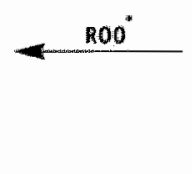

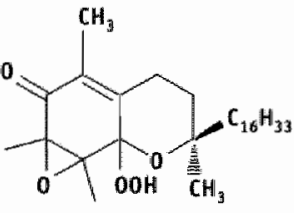

5<smiles>C[13CH][13CH]</smiles>

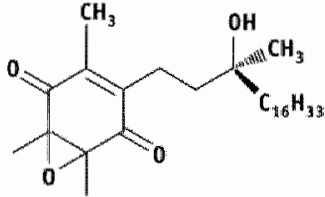

6

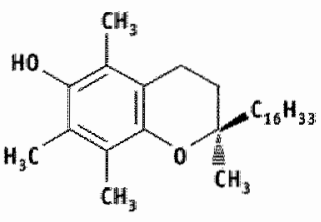

1

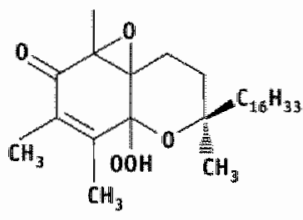

5

$$
\bigvee^{H_{2} \mathrm{O}}
$$

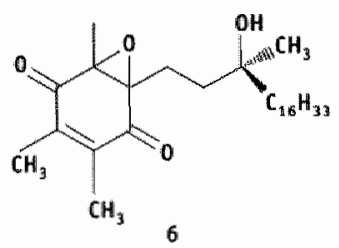

Figure 6 . Reactians of atocopherol with peroxyl radicals. ( $1=0$-tocopherol; $2=\alpha$-tocopheroxyl radical.

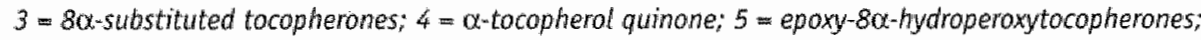
$6=$ epoxy- $\alpha$-tocopherol quinones; $7=\alpha$-tocopherol hydroquinone $)$. 
During peroxyl radical scavenging also tocopherol dimers and trimers can be formed, but these are just minor products $[12,13,49]$.

Tocopherols also react with a variety other reactive oxidants like singlet oxygen [ 50 , 51], alkoxyl radicals [52-54], peroxynitrite [55], nitrogen dioxide [56], ozone [57, 58] and superoxide [59]. Reaction of tocopherol with these compounds also contributes to the cellular antioxidant defence $[13,49]$.

Not only tocopherol itself contains antioxidant activity, also $\alpha$-tocopherolhydroquinone can function as effective antioxidant. Like tocopherol it can inhibit lipid peroxidation $[43,60]$. Thus the antioxidant activity of tocopherol can be extended by its metabolites $[61,62]$. It has even been stated that tocopherolhydroquinone is a much more potent antioxidant in the lipid peroxidation than tocopherol itself [60]. Tocopherolhydroquinone scavenges peroxyl radicals primarily by electron transfer to form tocopherol quinone. However the formation of epoxy-a-tocopherol quinones suggests that a radical addition/elimination reaction also occurs [46].

\subsubsection{Pro-axidant activity}

Opposed to the antioxidant effects of vitamin $E$, alpha-tocopherol can also have a pro-oxidant effect. This activity is caused by the reaction of $\alpha$-tocopherol with transition metals ( $\mathrm{e} . \mathrm{g} . \mathrm{Cu}^{2 *}$ ). The transition metal is reduced and an $\alpha$-tocopheroxyl radical is formed. Both the reduced metal (e.g. $\mathrm{Cu}^{*}$ ) and the tocopheroxyl radical are able to promote the lipid peroxidation [63-65]. In the CHAOS epidemiological study, an initial increase of fatal myocardial infarctions was observed after relatively high dose of $\alpha$-tocopherol supplementation [66]. This increase can be explained by interaction of vitamin $E$ with transition metal ions present in unstable plaques (prooxidant effect) [67]. The pro-oxidative effects of excessive vitamin $E$ depends on the type of dietary fat. A diet with high content of polyunsaturated fatty acids (PUFA) increases the content of the membrane with PUFA which makes the membrane much more prone to oxidation [64]. A diet rich in PUFA and vitamin E can promote the process of lipid peroxidation in smokers [68].

Antioxidants are converted in oxidation products when they have performed their function as antioxidant. Remarkably, little is known about the toxicity of these metabolites that are formed. It is known that tocopherol quinone, a metabolite of tocopherol formed after antioxidant action can have a cytotoxic effect. This toxicity is dependent on the ability to generate oxygen radicals, oxidise cellular components and function as arylating electrophiles; forming Michael adducts with nucleophilic thiol groups. This arylating function of quinone depends on the number and position of substituents in the quinone. The different quinone forms of tocopherol differ in the number and position of methyl groups on the chroman head $[12-15,17,21$, 69]. $\alpha$-Tocopherol quinone, which is fully methylated, is incapable of forming adducts with thiols, while $\gamma$, and $\delta$-tocopherol quinone, which do not have a 
completely methylated chroman head, can form these adducts [70]. The difference in the ability of formation of these Michael adducts may be the basis for the difference in cytotoxicity, in cell culture, of various forms of tocopherol quinone. It was shown that $\gamma$-tocopherol quinone but not $\alpha$-tocopherol quinone diminished the number of viable cells and stimulated apoptosis. [70-74]. The difference in toxicity between $\alpha$-tocopherol quinone and the other tocopherol quinones was in line with the results of a study performed in 1930. Experimental animals were fed cod liver oil (contains mainly $\alpha$-tocopherol) or wheat germ oil (contains $\gamma$ - and $\delta$-tocopherol) which was pre-treated with $\mathrm{FeCl}_{3}$ to destroy vitamin $\mathrm{E}$. Although at that time it was not realised, that tocopherol quinones were formed by the pre-treatment of the dietary supplements, they unidoubtedly were. Animals fed processed cod oil show little toxic effects while animals fed the processed wheat germ oil develop lymphoblastomas or malignant sarcomas $[75,76]$. The contrasting biological effect between both processed oils may naw be explained by the difference in toxicity of the different quinones formed.

\subsubsection{Non-antioxidant function}

Besides working as an antioxidant or pro-oxidant, multiple other functions of vitamin E or its metabolites have been described. These functions cannot be assigned to their known antioxidant or pro-oxidant functions and are called the non-antioxidant effects of vitamin $\mathrm{E}$.

It is for instance described that alpha-tocopherol can activate protein phosphatase 2A (PP2A) by binding to specific cellular sites of the protein. As a consequence of this, protein kinase $C \alpha(P K C \alpha)$ is dephosphorylated and inhibited which affects the AP1 transcription factor, resulting in a change in the level of gene transcription and finally inhibition of cell proliferation (especially of vascular smooth muscle cells). $\beta$-Tocopherol, shows no effect at the level of cell proliferation or protein kinase $C$ activity but rather it prevents the effect of $\alpha$-tocopherol [77-82].

Vitamin E also plays a central role in the cholesterol biosynthesis. Many researchers have shown that tocotrienols modulate the intracellular mechanism for the controlled degradation of 3-hydroxy-3-methylglutaryl coenzyme A (HMG-CoA) reductase, the enzyme controlling the rate of cholesterol synthesis. Tocotrienols inhibit HMG$\mathrm{COA}$ reductase by reduction of the synthesis of this protein and increasing of the degradation rate of the enzyme, resulting in a decrease of cholesterol levels. In contrast to tocotrienols, tocopherols can increase the hepatic HMG-COA reductase activity. So the farnesylated sidechain of tocotrienols is needed for the inhibition of HMG-CoA reductase [14, 83-90].

It is also described that the final products of $\gamma$-tocopherol metabolism, $\gamma$-CEHC, possess strong natriuretic activity due to inhibition of a $\mathbb{K}^{*}$-channel in the thick ascen- 
ding limb of the kidney. It is proposed that this metabolite of $\gamma$ tocopherol is identical to the low molecular weight "natriuretic hormone", which controls the extracellular fluid in the human body. This factor plays an important role in hypertension, congestive heart failure and cirrhosis $[91,92]$.

Another non-antioxidant effect of vitamin $E$ is stabilising of the membrane [93]. Vitamin $E$ integrates in membranes where it forms complexes with membrane lipid components that have a tendency to destabilise the bilayer structure. So the effects of these destabilising components is counteracted by vitamin $E$ resulting in a more stable membrane [13, 94].

The first step in the formation of a thrombus is platelet aggregation and adherence to vascular endothelium forming a fibrous plaque. It is suggested that tocopherols and tocotrienols can have positive effects on platelet adhesion/aggregation due to suppression of thromboxane synthesis. There are two mechanisms by which this synthesis cam be suppressed by vitamin E. The first is suppression of phospholipase A2 which results in reduction of the release of arachidonic acid (which is a precursor for prostaglandin and eventually thromboxane) from membrane bound phospholipids. The other mechanism of suppression of thromboxane synthesis is the inhibition of the transcriptional activity of the cyclooxygenase gene. Due to this inhibition the transformation of arachidonic acid into prostaglandins is decreased $[13,14,81,94$ 961. High plasma levels of apolipoprotein B-100 (apoB), the protein moiety of LDL, are another important risk factor for the development of atherosclerosis. Several epidemiologic studies shave shown that $\gamma$-tocotrienol can reduce the apoB plasma levels by 10 to $15 \%$. The mechanism of this reduction is not clear yet but it is speculated that $L D L$ receptors in the liver are upregulated, facilitating the clearance of $L D L$-apoB from the bloodstream or that the production of VLDL and $L D L$ is decreased [14].

As described above, the different forms of vitamin E can perform multiple roles. Some of these functions are directly or indirectly related to cardiovascular diseases. As antioxidant, vitamin $E$ can protect against lipid peroxidation and so decrease the risk for cardiovascular diseases. Acting as a pro-oxidant, vitamin $E$ can increase the risk for cardiovascular diseases and numerous non-antioxidant functions of vitamin $E$ or its metabolites can play important roles in the development of cardiovascular diseases. In the past numerous human vitamin $E$ intervention studies have been performed. The CHAOS study (Cambridge Heart Antioxidant Study) showed a decrease in nonfatal myocardial infarction but a rise in fatal myocardial infarction [66]. The GISSI Prevenzione studies failed to detect such benefit [66, 97, 98]. Overall it can be concluded that these clinical intervention studies have disappointing and paradoxical outcomes. 


\subsection{Glutathione and glutathione dependent enzymes}

\subsubsection{Introduction}

As described in part 2.2, reduced glutathione (GSH) is an important contributor of the non-enzymatic antioxidant defence mechanism of the body. It is present in milimolar concentrations intracellular and it is a versatille and ubiquitous cellular antioxidant $[47,99]$. Glutathione represents at least $90 \%$ of total nonprotein low molecular weight thiols present in cells [100]. It is a relative simple tripeptide consisting of glutamic acid (Glu), cysteine (Cys) and glycine (Gly).

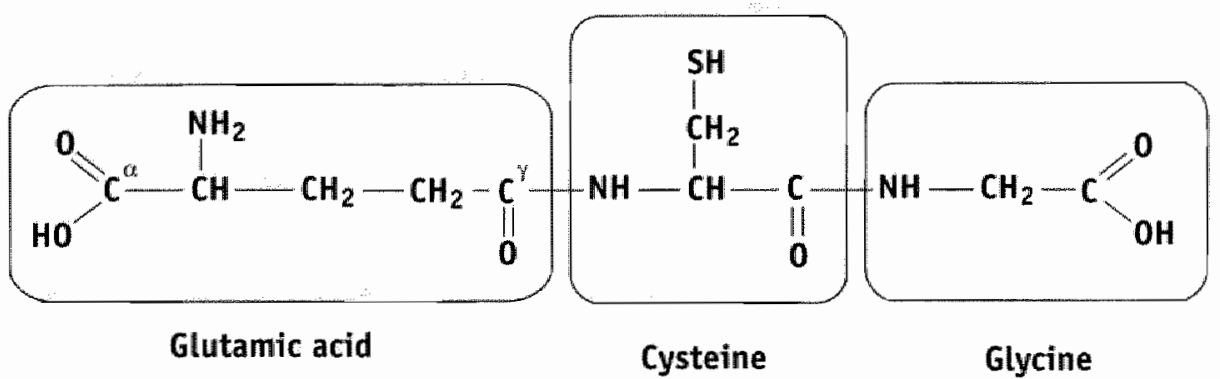

Figure \%. Structure of the tripeptide reduced glutathione (GSH:L-Y-glutamyl-L-cysteinyl-glycine).

The antioxidant reaction of GSH (reacting with free radicals) generates thiyl radicals (GS*), which can form the glutathione disulfide (GSSG). Less than $5 \%$ of total glutathione in the cells is GSSG [100].

Besides working as a scavenger of reactive species, GSH is involved in a variety of other metabolic functions like DNA repair, activation of transcription factors, cell cycle regulation modulation of calcium homeostasis and regulation of enzyme activity. Most of these functions of glutathione are related to its ability to maintain a reducing cellular environment [101].

GSH can also play a role in the intracellutar copper transport and detoxification. GSH is used as a cosubstrate by different enzymes, involved in cell defence, such as glutathione peroxidases (GPX), glutathione reductase (GRD), gamma-glutamyl-transpeptidase (GGT) and glutathione S-transferases (GST).

The intracellular glutathione content can be changed by many different conditions. These include the presence of heavy metals, high glucose concentrations and heat shock. Exposure to reactive oxygen and nitrogen species can increase the GSH content by increasing the rate of GSH synthesis. Due to use and synthesis a balance in the GSH content in the cell is formed. GSH depletion occurs by GPX or GST. 


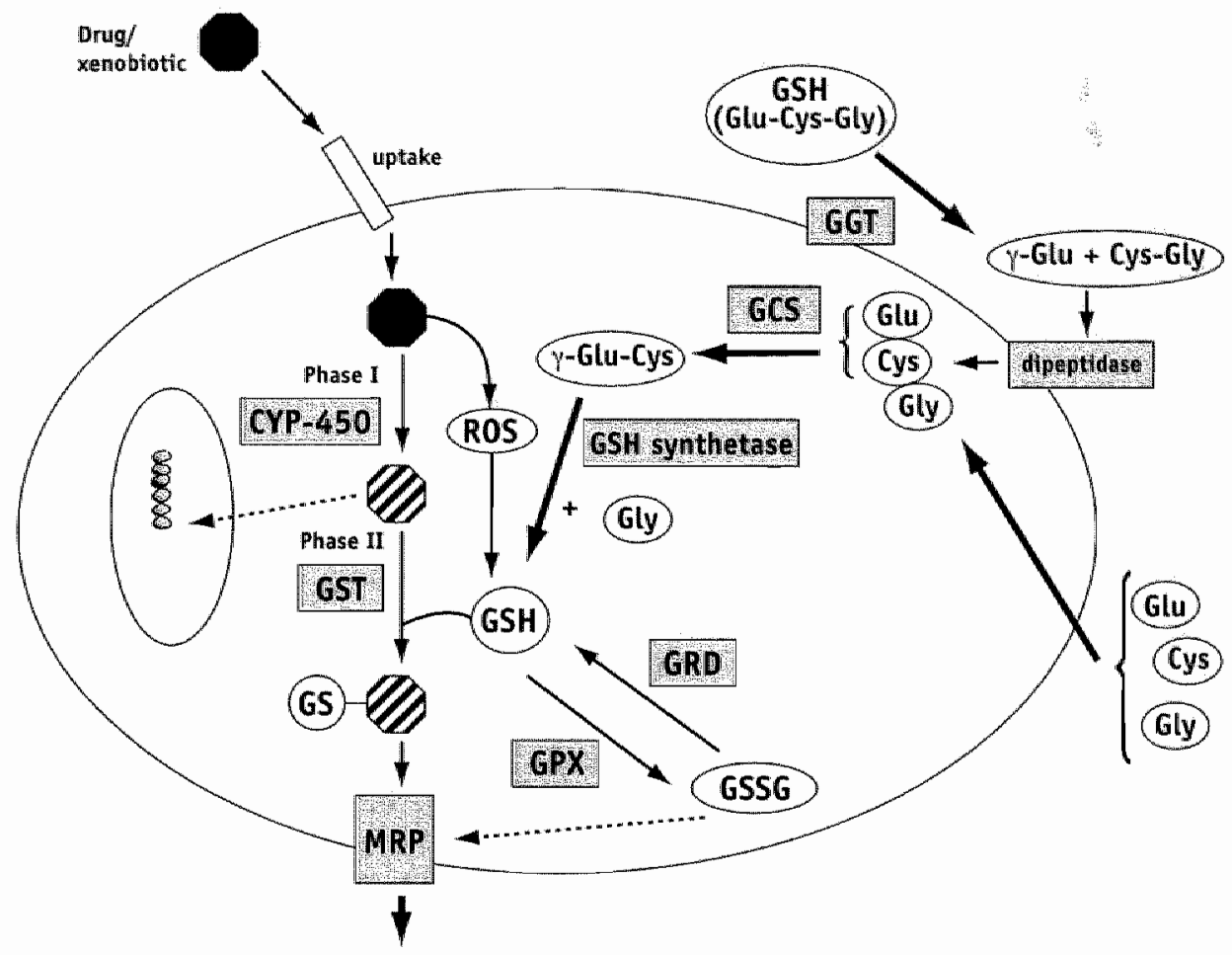

Figure 8. Glutathione metabolism and glutathione dependent cellular defence mechanisms.

Drugs and xenobiotics are token up by the cell and metabolised by cytochrome 94505 . This potentially generates electrophilic cytotoxic intermediates (dashed symbols) and ROS (Phase I). In the detoxiffi. cation of these products GSH plays an important role. GST catalyses glutathione conjugation reactions (phase II). These glutathione comjugates are recognised by MRP family members and transported out of the cell. GSH is also important for the GPX catalysed reduction of ROS, which result in the formation of GSSG. This is reduced by GRD or excreted via MRP. Substrates for the GSH synthesis are provided by transport of aminaacids across the membrane or by the action of GGT and dipeptidases. The symthesis of GSH results from the effort of GCS and GSH synthetase. Thick arrows indicate processes involved in the GSH synthesis.

\subsubsection{Uptake and synthesis}

Substrates for the GSH synthesis are provided by transport of aminoacids across the plasma membrane or by the action of GGT and dipeptidases. GGT is a membrane bound protein found in the serum of a wide range of normal and neoplastic cells [102, 103]. It catalyses the first step in the degradation of extracellular GSH. 
In GSH, the aminoacid glutamic acid is bound to the cysteine residue with a gammaglutamyl binding. This Glu-Cys bond is not sensitive for regular proteolysis so GSH cannot be cleaved which makes the molecule more stable. GGT is able to hydrolyse the gamma-glutamyl bond between Glu and Cys. In this way cysteinyl-glycine is released, which is subsequently cleaved to Cys and Gly by plasma membrane dipeptidase activities [99]. These two aminoacids can cross the plasma membrane and are again used in the GSH synthesis.

$$
\text { GSH } \rightarrow-y-\text { glutamate }+ \text { Cys - Gly }
$$

GGT would thus play a role in preserving cellular levels of GSH by GSH cycling at the plasma membrane [104].

The "de novo" synthesis of GSH results from the effort of two ATP-dependent enzymes, $\gamma$-glutamylcysteine synthetase ( $\gamma$-GCS) (formerly known as glutamate-cysteine ligase) and glutathione synthetase. GCS is rate limiting for the synthesis of GSH. This enzyme consists of two nonidentical subunits, a heavy subunit and a light subunit $[105$, 106]. The heavy subunit contains all structural requirements for the enzymatic activity and feedback inhibition. The function of the light subunit is not directly associated with the enzymatic activity but it exerts some effect on the stability of the enzyme and on the controlling of the kinetic properties of the heavy subunit [107109]. The promoter regions of both subunits contain a number of transcription factor binding sites including activator protein 1 (AP-1), nuclear factor $\kappa B$ (NFKB) and antioxidant response element (ARE) sites, which are potential targets for regulation of the enzyme [110]. The activity of $\gamma$-GCS is regulated by nonallosteric feedback inhibition by GSH which means that when the GSH concentration decreases, the feedback inhibition by GSH also decreases and $\gamma$-GCS synthesise more GSH [111].

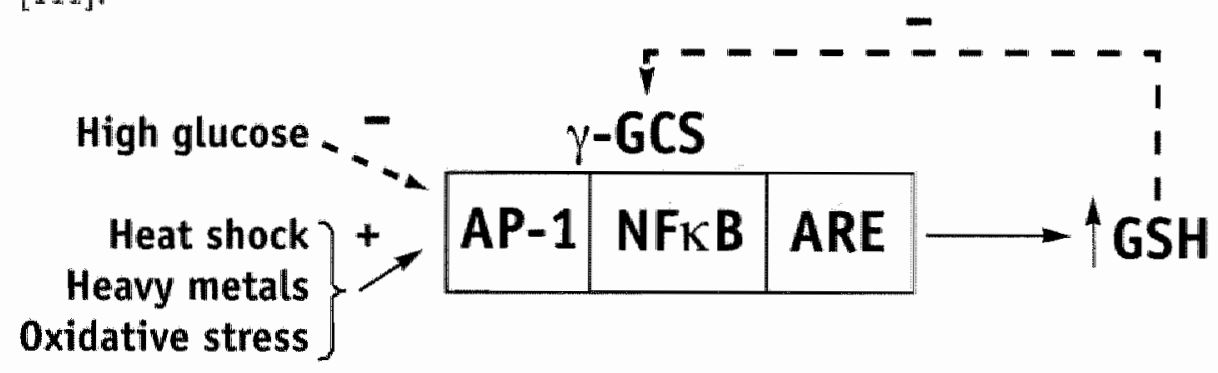

Figure 9. Regulation of GSH concentration by $\psi \mathrm{GCS}$.

The activity of $\gamma$-GCS can be influenced by many different conditions. High glucose concentration lowers the GSH concentration by decreasing the expression of $\gamma-G C S$ mRNA which leads to a decrease in enzyme protein and enzyme activity [112]. 
The GSH concentration can be increased by heat shock [113] heavy metals [114] and oxidative stress e.g. $\mathrm{NO}^{\circ}$ or $\mathrm{H}_{2} \mathrm{O}_{2}[110,115]$. Due to these different conditions the tramscriptional levels of $\gamma$-GCS increase, the $\gamma$-GCS activity increases and more GSH is produced.

\subsubsection{Functions of glutathione}

\subsubsection{Enzyme substrate}

GSH is used as a substrate by various enzymes, involved in cell defence. The most. important ones are described below.

\subsubsection{1a Glutathione peroxidase (GPX)}

Glutathione peroxidase (GPX) catalyses the reduction of a large variety of hydroper. oxides into their corresponding, less reactive, alcohols at the expense of GSH, which is oxidised to GSSG. Distinct families of enzymes display GPX activity these can be classified in selenium-dependent en selenium-independent [116-118]. The seleniumdependent enzymes are formed by the classical glutathione peroxidases (GPX) [119] and the phospholipid hydroperoxide GPX (PLHG-PX), originally called peroxidation inhibiting protein (PIP) [120]; the selenium-independent enzymes are formed by glutathione-S-transferases (GST). The enzymes can be distinguished by different substrate selectivity [118]. Both the selenium-dependent glutathione peroxidases use hydrogen peroxide and organic hydroperoxides as substrate. Phospholipid hydroperoxides cam only directly be accepted as substrate by PLHG-PX [120]. In order to detoxify phospholipid hydroperoxide by the classical selenium-dependent GPX; it has to be deacylated by phospholipase $A_{z}$. A lysophospholipid and a free lipid hydroperoxide is formed which can be converted via the classical selenium-dependent GPX [121].

$$
\begin{gathered}
2 \mathrm{GSH}+\mathrm{ROOH} \stackrel{\text { GPF }}{\rightarrow} \mathrm{GSSG}+\mathrm{H}_{2} \mathrm{O}+\mathrm{ROH} \\
2 \mathrm{GSH}+\mathrm{H}_{2} \mathrm{O}_{2} \stackrel{\text { GPX }}{\rightarrow} \mathrm{GSSG}+2 \mathrm{H}_{2} \mathrm{O}
\end{gathered}
$$

The selenium-independent glutathione peroxidase (GST) is only active with organic hydroperoxides; they are inactive with hydrogen peroxide. The GST catalysed reaction between hydroperoxide and GSH is performed in two steps [117]. The first one is catalysed by GST:

$$
\mathrm{GSH}+\mathrm{ROOH} \stackrel{\mathrm{GST}}{\rightarrow} \mathrm{GSOH}+\mathrm{ROH}
$$

This reaction is followed by a non-enzymatic reaction of sulfenic acid with GSH [122].

$$
\mathrm{GSOH}+\mathrm{GSH} \rightarrow \mathrm{GSSG}+\mathrm{H}_{2} \mathrm{O}
$$


Phospholipid hydroperoxide can only be detoxified by the selemium-independent class of enzymes via phospholipase $A_{2}$. However, the membrane-bound form of GST is able to reduce phospholipid hydroperoxides without the participation of phospholipase $A_{2}[123]$.

Glutathione peroxidase activity can, either alone or in combination with phospholipase $A_{z r}$ form an important defence mechanism against lipid-hydroperoxidedependent' lipid peroxidation [121, 123]. So GPX is used for the protection and detoxification of biomembranes and for maintaining of the structural and functional integrity of the cytosolic compartment.

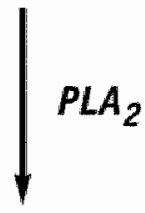 \\ lipid hydroperoxide \\ lysophospholipid}

Phospholipid hydroperoxides
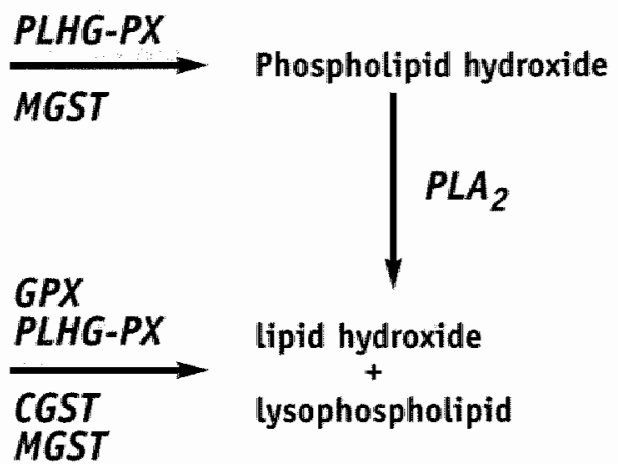

Figure 10. Reduction of phospholipid hydroperoxides by GPX5 and phospholipase $A_{2}\left(P L A_{2}\right)$.

\subsubsection{Glutathione reductase (GRD)}

Glutathione reductase (GRD) has a disulfide in its catalytic site. The enzyme exists as a dimer of two identical subunits [102, 116]. The cellular function of GRD is to maintain the GSH:GSSG ratio at about 20:1. This is achieved by using NADPH as coenzyme in the reduction of GSSG to GSH.

$$
\mathrm{NADPH}+\mathrm{H}^{+}+\text {GSSG } \stackrel{\text { GRD }}{\rightarrow} \mathrm{NAOP}^{+}+2 \mathrm{GSH}
$$

In normal cases the reduction of GSSG by glutathione reductase is relatively rapid, but in cases of oxidative stress GSSG can accumulate. In this case GSSG is either transported from the cells or can exchange with protein sulfhydryls to produce protein-glutathione mixed disulfides [124]:

$$
\text { GSSG + protein - SH } \leftrightarrows \text { protein - SSG + GSH }
$$




\subsubsection{Glutathione 5-transferase (GST)}

GST is a superfamily of phase II enzymes which exists of a number of cytosolic GSTs (alpha (A), mu (M), pi (P), theta(T) and zeta (Z)) [125-127], three microsomal (MGST 1, MGST 2 and MGST 3) and one mitochondrial GST (kappa (K)) each of which displays distinct catalytic as well as binding properties $[125,126]$.

The microsomal GSTs are members of the MAPEG (membrane-associated proteins in eicosanoid and glutathione metabolism)-family, which consists of six human proteins. The proteins within this family which contain GST activity are microsomal GST 1 (MGST 1), MGST 2 and MGST 3.

A standardised nomenclature for human GSTs was introduced in 1992 [128] and was extended in 1995 [129]. This nomenclature identifies each GST by species using lower case letter( $s$ ) preceding "GST" ( $h$ for human, $r$ for rat, $m$ for mouse etc.). This is followed by an upper case letter denoting the class ( $A, M, P, T, Z$ ), then an Arabic numeral indicating the subunit $(1,2,3 \ldots)$ and in a few cases a lower case letter for the allelic variants of the same gene $(a, b, c \ldots)$.

All isoenzymes of GST exist as multimeric proteins. The cytosolic GSTs appear as dimeric proteins with subunits of approximately $25 \mathrm{kDa}$ [130]. The microsomal GSTs exists as a trimer of three identical polypeptides each of $17.2 \mathrm{kDa}$ [131]. Only the subunits within each class hybridise in the cytosolic GSTs to give active dimers [126]. Each subunit of the enzyme has an active site composed of two distinct functional regions. A hydrophilic G-site which binds the physiological substrate GSH and a hydrophobic $\mathrm{H}$-site which is responsible for the binding and orientation of structurally diverse electrophilic substrates $[132,133]$. Only about $30 \%$ sequence similarity exists between the different isoenzymes, but their quaternary structure is remarkably similar [134].

The first and most important function of the enzyme is conjugation of electrophilic compounds with GSH. GST brings the substrate (electrophilic compound) into close proximity with GSH by binding both the substrate and GSH. The thiol of GSH is first activated to the thiolate anion (GS) to increase its nucleophilicity. $\mathrm{GS}^{-}$attacks on the electrophilic substrate (R-X) with a GSH-conjugate as result [135]. In most cases the substrate is detoxified because the reactivity of the substrate with cellular macromolecules is decreased, but in a few cases the conjugate is more reactive than the substrate.

$$
\mathrm{GSH}+\mathrm{RX} \stackrel{\text { GST }}{\rightarrow} \mathrm{GSR}+\mathrm{HX}
$$

The formed glutathione conjugates are metabolised further by cleavage of the glutamate and glycine residues. The resulting cysteine S-conjugate may be metabolised by $\mathrm{N}$-acetyl-transferase to mercapturic acids, which are non-toxic and are excreted via the urine [136]. Mercapturic acids also can be substrates for the cysteine 
conjugate beta-lyase, which catalyses either a beta-elimination or a transamination reaction to produce unstable thiols. These thiols rearrange to form potent acylating species that can covalently bind to cellutar macromolecules, thereby producing cytotoxicity, mutagenicity, and carcinogenicity [137].

The second function of GST is performing GPX activity towards lipid hydroperoxides, as described in part 2.4.3.1.a [122]. The third function of GSTs is intracellular transport of hydrophobic molecules, e.g. of $\alpha$-tocopherol quinone. $\alpha$-Tocopherol quinone binds to GST and may be transported to the site of metabolism or excreted in the bile [138]. The fourth function of GSTs is reduction of the free concentration of toxic compounds through non-catalytic binding [130].

The cytosolic classes of GSTs are differentially expressed in various tissues and various tissues may express different isoenzymes. The alpha and mu class isoenzymes are predominantly expressed in the liver and kidney and to a much lower and variable extent in other tissues [126]. The most widely distributed isoenzyme is the pi class; it is the GST isoenzyme most abundantly present in many tissues. GST P occurs mostly in erythrocytes, placenta [139] and human skin, and is the GST isoenzyme mostly expressed in tumour cells [139, 140].

The genes for the mu and pi isoform of GST are polymorphic, gene deletions for these genes occur quite often in human populations. The GST isoenzymes of the mu class are expressed in only $60 \%$ of the human population. It has been reported that people homozygous for GST M1 deletions have an increased risk for the development of lung, bladder [141, 142] and thyroid cancer [143]. This is probably due to the fact that GST M and GST $P$ are important for the detoxification reactions of PAH carcinogenic intermediates [144]. So inhibition of the GST activity can increase the occurrence of different types of cancer because the harmful compounds cannot be detoxified. Also the risk for other diseases will increase e.g. the risk for cardiovascular diseases, e.g. because the detoxification of harmful products of lipid peroxidation (4-hydroxy-2-nonenal) which are usually detoxified by GST [132], is also diminished. In tumour cells, however, GST may detoxify chemotherapeutics or its metabolites decreasing the efficacy of the drug. In this way GST expression contributes to resistance against cytostatic drugs [145]. In this case inhibition of the GST will be beneficial.

Another possible effect of inhibition of GST activity can be achieved by a conformational change in the molecule induced by the inhibitor. In normal configuration GST can form a complex with Jun-JNK signal transduction proteins. In this way the C-Jun terminal kinase is inhibited. After a conformational change of GST it cannot form a complex with Jun-JNK enabling JNK phosphorylation of C-Jun, which is a stable and active transcription factor [146]. Overexpression or hyperactivation of CJun can lead to uncontrolled proliferation and apoptosis.

A number of GST inhibitors have been described in literature but the only in vivo 
active inhibitors of GSTs are ethacrynic acid and a number of glutathione derived structures. However the glutathione derived structures preferentially inhibit GST A [147], whereas for inhibition of multiple drug resistance it is better to inhibit GST $P$, because GST $P$ is the predominant form of GST present in human tumours. GST $P$ is preferentially inactivated by sulfhydryl group modifiers such as NEM [148]. The cysteine residues at position 14,47,101 and 169 from the $\mathrm{N}$-terminus are involved in this inhibition. Cys47 is the most reactive thiol group [149, 150].

The three microsomal GSTs are members of the MAPEG-proteins, which is a widespread superfamily. All the members of the family have a comparable size, ranging from 147 to 161 amino acids [151, 152]. The amino acid sequence of MGST is not related to that of the cytosolic transferases and the trimer of MGST consists of 154 aminoacids per subunit [153]. Of the three microsomal GSTs the MGST1 is most widely expressed. MGST1 makes up to $3 \%$ of the protein in the liver microsomes [151] and $80 \%$ of it is located on the endoplasmic reticulum [154].

The cytosolic and microsomal GST catalyse the same type of reactions but there are also various differences between the cytosolic and microsomal GSTs. Firstly, the molecular weight of the subunits of MGST is much lower compared to the CGST subunits. Secondly, each subunit of MGST contains only one cysteine residue whereas CGST subunits contain more than one cysteine group. Thirdly, the CGST and MGST differ in the substrate specificity, MGST has a very restricted substrate specificity compare to CGST [155]. A fourth difference between CGST and MGST is expressed when GST performs its peroxidase activity. MGST can reduce both organic hydroperoxides and phospholipid hydroperoxides itself. CGST can reduce organic hydroperoxides, for the reduction of phospholipid hydroperoxides it needs the participation of phospholipase $A_{2}[123,131]$. The fifth difference between MGST and CGST is a difference in modification. MGST is activated by modification of the sylfhydryl group with the thiol-modifying compound $\mathrm{N}$-ethylmaleimide (NEM) [156-160], limited proteolysis, thiol-disulfide exchange and ROS (e.g. $\mathrm{ONOO}^{-}, \mathrm{H}_{2} \mathrm{O}_{2}$, and $\mathrm{O}_{?}^{\circ-}$ ) [158, 161]. MGST is activated when SH-reactive electrophiles need to be detoxified [162]. Of the CGSTs it is known that they can be inactivated by NEM or other forms of ROS, e.g. $\mathrm{H}_{2} \mathrm{O}_{2}[148]$.

\subsubsection{1d Multidrug resistance-associated protein (MRP)}

The formed GSH-conjugates, due to GST activity, have to be released from the intracellular compartment because these products give rise to a potent product inhibition of the GSTs [163].

The GSH-conjugates are eliminated from the cell, to undergo further metabolism and to be excreted from the organism, by energy dependent efflux pumps. An example of such a pump is the glutathione S-conjugate transporter, also called the Multidrug Resistance-associated Protein (MRP) $[118,164]$. MRP is a multigene family of trans- 
port proteins that comprise at least six members. MRP1 and MRP2 are the most important proteins of this family. It can transport drugs and glutathione conjugates out of the cell. Also GSSG can be transported out of the cell by MRP. GSH itself is a poor substrate for the protein, but GSH is either required as an activator or as cotransport substrate for the protein [165].

Changing the expression or activity of MRP can have a variety of clinically important effects. Firstly, the excretion of endogenous compounds is impaired resulting in different types of diseases e.g. hyperbilirubinemia. Secondly, the clearance of many clinically important drugs including cancer chemotherapeutics can be altered. Thirdly, cell redox status or response to oxidative stress can be altered since GSSG is a substrate for the enzyme [166].

\subsubsection{2 antioxidant function}

The antioxidant role of GSH is the detoxification of electrophilic/ oxidising drugs and protection against lipid peroxidation. The thiol moiety of GSH is responsible for this antioxidant effect. The reduced form of the tripeptide is able to scavenge reactive species like ROS e.g. $\mathrm{OH}^{*}$, $\mathrm{HOCl}$, peroxynitrite, $\mathrm{RO}^{*}$, carbonyl-centred radicals and ${ }^{\prime} \mathrm{O}_{2}$.

GSH is also able to bind $\mathrm{Cu}^{+}$through the cysteine thiol group, which leads to copper delivery to the apoprotein of copper enzymes. By binding of copper, GSH reduces the dangerous effects of free intracellular copper by decreasing potentially toxic reactions among metals and oxygen (Fenton reaction) [167].

\subsubsection{3 pro-oxidant activity}

When the gamma-glutamyl bond between Glu and Cys in GSH is hydrolysed by GGT (part 2.4.2) a cysteinyl-glycine is released. Most of the times this product is cleaved and the aminoacids are used in the GSH synthesis. However the cysteinyl-glycine moiety can also have a pro-oxidant effect [168]. The reactive thiol in the Cys-Gly can interact, more efficiently than does GSH, with trace levels of iron ions present in the cell environment. This could cause the reduction of ferric iron ( $\mathrm{Fe}^{3+}$ ) to ferrous iron $\left(\mathrm{Fe}^{2+}\right)$ which is the start of a redox-cycling process resulting in the production of ROS, i.e. superoxide anion in the first place, as well as thiyl radicals $\left(-S^{*}\right)$, and eventually stimulation of oxidative reactions like lipid peroxidation. So during the catabolism of GSH some pro-oxidant species can be formed, which can induce lipid peroxidation but can also react with critical targets in the intracellular signal transduction cascade.

\subsubsection{4 non-antioxidant function}

In cases of oxidative stress GSSG can accumulate and form protein-glutathione mixed disulfides. The formation of these protein-glutathione mixed disulfides can 
result in impaired protein function. A significant number of proteins that have critical thiols and are involved in signalling functions, e.g. receptors, proteins involved in ubiquination, protein kinases and some transcription factors, can be altered in their function. In this way GSSG acts as a non-specific signalling molecule [1.06, 124].

When transcription factors are altered the capability of the protein to bind to DNA is inhibited. This results in inhibition of the effects of transcription factors and eventually to apoptosis [167]. Therefore, it can be concluded that the GSH/GSSG redox pair can work as a sensor of oxidative stress.

\subsection{Interplay between vitamin $\mathrm{E}$ and glutathione (-dependent enzymes)}

\subsubsection{Interplay of vitamin $E$ and GSH in the lipid peroxidation}

Lipid peroxidation has been implicated as a major process in cellular damage. GSH is found to be a potent inhibitor of microsomal lipid peroxidation. Addition of GSH to rat liver microsomes, in which lipid peroxidation is induced, delayed the occurrence of lipid peroxidation (lag time). However, the maximal degree of lipid peroxidation (measured as thiobarbituric (TBA)-reactive material) is equal in incubation with or without GSH (Figure 11.) [169].

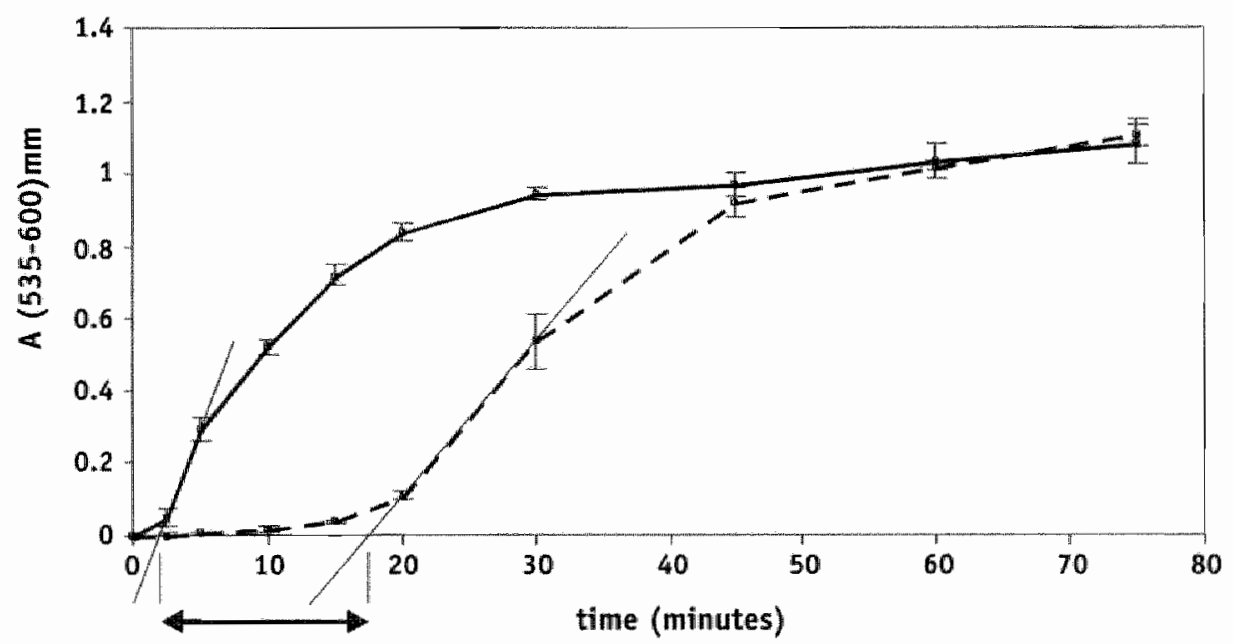

Figure 11. Influence of $\mathrm{GSH}(1 \mathrm{mM})$ on the time-course of lipid peroxidation in control microsomes with (-) and without (-) addition of $65 \mathrm{H}$.

This GSH-dependent protection proceeds via a heat-labile factor, probably an enzyme, because the protection is lost after heating of the microsomes [169-171]. The 
GSH-dependent protection is also absent in vitamin E depleted microsomes [170, 172]. It was suggested that interplay exist between vitamin $E$ radicals and GSH. Probably, the nonenzymatic reaction between $G S H$ and vitamin $E$ radical is too slow due to the location of vitamin $E$ radical (membrane) and GSH (cytosol) in different compartments. The enzyme involved, functions as a free radical reductase (FRR). It regenerates the $\alpha$-tocopherol radical to $\alpha$-tocopherol $[169,170,173]$. Additional studies indicate that the enzyme contains an essential and vulnerable thiol moiety itself and is selective for GSH as cofactor. GSSG and other disulfides e.g. cysteine, cystamine, mercaptoethanol and dithiothreitol, had no effect on the reductase activity of FRR $[160,174-176]$.

The maximal degree of lipid peroxidation in control microsomes and GSH-suppleted microsomes can be explained by the fact that FRR itself is vulnerable to oxidative stress. A product of the lipid peroxidation, 4-hydroxy-2-nonenal, blocks the reductase function of FRR by alkylating the SH-moiety in the enzyme [160]. The free radical reductase is not specific for $\alpha$-tocopherol, but also acts with other compounds containing a free hydroxyl group such as propofol [177] or same flavonoids such as fisetin and naringenim [178].

Not all the formed $\alpha$-tocopherol radicals are reduced to $\alpha$-tocopherol by GSH and FRR. The $\alpha$-tocopherol radicals that are not reduced can be oxidised further to $\alpha$ tocopherol quinone. In microsomes with a low $\alpha$-tocopherol level, $\alpha$-tocopheroll quinone antagonises the reduction of $\alpha$-tocopherol radical to $\alpha$-tocopherol and in this way inhibits the GSH-dependent protection against lipid peroxidation. A possible explanation for this effect is that $\alpha$-tocopherol quinone competes with $\alpha$-tocopherol for binding to the FRR. The $\alpha$-tocopherol binding is superior to the binding of $\alpha$ tocopherol quinone to FRR [179].

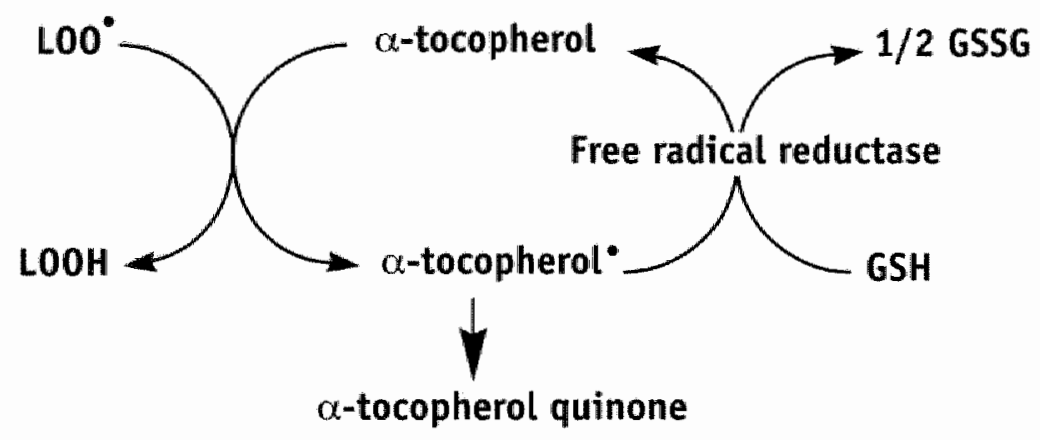

Figure 12. Interaction of $\alpha$-tocopherol and 65H in the protection against lipid peroxidation.

$\alpha$-Tocopheral radicals are regenerated to $\alpha$-tocopherol by GSH. The reaction is catalysed by a free radical reductase. Not all $\alpha$-tocopherol radicals will be reduced to $\alpha$-tocopherol. Some $\alpha$-tocopherol radicals will oxidise further to $\alpha$-tocopherol quinone. 


\subsubsection{Reduction of $\alpha$-tocopherol quinone by GSH}

It is demonstrated that $\alpha$-tocopherol quinone can be converted into $\alpha$-tocopherol in humans [48]. As described in the previous section (2.5.1) $\alpha$-tocopherol is regenerated form the $\alpha$-tocopherol radical by a microsomal $6 S H$-dependent free radical reductase. The assumption that $\alpha$-tocopherol quinone can also be reduced to $\alpha$ tocopherol by GSH was examined, both after direct interaction of a-tocopherol quinone and GSH and in liver microsomal membranes. These membranes contain an important radical-producing system, contain a high content of $\alpha$-tocopherol and once the lipophilic $\alpha$-tocopherol quinone is formed it is likely to be retained within the microsomal membrane.

Moreover, the microsomes contain the GSH-dependent free radical reductase [169, 180]. It was shown that no reduction of $\alpha$-tocopheral quinone by GSH to $\alpha$-tocopherol or $\alpha$-tocopherol hydroquinone accurred either directly in solution or in microsomes. So the observed reduction of $\alpha$-tocopherol quinone to $\alpha$-tocopherol in humans is not due to direct interaction or to a GSH-dependent reaction with $\alpha$ tocopherol quinone in liver microsomes [179]. The mechanism of the reduction of $\alpha$-tocopherol quinone to $\alpha$-tocopherol is not known yet. It is assumed that it occurs by vitamin C [181]. But other investigators found that it would not happen by one of the natural reductants [61] or even would not happen at all [182].

\subsubsection{Effect of vitamin E on GST activity}

It is known that the pi form of GST is very susceptible to oxidative stress [139]. So it was assumed that antioxidants like vitamin $\mathrm{E}$ could have a protective effect on GST P.

Indeed, Chen et al. showed that vitamin $E$ treatment had a detoxifying effect in rats with benzo(a)pyrene induced carcinogenesis. A possible explanation for this increase in detoxifying capacity can be an increase in the activity of GST due to vitamin E treatment [183]. It is also shown that vitamin E can protect GST, because deficiency of vitamin $\mathbb{E}$ can lead to impairment of GST in microsomes [184].

However, contrary to these two findings, some researchers have shown that rats fed a diet deficient in vitamin $E$ and selenium have an increased GST activity [185, 186]. And it was also demonstrated that tocotrienol and tocopherol treatment of rat hepatocyte cultures significantly decreased GST activities at day 1-3 [187]. In vitro studies with isolated human GST P1-1 isoenzyme also show that tocopherols, tocotrienols, $\alpha$-tocopherol derivatives and $\alpha$-tocopherol quinone can inhibit the GST activity in a concentration dependent manner [188-190]. This inhibition is noncompetitive with respect to the substrates GSH and 1-chloro-2,4-dinitrobenzene (CDNB). 


\subsection{Concluding remarks}

As described in part 2.3.3, vitamin $\mathrm{E}$ has multiple functions. It has antioxidant activity, some pro-oxidant an also non-antioxidant effects. In all three groups of effects, anti-, pro-, and non-antioxidant, vitamin $\mathrm{E}$ can interplay with glutathione (-dependent enzymes) (part 2.5).

It is known that the various vitamers of vitamin $E$ have comparable antioxidant activity. Some metabolites ( $\alpha$-tocopherolhydroquinone) have antioxidant activity and vitamin E participates in an elaborate antioxidant network, which also involves GSH. Apparently the antioxidant/ pro-oxidant effects of vitamin $E$ are not specific. It is also possible that vitamin $\mathrm{E}$ or its metabolites display pro-oxidant activity, depending on the oxidation state of the cell. The non-antioxidant functions of vitamin $E$ are more specific because the different vitamers can perform different or even antagonistic activities. For instance, $\alpha$-tocopherol inhibits PKC and $\beta$-tocopherol antagonises this; tocotrienol inhibit HMG-COA reductase and tocopherols do not. However, multiple vitamers of vitamin E can inhibit GST activity.

To test the antioxidant effects of vitamin $E$ some human clinical intervention studies have been performed. However the results are disappointing. The non-antioxidant functions of vitamin $\mathrm{E}$ have not been investigated in clinical intervention studies. The question can be raised what the most important function of vitamin $E$ is: antioxidant or non-antioxidant.

In 1967 it was already proposed by Olson et al. that $\alpha$-tocopherol functions, in cooperation with a regulatory gene, to control excessive synthesis of catabolic enzymes. Vitamin E deficiency reduces the serum creatine phosphokinase content by reduction of its synthesis [191]. More recently, Azzi and Stocker have also displayed that the antioxidant effect of vitamin $E$ is not the primary action of vitamin $E$. Diverse cellutar functions of vitamin $E$, unrelated to their antioxidant activity, are known (part 2.3.3.3). For this functions vitamin $E$ would act as sensor for oxidative stress due to its oxidisability; which means that it triggers the cellular response toward oxidative stress [79, 192]. Also some gene-regulatory functions of $\alpha$-tocopherol have been displayed [193-195], e.g. up-regulation of $\alpha$-tropomyosin expression by $\alpha$-tocopherol, and not by $\beta$-tocopherol. Probably this is indirectly elicited via inhibition of PKC activity due to $\alpha$-tocopherol [196]. Overexpression of tropomyosin in vascular smooth muscle cells diminishes the blood pressure via decreasing the contractility of the smooth muscle cells.

Despite the uncertainty about the primary function of vitamin $E$ it is used in a lot of products including cosmetic products and food supplements. Probably it would be better to know more about the status, e.g. oxidant status, of the "patient", before 
using vitamin $E$ as a supplement [67]. As indicated in Figure 13., vitamin $E$ and GSH can perform different actions during the diverse oxidation states of the cell.

At beginning oxidative damage it is useful to have more vitamin $E$ and GSH, but at severe oxidative damage these compounds can display pro-oxidant activity.

\section{highly reduced}

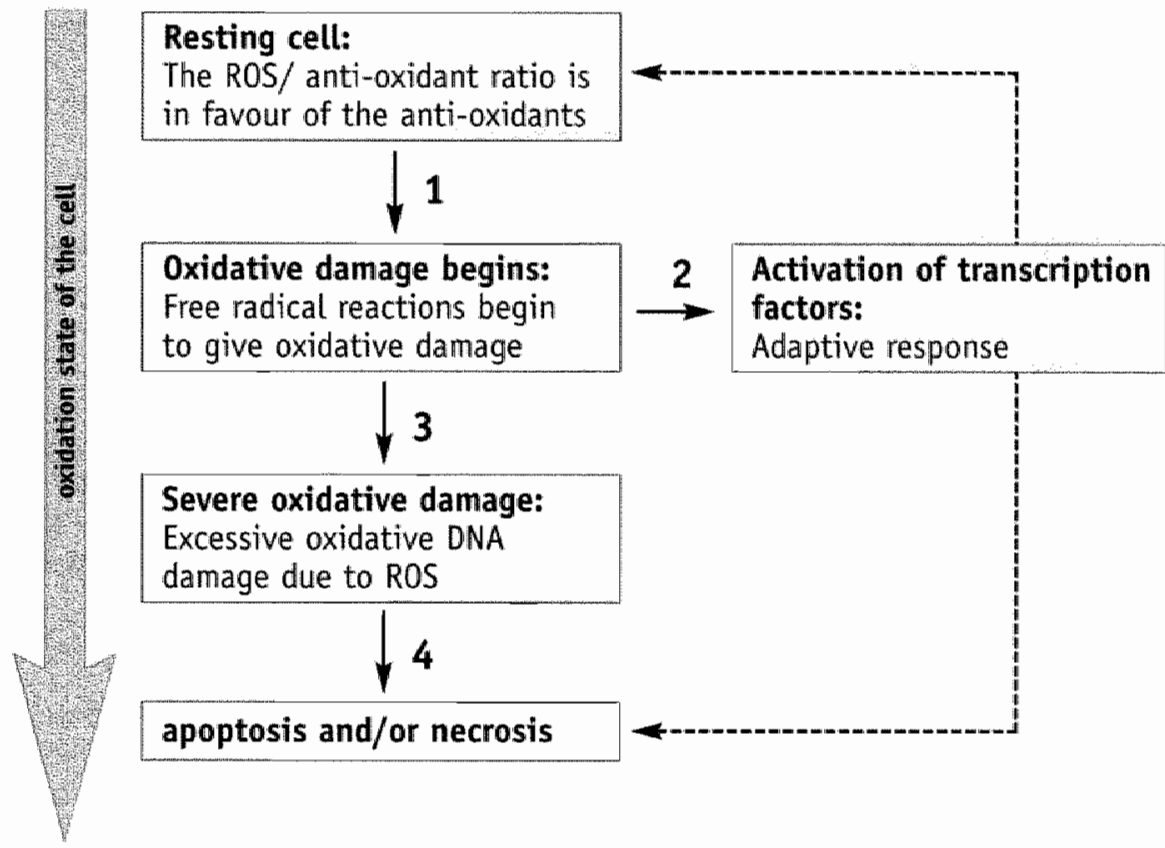

\section{highly oxidised}

Figure 13. The paradoxical functions of vitamin E and glutathione.

In a reduced state a functional cellular antioxidant network with vitamin $E$ and gilutathione is active. To combat oxidative damage these compounds act together with FRR to prevent the process of lipid peroxidation. (1) Changing the ratio of ROS/ antioxidants towards ROS will induce oxidative damage. Supplementation of vitamin E or GSH will protect the cell. (2) During adaptation to oxidative stress the non-antioxidant functions of vitamin $E$ and GSH take place. The consequences of these non-antioxidant functions can be opposite. (3) When the antioxidant functions are not adequate, severe oxidative damage takes place in the cell. Vitamin $E$ and GSH can display a pro-oxidant action by accelerating oxidative damage by reacting with traces of transition metal ions. Also $\alpha$-tocopherol quinone can perform pro-oxidant effects in the pracess of lipid peroxidation. (4) Eventually this will lead to opoptosis and/or necrosis. 


\section{References}

1. Bast, A: Haerien, G.R.: Doelman, C.J. Oxidants and antioxidants: state of the art. The American journal of medicine 1991, 91, 2S-13S.

2. Bast, A.; Haenen, G.R.M.M. Zin en onzin van antioxidantia. Pharnaceutisch Weekblad 1991, 126, 600-605.

3. Halliwell, B. How to characterize an antiaxidant: an update. Biochemical Society Symposium 1995, 61, 73-101.

4. Sies, H.; Stahl, W. Sundquist, A.R. Antioxidant functions of vitamins: Vitamins $E$ and C. Beta-carotene, and other carotenoids. Annals of The New York Academy of Sciences 1992, 669, 7-20.

5. Noguchi, N., Watanabe, A.: Shi, H. Diverse functions of antioxidants. Free Radical Research 2000, 33, 809-817.

6. Evans, $P_{\text {; }}$ Halliwell, B. Micronutrients: oxidant/antioxidant status. British Journal of Nutrition 2001, 85 Suppl 2, 567-74.

7. Chaudiere, J.; Ferrari Iliou, R. Intracellular antioxidants: from chemical to biochemical mechanisms.

Food and Chemical Toxicology 1999, 37, 949-962.

8. Evans, H.M.; Bishop, K.S. On the relationship between fertility and nutrition. The Journal of Metabolic Science 1922, 1, 319-356.

9. Mason, K.E. Differences in testis injuny and repair after vitamin A-deficiency, vitamin Edeficiency, and inanition.

The American Joumal of Anatomy 1933, 52, 153-227.

10. Evans, H.M.; Emerson, 0.H.; Emerson, G.A. The isolation from wheat-germ oil of an alcohol, alpha-tocopherol, having the properties of vitamin $E$.

Journal of Biological Chemistry 1936, 113, 319.

11. Fernholz, E. On the constitution of alpha-tocopherol. Journal of the American Chemical Society 1938, 60, 700-705.

12. Kamal-Eldin, A.: Appelquist, L.A. The chemistry and antioxidant properties of tocopherols and tocotrienols.

Lipids 1996, 31, 671-701.

13. Wang, X. Quinn, P.J. Vitamin $E$ and its function in membranes.

Progress in lipid research 1999, $38,309-336$.

14. Theriault, A.; Chao, J.T.; Wang, Q.; Gapor, A.; Adeli, K. Tocotrienol: a review of its therapeutic potential.

Clinical Biochemistry 1999, 32, 309-319.

15. Bouemfeind, J.C. The tocopherol content of food and influencing factors. Critical Reviews in Food Science and Nutrition 1977, 8, 337-382.

16. Cheeseman, K.H.; Holley, A.E.; Kelly, F.J.; Wasil, M.; Hughes, L.; Burton, G. Biokinetics in humans of RRR-alpha-tocopherol: the free phenol, acetate ester, and succinate ester forms of vitamin $E$.

Free Radical Biology \& Medicine 1995, 19, 591-598.

17. Bjomeboe, A.; Bjorneboe, G.E.A.; Drevon, C.A. Absorption, transport and distribution of vitamin $E$.

Journal of Nutrition 1990, 120, 233-242.

18. Sato, $Y_{n}$; Hagiwara, $K_{n}$; Arai, $K_{2}$, Inoue, $K_{n}$ Purification and characterization of the alpha-tocopherol transfer protein from rat biver. 
Federation of European Biochemical Societies 1991, 288, 41-45.

19. Burton, G.W. Traber, M.G. Vitamin E: antioxidant actinity bioknetics, and broavailabibity. Annual Review of Nutrition 1990, 10, 357-382.

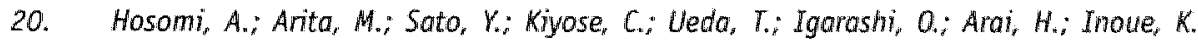
Affinity for alpha-tocopherol transfer protein as a determinant of the biological activinties of vitamin $E$ analogs.

Federation of European Biochemical Societies 1997, 409, 105-108.

21. Drevon, C.A. Absorption, transport and metabolism of vitamin $E$. Free Radical Research Communications 1991, 14, 229-246.

22. Traber, M.G.; Araj, H. Molecular mechanisms of vitanin E tranisport. Annual Review of Nutrition 1999, 19, 343-355.

23. Parker, R.S. Dietary and biochemical aspects of vitamin $E$. Advances in Food and Nutrition Research 1989, 33, 157-232.

24. Azzi, A.; Breyer, I.; Feher, M., Ricciarelli, R.; Stocker, A.; Zimmer, S.; Zingg, J. Nonantioxidant functions of alpha-tocopherol in smooth muscle cells. Journal of Nutrition 2001, 131, 378S-381S.

25. Zimmer, S.; Stocker, A.; Sarbolouki, M.N.; Spycher, S.E.; Sassoon, J,; Azzi, A. A novel human tocopherol-assaciated protein: cloning, in vitro expression, and characterization. The Journal of Biological Chemistry 2000, 275, 25672-25680.

26. Kappus, H.; Diplock, A.T. Tolerance and safety of vitamin E: a toxicological position report.

Free Radical Biology \& Medicine 1992, 13, 55-74.

27. Traber, M.G.; Winkthofer Roob, B.M.; Roob, J.M.; Khoschsorur, G.; Aigner, R.; Cross, G.; Ramaknishnan, $R_{n}$; Brigelius Flohe, R. Vitamin E kinetics in smokers and nomsmokers. Free Radical Biology \& Medicine 2001, 31, 1368-1374.

28. Larnaout, A.; Belal, S.; Zouari, M.; Fki, M.; Ben Hamida, C.; Goebel, H.H.; Ben Hamida, M.; Hentati, F. Friedreich's ataxia with isolated witamin $E$ deficiency: a neuropathological study of a Tunisian patient.

Acta Neuropathologica 1997, 93, 633-637.

29. Laplante, P.; Vanasse, M.; Michaud, $J_{\text {; }}$ Geoffroy, G.; Brochu, P. A progressive neurological syndrome associated with an isolated vitamin E deficiency.

Canadian Journal of Neurological Sciences 1984, 11, 561-564.

30. Krendel, D.A.; Gilchrist, J.M.; Johnson, A. O.; Bossen, E.H. Isolated deficiency of vitainin $E$ with progressive neurologic deterioration.

Neuralogy 1987, 37, 538-540.

31. Stumpf, D.A.; Sokol, Ru; Bettis, D.; Neville, H.; Ringel, S.; Angelini, C.; Bell, R. Friedreich's disease: $V$. Variant form with vitamin $E$ deficiency and normal fat absorption.

Neurology 1987, 37, 68-74.

32. Parks, E.; Traber, M.G. Mechanisms of vitamin E regulation: Research over the past decade and focus on the future.

Antioxidants \& Redox Signaling 2000, 2, 405-412.

33. Blatt, D.H.: Leonard, S.; Traber, M. Vitamin E kinetics and the function of tocopherol regulatory proteins.

Nutrition 2001, 17.

34. Sontag. T.J.; Parker, R.S. Cytochrome P450 omega-Hydroxylase Pathway of Tocopheral Catabolism. Novel mechanism of regulation of vitamin $E$ status. 
Jounal of Biological chemistry 2002, 277, 25290-25296.

35. Brigelius Flohe, R.; Kelly, F.J.; Salonen, J.T.: Neuzil, J.; Zingg, J.M.; Azzi, A. The European perspective on vitamin E: current knowledge and future research. American Journal of Clinical Nutrition 2002,76, 703-716.

36. Pope, 5.A.S.; Burtin, G.E,; Clayton, P.T.; Madge, 0.J.; Maller, D.P.R. New synthesis of (4) alpha-CMBHC and its confirmation as a metabolite of alpha-tocopherol (vitamin E). Bioarganic \& Medicinal Chemistry 2001, 9, 1337-1343.

37. Houte van, H.; De Hoffmann, E.; Van Veldhoven, P.P.; Mannaerts, G.P.; Carchon, H.; Baes, M.I.; Declerca, P.E. Oxidative catabolism of alpha-tocopherol in rat liver microsomes.

Lipids 2001, 36, 367-372.

38. Brigelius Flohe, R.; Traber, M.G. Vitamin E: function and metabolism. FASEB Journal 1999, 13, 1145-1155.

39. Parker, R.S.; Swanson, J.E. A novel 5'carboxychroman metabalite of alpha-tocopherol secreted by HEPG2 cells and excreted in human urine.

Biochemical and Biophysical Research Communications 2000, 269, 580-583.

40. Birringer, M.; Pfluger, P.; Kluth, D.: Landes, N.; Brigelius Flohe, R. Identities and Differences in the Metabolism of Tocotrienols and Tocopherols in HepG2 Cells. Journal of Nutrition 2002, 132, 3113-3118.

41. Birringer, M.; Drogan, $D_{*}$; Bregelius-Flohe, $R$. Tacopherals are metabolized in HepG2 cells by side chain (1)-axidation and consecutive $\beta$-axidation.

Free Radical Biology \& Medicine 2001, 31, 226-232.

42. Hayashi, $T_{r}$; Kanetoshi, A.; Nakamura, M.; Tamura, M.; Shirahama, H. Reduction of alpha-tocopheralquinone to alpha-tocopherolhydroquinone in rat hepatocytes.

Biochemical Pharmacology 1992, 44, 489-493.

43. Siegel, D.; Bolton, E., M; Burr, J., A; Liebler, D., $C_{*}$ Ross, D. The reduction of alphatocopherolquinone by human $N A D(P) H$ : quinone axidoreductase: the role of alphatocopherolhydroquinone as a cellular antioxidant.

Molecular Pharmacology 1997, 52, 300-305.

44. Dinkova-Kostova, D.T, Talalay, P. Persuasive evidence that quinone reductase type 1 (DT diaphorase) protects cells against the toxicity of electrophiles and reactive forms of axygen.

Free Radicat Bialogy Medicine 2000, 29, 231-240.

45. Chow, $C, K$. On the formation and measurement of alpha-tocopherolquinone and alphatocopherolhydroquinone in rat tissues.

Nutrition Reviews 1983, 41, 98-99.

46. Liebler, D.C.: Burr. J.A. Antioxidant reactions of alpha-tocopherolhydroquinone. Lipids 2000, 35, 1045-1047.

47. Liebler, D.C. The role of metabolism in the antioxidant function of vitamin $E_{\text {. }}$ Critical Reviews in Toxicology 1993, 23, 147-169.

48. Moore, A.N.J.; Ingold, K.U. alpha-Tocopherol quinone is converted into vitamin $E$ in man.

Free Radical Biology \& Medicine 1997, 22, 931-934.

49. Liebler, D.C.: Antioxidant chemistry of alpha-tocopherol in biolagical systems. Roles of redox cycles and metabolism, in Sub-cellular biochemistry: reviews and essays with the structure, fumction, genetics, biogenesis and evolution of sub-cellular components, wol 30. Edited by Kagan.

New York, Plenum Press, 1998, pp 301-317. 
50. d'Ischia, M.; Novellino, L. Nitric oxide-induced oxidation of alpha-tocopherol. Bioorganic \& Medicinal Chemistry 1996, 4, 1747-1753.

51. Clough, R.L.; Yee, B., G.; Foote, C.S. Chemistry of singlet axygen. The unstable primany product of tocopherol photooxidation.

Journal of the American Society 1979, 101, 683-686.

52. Suarna, C.; Craig, D.C., Cross, K.J.; Southwell-Keely, P. Oxidations of vitamin E (alphatocopherol) and its madel compound $2,2,5,7,8$-pentamethyl-6-hydroxychroman. A mew dimer.

Journat of Organic Chemistry 1988, 53, 1281-1284.

53. Suarna, C.; Southwell-Keely, P. New oxidation products of alpha-tacopheral. Lipids 1988, 23, 137-139.

54. Suarna, C.; Baca, M.; Southwell-Keely, P. Oxidation of the alpha-tacopherol model compound $2,2,5,7,8$-pentamethyl-6-chromanol in the presence of alcohols.

Lipids 1992, 27, 447-453.

55. Hogg. N.H., Joseph, J.; Kalyanaraman, B. The oxidation of alpha-tocopherol and trolox by peroxynitrite.

Archives of Biochemistry and Biophysics 1994, 314, 153-158.

56. Cooney, R.V.; Harwood, P.J.; Franke, A.A.; Narala, K.; Sundstram, A.; Berggren, P.; Mordan, L.J. Products of gamma-tocopherol reaction with NO2 and their formation in rat insulinoma (RINm5F) cells.

Free Radical Biology \& Medicine 1995, 19, 259-269.

57. Liebler, D.C.; Matsumoto, $S_{n} ;$ Iitaka, $Y_{*} ;$ Matsuro, M. Reactions of vitamin $E$ and its model compound 2,2,5,7,8-pentamethylchroman-6-ol with ozone.

Chemical Research Toxicology 1993, 6, 69-74.

58. Giamwala D.H.; Church. D.F.; Pryor, W.A. Kinetics of ozonation. Reactions of ozone with alpha-tocopherol and oleate and linoleate esters in carbon tetrachloride and in aqueous micellar solvents.

Journal of the American Chemical Saciety 1986, 108, 6646-6651.

59. Matsuo, M.; Matsumoto, 5. Oxygenations of vitamin E (alpha-tocopherol) and its model compound 2,2,5,7,8-pentamethylchroman-6-ol in the presence of the superoxide radical solubilized in aprotic solvents: Unique epoxidations and recyclizations.

Journal of Organic Chemistry 1987, 52, 3514-3520.

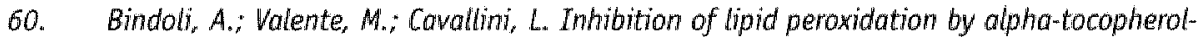
quinone and alpha-tocopherolhydroquinone.

Biochemistry International 1985, 10,753-761.

61. Kohar, I.; Baca, M.; Suarna, C.; Stocker, R.; Southwell-Keely, P.T. is alpha-tocopherol a resenvir for alpha-tocopheryl hydroquinone?

Free Radical Biology \& Medicine 1995, 19, 197-207.

62. Shi, H.; Noguchi, N.; Niki, E. Comparative study of antioxidative action of alpha-tocopheryl hydroquinone, ubiquinol, and alpha-tocopherol against lipid peraxidation.

Free Radical Biology \& Medicine 1999, 27, 334-346.

63. Maiorino, M.; Zamburlini, A.; Roveri, A.; Ursini, F. Prooxidant role of witamin E in copper induced lipid peroxidation.

Federation of European Biochemical Societies 1993, 330, 174-176.

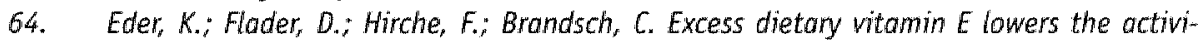
ties of antioxidative enzymes in erythrocytes of rats fed salmon oil.

Joumal of Nutrition 2002, 132, 3400-3404.

65. Minotti, G., Aust, S.D. Redox cycling of iron and lipid peraxidation. 
Lipids 1992, 27, 219*226.

66. Stephens, N.G.; Parsons, A. Schofield, P.M. Randomised controlled trial of vitamin $E$ in patients with coronary disease: Cambridge Heart Antioxidant Study (CHAOS).

Lancet 1996, 347, 781-786.

67. Halliwell, B. The antioxidant paradox. Lancet 2000, 355, 1179-1180.

68. Weinberg, R.B.; VanderWerken, B.S.; Anderson, R.A.; Stegner, J.E.; Thomas, M.J. Prooxidant effect of vitamin $E$ in cigarette smokers consuming a high polyunsaturated fat diet.

Anteriosclerosis Thrombosis and Vascular Biology 2001, 21, 1029-1033.

69. Meydami, M. Vitamin $E$. Lancet $1995,345,170-175$.

70. Corrwell, D.G.; Williams, M.V.; Wani, A.A.; Wami, G.; Shen, E.; Jones, K.H. Mutagenicity of tocopheryl quinones: Evolutionary advantage of selective accumulation of dietary alpha-tocopherol.

Nutrition and Cancer 2002, 43, 111-118.

71. Lindsey, J.A.; Zhang, H.F.; Kaseki, H.; Morisaki, N.; Sato, T.; Cornwell, 0.G. Fatty acid metabolism and cell proliferation. WII. Antioxidant effects of tocopherols and their quinones.

Lipids 1985, 20, 151-157.

72. Comwell, D.G., Huttner, J.J.; Milo, G.E.; Panganamala, R.V.; Sharma, H.M.; Geer, J.C.

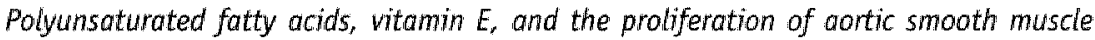
cells.

Lipids 1979, 14, 194-207.

73. Thornton, D.E.; Jones, K.H.; Jiang. Z; Zhang, H.; Liu, G.; Cornwell, D.G. Antioxidant and cytotoxic tocopheryl quinones in normal and cancer cells.

Free Radical Biology \& Medicine 1995, 18, 963-976.

74. Jones, K.H.; Liu, J.J.; Roehm, J.S.; Eckel, J.J.; Eckel, T.T.; Stickrath, C.R.; Triala, C.A.; Jiang, Z.; Bartali, G.M.; Cornwell, D.G. Gamma-tocopheryl quinone stimulates apoptosis in drug-sensitive and multidrug-resistant cancer cells.

Lipids 2002,37, 173 184 .

75. Rowntree, L.G.; Steinberg, $A_{\text {, }}$ Dorrance, G.M.; Ciccone, E.F. Sarcoma in rats from the ingestion of a crude wheat-germ oil made by ether extraction.

The American Joumal of Cancer 1937, 31, 359-372.

76. Taylor, M.W. Nelson, V.E. Some abservations on ferric chloride addition to the diet. Proceedings of the society for experimental biology and medicine 1930, 27, 764.

77. Azzi, A.; Boscoboinik, D.; Clement, S.; Ozer, N.K.; Ricciarelli.R; Stocker, A.; Tasinato, A.; Sirikci, 0 . Sigmalling functions of alpha-tocopherol in smoath muscle cells. International joumal for witamin and nutrition research 1997, 67, 343-349.

78. Azzi, A.; Boscaboinik, D.; Clement, S.; Ozer, N.; Ricciarelli, R.; Stocker, A. Vitamin E medioted response of smooth muscle cell to oxidant stress.

Diabetes Research and Clinical Practice 1999, 45, 191-198.

79. Azzi, A." Stacker, A. Vitamin E: non-antioxidant roles.

Progress in lipid research 2000, 39, 231-255.

80. Azzi", A.; Boscoboinik D.; Chatelain, E., Ozer, N.K.; Stauble, B. d-alpha-tocopherol control of cell proliferation.

Molecular Aspects of Medicine 1993, 14, 265-271.

81. Traber, M.G.: Packer, L. Vitamin E: Beyond antioxidant function. 
The American Journal of Cimical Nutrition 1995, 62 (suppl), 15015-15095:

82. Tosinato, A.; Boscoboinik, D.; Bartoli, G.M.; Maroni, P; Azzi, A. d-alpha-tacopherol inhibition of vascular smooth muscle cell pradiferation occurs at physiological concentrations, correlates with protein kinase C intibition, and is independent of its antioxi. dant properties.

Proceedings of the National Acodemy of Sciences USA 1995, 92, 12190-12194.

83. Pearce, B.C.; Parker, R.A.; Deason, M.E.; Qureshi, A.; Wright, J.J.K. Hypocholesterolemic activity of synthetic and natural tocotrienols.

Journal of Medicinal Chemistry 1992, 35, 3595-3606.

84. Khor, H.T. Ng, T.T. Effects of administration of alpha-tocopherol and tocotrienols on serum lipids and liver HMG COA reductase activity.

Intemational Journal of Food Sciences and Nutrition 2000, 51, S3-511.

85. Pearce, B.C.; Parker, R.A.; Deason, M.E.; Dischino, D.D., Gillespie, E.; Qureshi, A.; Volk. K.: Wright, J.J.K. Inhibitors of cholesteral biosynthesis. Hypocholesterolemic and antioxidant activities of benzopyran and tetrahydronaphthalene analogues of the tocotrienols.

Journal of Medicinal Chemistry 199.4, 37, 526-541.

86. Qureshi, A.A.; Sami, 5.A.; Salser, W.A., Khan. F.A. Dose-dependent suppression of serum cholesterol by tocotrienol-nich fraction (TRF25) of rice bran in hypercholesteralemic humans.

Atherosclerosis 2002, 161, 199-207.

87. Qureshi, A.; Pearce, B.C.; Nor, R.M.; Gapor, A.; Peterson, D.M.; Elson, C.E. Dietary alpha* tocopherol attenuates the impact of gamma-tocotrienol on hepotic 3-hydroxy-3-methylglutaryl coenzyme A reductose activity in chickens.

Journal of Nutrition 1996, 126, 389-394.

88. Qureshi, A.; Bradlow, B.A.; Brace, L.; Manganello, J.; Peterson, D.M.; Pearce, B.C.; Wright, J.J.K.; Gapor, A.; Elson, C.E. Response of hypercholesterolemic subjects to administration of tocotrienols.

Lipids 1995, 30, 1171-1177.

89. Napoli, C.; Leccese, M.; Palumbo, G.; Nigris, F.d.; Chiariello, P.; Zuliani, P.; Samma, P.; Di Loreto, M.; De Matteis, $C_{n}$; Cacciatore, F.; Abete, $P_{n}$; Liguori, A.: Chianiello, M.; DAAmiento, F.P. Effects of vitamin $E$ and HMG-COA reductase inhibition on cholesteryl ester transfer protein and lecithin-cholesterol acyltransferase in hypercholesterolemia. Coronary Artery Disease 1998, 9, 257-264.

90. Packer, L.; Weber, S.U.; Rimbach, G. Molecular aspects of alpha-tocotrienol antiaxidant action and cell signalling.

Journal of Nutrition 2001, 131, 3695-373s.

91. Wechter, W.J.; Kantoci, D.; Murray, E.D.J.; DAAmico, D.; Jung, M.E.; Wang. W.H. A mew endogenous natriuretic factor: LUU-alpha.

Proceedings of the National Academy of Sciences USA 1996, 93, 6002-6007.

92. Kantoci, D.; Wechter, W.J.; Murray, D.J.; Dewind, S.A.; Borchardt, D.; Khan, S.I. Endogenous natriuretic factors 6: The stereochemistry of a natriuretic $\gamma$-tocopherol metabolite $L L U-\alpha$.

The Journal of Pharmacology and Experimental Therapeutics 1997, 282, 648-656.

93. Patel, J.M.," Edwards, D.A. Vitamin E, membrane order, and antioxidant behowior in lung microsomes and reconstituted lipid vesicles.

Toxicology and Applied Pharmacology 1988, 96, 101-114.

94. Wang, $X . ;$ Quinn, $P . J$. The location and function of vitamin E in menibranes (Review). 
Molecular Membrane Biology 2000, 17, 143-156.

95. Jiang, a.; Elson Sehwab, I.; Courtemanche, C; Ames; B.N. gamma-tocopherol and its major metabolite, in contrast to alpha-tocopheral, inhibit cyclooxygenase activity in macrophoges and epithelial cells.

Proceedings of the National Academy of Sciences USA 2000, 97, 11494-11499.

96. Chan, A.C. Vitamin E and atherosclerosis.

Jourral of Nutrition 1998, 128, 1593-1596.

97. Marchioli, R. Dietary supplementation with n-3 polyunsaturated fatty acids and vitamin E after myocardial infarction: results of the GISSI-Prevenzione trial.

Lancet 1999, 354, 447-455.

98. Yusuf, S. Vitamin E supplementation and cardiovascular events in high-risk patients. The Heart Outcomes Prevention Study Investigators.

New England Journal of Medicine 2000, 342, 154-160.

99. Griffith, 0.W.; Meister, A. Glutathione: interorgan translocation, turnover, and metabolism.

Proceedings of the National Academy of Siciences USA 1979, 76, 5606-5610.

100. Reed, D.J.; Fariss, M.W. Glutathione depletion and susceptibility.

Pharmacological Reviews 1984, 36, 255-335.

101. Arrigo, A.P. Gene expression and the thiol redox state.

Free Radical Biology and Medicine 1999, 27, 936-944.

102. Black, S.M.; Wolf, C.R. The role of glutathione-dependent enzymes in drug resistance. Pharmacology and therapeutics 1991, 51, 139-15.4.

103. Whitfield, J.B. Gamma glutamyl transferase.

Critical Reviews in Clinical Laboratory Sciences 2001, 38, 263-355.

104. Paolicchi, A.; Dominici, S.; Pieri, L.; Maellaro, E.; Pompella, A. Glutathione catabolism as a signaling mechanism.

Biochemical Pharmacology 2002, 64, 1027.

105. Deneke, S.M.; Fanburg, B.L. Regulation of cellular glutathione.

American Journal of Physiology 1989, 257, L163-173.

106. Dickinsion, D.; Farman, H. Cellular glutathione and thiols metabolism.

Biochemical Pharmacology 2002, 64, 1019.

107. Wild, A.C; Mulcahy, R.T. Regulation of gamma-glutamylcysteine synthetose subunit gene expression: insights into transcriptional control of antioxidant defenses.

Free Radical Research 2000, 32, 281-301.

108. Seelig, G.F.; Simondsen, R.P.; Meister, A. Reversible dissociation of gamma-glutamyicysteine synthetase into two subunits.

Journal of Biological Chemistry 1984, 259, 9345-9347.

109. Mulcahy, R.T.; Gipp, J.J. Identification of a putative antioxidant response element in the 5-flanking region of the human gamma-glutamylcysteine synthetose heavy subunit gene.

Biachemical and Biophysical Research Communications 1995, 209, 227-233.

110. Moellening, D.; MC Andrew, J.; Patel, R.P.; Forman, H.J.; Mulcahy. R.T.: 10, H.; Darley Usmar, V.M. The induction of GSH synthesis by nanomolar concentrations of NO in endothelial cells: a role for gamma-glutamylcysteine synthetase and gamma-glutamyl transpeptidase.

Federation of European Biochemical Societies letters 1999, 448, 292-296.

111. Richman, P.G.; Meister, A. Regulation of gamma-glutamyl-cysteine synthetase by nonallosteric feedback inhibition by glutathione. 
Joumal of Biological Chemistry 1975, 250, 1422-1426.

112. Urata, Y.; Yamamoto, H.; Goto, 5.," Tsushima, H.; Akazawa, 5.; Yamashita, S.; Nagataki, S.; Kando, $T$. Long exposure to high glucose concentration impairs the responsive expression of gamma-glutamylcysteine symthetase by interleukim-1beta and tumor necrosis factor-alpha in mouse endothelial cells.

Jounal of Biological Chemistry 1996, 271, 15146-15152.

113. Kando, $T_{i}$ Y Yoshida, $K$; Urata, $Y_{\text {; }}$ Goto, 5.: Gasa, 5., Tamiguchi, N. gamma-Giutamylcysteine synthetase and active transport of glutathione S-conjugate are responsive to heat shack in $\$ 562$ erythroid cells.

Joumal of Biological Chemistry 1993, 268, 20366-20372.

114. Woods, J.S.; Ellis, M.E. Up-regulation of glutathione synthesis in rat kidney by methyl mercury. Relationship to mercury-induced oxidative stress.

Biochemical Pharmacology 1995, 50, 1719-1724.

115. Rahman, I.; Bel, A.; Mulier, B.; Lawson, M.F.; Harrison, D.J.; Macnee, W. Smith, C.A. Transcriptional regulation of gamma-glutanylcysteine synthetase-heavy subunit by oxidants in human alveolar epithelial cells.

Biochemical and Biophysical Research Communications 1996, 229, 832-837.

116. Douglas, K.T. Mechanism of action of glutathione-dependent enzymes.

Advances in Enzymology and Related Areas of Malecular Biology 1987, 59, 103-167.

117. Flohe, L. Glutathione peroxidase.

Basic Life Sciences 1988, 49, 663-668.

118. Hayes, J.D.; McLellan, L.I. Glutathione and glutathione-dependent enzymes represent a co-ordinately regulated defence against oxidative stress.

Free Radical Research 1999, 31, 273-300.

119. Mils, G.C. Hemoglabin catabolism I. Glutathione peroxidase, an erythrocyte enzyme which protects hemoglobin from oxidative breakdown.

Journal of Biological Chemistry 1957, 229, 189-197.

120. Ursini, F.; Maionino, M.; Valente, M.; Fern, L.; Gregalin, C. Purification form pig liver of a protein which protects liposomes and biomembranes from peroxidative degradation and exhibits glutathione peroxidase activity on phasphatidylcholine hydroperoxides.

Biochimica et Biophysica Acta 1982, 710, 197-211.

121. McCay, P.B.; Gibson, D. D.; Fong, K.; Hormbrook, K.R. Effect of glutathione peroxidase activity on lipid peroxidation in biological membranes.

Biochimica et Biophysica Acta 1976, 431, 459-468.

122. Prohaska, J.R. The glutathione peraxidase activity of glutathione S-transferases. Biochimica et Biophysica Acta 1980, 611, 87-98.

123. Sevanian. A.; Muakkassah Kelly, S.F.; Montestruque, 5. The influence of phospholipase A2 and glutathione peroxidase on the elimination of membrane lipid peroxides.

Archives of Biachemistry and Biophysics 1983, 223, 441-452.

124. Brigetius, R.; Muckel, C.; Akerboom, T.P., Sies, H. Identification and quantitation of glutathione in hepatic protein mixed disulfides and its relationship to glutathione disulfide.

Biochemical Pharmacolagy 1983, 32, 2529-2534.

125. Eaton, $D_{n} L$; Bammler. $T . K$. Cancise review of the glutathione S-transferases and their significance to toxicology.

Toxicological sciences 1999, 49, 156-164.

126. Awasthi, Y.C.; Sharma, R.; Singhal, S.S. Human glutathione S-transferases.

The International journal of biochemistry 1994,26, 295-308. 
127. Board, P.G.; Baker, R.T; Chelvanayagam, G.; Jermin. L.S. Zeta, a novel class of glutathione transferases in a range of species from plants to humans. Biochemical Jowrnal 1997, 328, 929-935.

128. Mannewik, B.; Awasthi, Y.C.; Board, P.G.; Hayes, J.D.; Di-Hio, C,; Ketterer, B.; Listowsky, I.; Morgensterm, R.; Muramatsu, M.; Pearson, WR.; at, e. Nomenclature for human glutathone transferases [letter].

Biochemical Jounal 1992, 282, 305-306.

129. Hayes, J.0., Pulford, 0.J. The glutathione 5-transferase supergene family: regulation of GST and the cantribution of the isoenzymes to cancer chemoprotection and drug resistance.

Critical reviews in biochemistry and molecular biology 1995, 30, 445-600.

130. Jakaby, W.B. The glutathione S-transferases: a group of multifunctional detoxification proteins.

Advances in enzymology and related areas of molecular biology 1978, 46, 383-414.

131. Lundqvist, G.; Yucel Lindberg. $T_{\text {; }}$ Morgenstern, R. The oligomeric structure of rat liver microsomal glutathione transferase studied by chemical cross-linking.

Biochimica et Biophysica Acta 1992, 1159, 103-108.

132. Ketterer B. Glutathione S-transferases and prevention of cellular free radical damage. Free Radical Research 1998, 28, 647-658.

133. Mannervik, $B$. The isoenzymes of glutathione transferase. Advances in enzymology and related areas of molecular biology 1985, 57, 357-417.

134. Salinas, A.E.; Wong, M.G. Glutathione S-transferases-a review. Current Medicinal Chemistry 1999, 6, 279-309.

135. Keen, J.H.; Habig. W.H.: Jakoby, W.B. Mechanism for the several activities of the glutathione S-transferases.

The Journal of Biological Chemistry 1976, 251, 6183-6188.

136. Habig. W.M.; Pabst, M.J.; Jakoby, W.B. Glutathione S-transferases. The first enzymatic step in mercapturic acid formation.

The Joumal of Biological Chemistry 1974, 249, 7130-7139.

137. Lash, L.H. Role of renal metabolism in risk to toxic chemicals. Environmental Health Perspectives 1994, 102 (Suppl) 11, 75-79.

138. Arita, $M_{n} ;$ Sato $Y_{. ;}$Arai, H.; Inoue, K. Binding of alpha-tocopherylquinone, an axidized form of alpha-tocopherol, to glutathione-S-transferase in the liver cytosol. Federation of European Biochemical Societies letters 1998, 436, 424-426.

139. Naeffes, V.M.; Evelo, C.T.; Baars, L.G.; Blanco, C.E. Eythrocyte glutathione 5 transferase as a marker of oxidative stress at birth.

Archives of disease in childhood 1999, 81, F130-F133.

140. Guthenberg. $C_{*}$ Mannervik, B. Glutathione S-tramsferase (transferase pi) from human placenta is identical or closely related to glutathione S-transferase (transferase tho) from erythrocytes.

Biochimica et Biophysica Acta 1981, 661, 255-260.

141. Poppel van, G.; Wogel de, N.; Bladeren van, P.J.; Kok. F.J. Increased cytogenetic damage in smokers deficient in glutathione S-transferase isozyme mu.

Carcinogenesis 1992, 13,303-305.

142. Salagavic, J.; kalina, I.; Stubna, J.; Habalova, V.; Hrivmak, M.; Valansky, L.; Kohut, A.; Biros, E. Genetic polymorphism of glutathione S-transferase $M 1$ and $T 1$ as a risk factor in lung and bladder cancers.

Neoplasma $1998,45,312-317$. 
143. Morari, E.C.; Leite, J.L.; Granja, F.; Da-Assumpcao, L. V.: Ward, L.S. The null genotype of glutathione S-transferase M1 and T1 locus increases the nisk for thyroid cancer.

Cancer Epidemiology Biomarkers and Prevention 2002, 11, 1485-1488.

144. Butkiewicz, D.; Grzybowska, E.; Phillips, D. H., Hemminki, K; Chorary. M. Polymorphisms of the GSTP1 and GSTM1 genes and PAH-DNA adducts in human mononuclear white blood cells.

Environmental and Moleculor Mutagenesis 2000, 35, 99-105.

145. Schultz, M.; Dutta, S.; Tew. K.D. Inhibitors of glutathione S-transferases as therapeutic agents.

Advanced Drug Delivery Reviews 1997, 26, 91-104.

146. Adler, V.; Yin, Z.; Fuchs, S.Y.; Benezra, H.; Rosanio, L.; Tew, K. D.; Pincus, M.R.; Sardana, M.; Henderson, C.J.; Wolf. C.R.; Davis, R.J.; Ronai, Z. Regulation of JNK signaling by GSTp.

The EMBO journal 1999, 18, 1321-1334.

147. Ouwerkerk-Mahadevan, S.; Mulder, G.J. Inhibition of glutathione conjugation in the rat in vivo by analogues of glutathione conjugates.

Chemica-Biological Interactions 1998, 111-112, 163-176.

148. Shen, H.X.; Tamai, K.; Satoh, K.; Hatayama, I.; Tsuchida, 5.; Sato, K. Modulation of class Pi glutathione transferase activity by sulfhydryl group modification.

Archives of Biochemistry and Biophysics 1991, 286, 178-182.

149. Nishihira, J.; Ishibashi, T.; Sakai, M.; Nishi, S.; Kumazak, T.; Hatanaka, Y.; Tsuda, S.; Hikichi, K. Characterization of cysteine residues of glutathione S-transferase P: evidence for steric hindrance of substrate binding by a bulky adduct to cysteine 47.

Biochemical and Biophysical Research Communications 1992, 188, 424-432.

150. Chang, M.; Shin, Y.G.; van Breemen, R.B.; Blond, S.Y.; Bolton, J.L., Structural and functional consequences of inactivation of human glutathione 5-transferase P1-1 mediated by the catechol metabolite of equine estrogens, 4-hydroxyequilenin.

Biochemistry 2001, 40, 4811-4820.

151. Jakobsson, P.J.; Morgenstern, R.; Mancini, 7., Ford Hutchinson, A.; Persson, B. Membrane-associated proteins in eicosanoid and glutathione metabolism (MAPEG). A widespread protein superfamily.

American journal of respiratory and critical care medicine 2000, 161, $520-24$.

152. Jakobsson, P.J.; Morgenstern R.; Mancini, J.; Ford Hutchinson, A.; Persson, B. Common structural features of MAPEG - A widespread superfomily of membrane associated proteins with highly divergent functions in eicasanoid and glutathione metabolism.

Protein Science 1999, 8, 689-692.

153. DeJong, J.L.; Morgenstern, R.; Jornvall, H.; DePjerre, J.W.; Tu, C.P. Gene expression of rat and human micrasomal glutathione S-transferases.

Journal of Biological Chemistry 1988, 263, 8430-8436.

154. Morgenstern, R:; Lundqvist, G.; Andersson, G.; Balk, L.; DePierre, J. W. The distribution of microsomal glutathione transferase among different arganelles, different organs, and different organisms.

Biochemical Pharmacalogy 1984, 33, 3609-3614.

155. Morgenstem, R.; Guthenberg, C.; Depierre, J.W. Microsomal glutathione S-transferase. Purification, initial characterization and demonstration that it is not identical to the cytosolic glutathione S-transferases $A, B$ and $C$.

European Journal of Biochemistry 1982, 128, 243-248.

156. Morgenstem, R.; DePierre, J.W; Ernster, L. Activation of microsomal glutathione 
Sutronsferase activity by sulfhydryl reagents.

Biochemical and Biophysical Research Communications 1979, 87, 657-663.

157. Horbach, M.E.; Sies, H.; Akerboom, T.P. Identification of a hepatic plasma membrane glutathione S-transferase activated by N-ethylmaleimide.

Biochimica et Biophysica Acta 1993, 1148, 61-66.

158. Ji, $Y$, Bennett, B.M. Activation of microsomal glutathione S-transferase by peroxynitrite.

Molecular Pharmacology 2002,63,136-146.

159. Ji, $Y_{;} ;$Toader, $V_{i}$; Bennett, B.M. Regulation of microsomal and cytosalic glutathione Stransferase activities by 5 -nitrosylation.

Biochemical Pharmacology 2002, 63, 1397-1404.

160. Haenen, G.R.M.M.; Tai Tin Tsoi, J.N.L.; Vermeulen, N.P.E.; Timmerman, H.; Bast, A. 4hydraxy-2,3-trans-nonenal stimulates microsomal tipid peroxidation by reducing the glutathione-dependent protection.

Archives of Biochemistry and Biophysics 1987, 259, 449-456.

161. Aniya, $Y_{;}$; Naito, A. Oxidative stress-induced activation of micrasomal glutathiane Stransferase in isolated rat liver.

Biochemical Pharmacology 1993, 45, 37-42.

162. Hianen, G.R.; Vermeulen, N.P.; Tai Tin Tsai, J.N.; Ragetli, H.M.; Timmerman, H.; Blast, A. Activation of the microsomal glutathione-S-transferase and reduction of the glutathione dependent protection against lipid peroxidation by acrolein.

Biochemical Pharmacology 1988, 37, 1933-1938.

163. Burg, D.; Mulder, G.J. Glutathione canjugates and their synthetic derivatives as inhibitors of glutathione-dependent enzymes inwolved in cancer and drug resistance. Drug Metabolism Reviews 2002, 34, 821-863.

164. Suzuki, M.; Sugiyama, \%. Excretion of GSSG and glutathione conjugates mediated by MRP1 and CMOAT/MRP2.

Seminars in tiver disease 1998, 18, 359-376.

165. Borst, $P_{,,}$Evers, R.; Kool, M.; Wijnholds, J. The multidrug resistance protein family. Biochimica et Biophysica Acta 1999, 1461, 347-357.

166. Gerk, P.M.; Vore, M. Regulation of expression of the multidrug resistance-associated protein 2 (MRPZ) and its role in drug disposition.

Journal of Pharmacology and Experimental Therapeutics 2002,302, 407-415.

167. Filomeni, G.; Rotilio, G.; Cirialo, M. Cell signating and the glutathione redox system. Biochemical Pharmacology 2002, 64, 1057.

168. Stark, A.A.; Zeiger, E; Pagano, D.A. Glutathione metabolism by gamma-glutamyltranspeptidase leads to lipid peroxidation: charocterization of the system and relevance to hepatocarinogenesis.

Carcinogenesis 1993, 14, 183-189.

169. Haenen, G.R.M.M.; Bast, A. Protection against lipid peroxidation by a microsomal glutathione-dependent labile factor.

Federation of European Biochemical Sacieties 1983, 159, 24-28.

170. Haenen, G.R.M.M.; Bastiaans, H.M.M.; Bast, A.: Mechanism of the glutathione-dependent protection against microsomal lipid peroxidation, in Oxygen Radicals. Edited by Yoshikawa.

Amsterdam, Exerpta Medica, 1992, pp 731-736.

171. Scholz, R.W.; Graham, K.S.; Gumpricht, E.; Reddy, C.C. Mechanism of interaction of vita$\min E$ and glutathione in the protection against membrane lipid peroxidation. 
Annals of The New York Academy of Sciences 1989, 570, 514-517.

172. Reddy, C.C.; Scholz, R.W.; Thamas, C.E.; Edward, J.M. Vitamin E dependent reduced glutathione inhibition of rat liver microsiomal lipid peroxidation.

Life Science 1982, 31, 571-576.

173. Graham, K.S.; Reddy. C.C.; Scholz, R.W. Reduced glutathione effects on alphatocopheral concentration of rat liver microsomes undergoing NADPH-dependent lipid peroxidation. Lipids 1989, 24, 909-914.

174. Scholz, R.W.; Reddy, P. K; Wynn, M.K.; Groham, K.S.; Liken, A.D.; Gumpricht; E.; Reddy, C.C. Glutathione-dependent factors and inhibition of rat liver microsomal lipid peroxidation.

Free Radical Biology \& Medicine 1997, 23,815-828.

175. Burk. R.F. Glutathione-dependent protection by rat liver microsomal protein against Lipid peroxidation.

Biochemica et Biophysica Acta 1983, 757, 21-28.

176. Haenen, G.R.; Vermeulen, N.P.; Timmerman, H.; Bast, A. Effect of thiols on lipid peroxidation in rat tiver microsomes.

Chemico-Biological Interactions 1989, 71, 201-212.

177. Aarts, L.; Hee van der, R.; Dekker, I., Jong de, J.; Langemeijer, H.; Bast, A. The widely used anesthetic agent propofol can replace alpha-tocopherol as an antiaxidant.

Federation of European Biochemical Sacieties 1995, 357, 83-85.

178. Acker van, F.A.A.; Schouten, 0.; Haenen, G.R.M.M.; Vijgh van der, W.J.F; Bast, A. Flavonoids can replace alpha-tacopherol as an antioxant.

Federation of European Biochemical Societies letters 2000, 473, 145-148.

179. Haaften van, R.I.M.; Evelo, C.T.; Haenen, G.R.M.M.; Bast, Aw No reduction of alphatocopherol quinone by glutathione in rat liver microsomes.

Biochemical Pharmacology 2001, 61, 715-719.

180. McCay, P.B.; Brueggemann, G.; Lai, E.K.; Powell, S.R. Evidence that alpha-tocopheral functions cyclically to quench free radicals in hepatic microsomes.

Annals of The New York Academy of Sciences 1989, 570, 32-45.

181. Wijesundara, M.B.J.; Berger, S. The redox pair vitamin $E$ and vitamin $C$, a 13C-NMR study.

Liebigs Annalen der Chemie 1994, 1239-1241.

182. Hughes, P.E.; Tove; S.B. Symthesis of alpha-tocopherolquinone by the rat and its reduction by mitachondria.

The Journal of Biological Chemistry 1980, 255, 7095-7097.

183. Chen, L.H.; Shiau, C.C. Induction of glutathione-S-transferase activity by antioxidants in hepatocyte culture.

Anticancer Research 1989, 9, 1069-1072.

184. Tampo, Y.; Yonaha, M. Vitamin $E$ and glutathione are required for preservation of inicrosomal glutathione $S$-transferase from oxidative stress in microsomes.

Pharmacology and toxicology 1990, 66, 259-265.

185. Stone, W.L.: Dratz, E.A. Increased glutathione-S-transferase activity in antioxidantdeficient rats.

Biochimica et Biophysica Acta 1980, 631, 503-506.

186. Mehlert, A.; Diplock, A.T. The glutathione 5-transferases in selenium and vitamin $E$ deficiency.

Biochemical Journal 1985, 227, 823-831.

187. Ong, F.B.; Wan-Ngah, W.Z.; Shamaan, M.A.; Md-Top, A.G.; Marzuki, A.; Khalid, A.K. 
Glutathione S-transferase and gamma-glutamyl transpeptidase activities in cultured rat hepatocytes treated with tocotrienol and tocopherol.

Comparative Biochemistry and Physiology C 1993, 106, 237-240.

188. Haaften wan, R.I.M.: Haenen, G.R.M.M.; Evelo, C.T.A.; Bast, A. Tocotrienols inhibit human glutathione S-transferase P1-1.

IUBMB Life 2002, 54, 81-84.

189. Haaften van, R.I.M.; Evelo, C.T.A.; Penders, J.; Ejjnwachter, M.P.F,; Haenen, G.R.M.M.; Bast. A. Inhibition of human glutathione S-transferase P1-1 by tocopherols and alphatocopheral deriwatives.

Biochimita et Biophysica Acta 2001, 1548, 23-28.

190. Haaften van, R.I.M.; Evelo, C.T.A.; Haenen, G.R.M.M.; Bast, A. Alpha-tocopherol inhibits human glutathione S-transferase pi.

Biochemical and Biophysical Research Communications 2001, 280, 631-633.

191. Olson, R.E., Carpenter, P.C. The regulatory function of vitamin $E$. Advances in Enzyme Regulation 1967, 5, 325-334.

192. Stocker, A.; Zimmer, S.; Spycher, S.E.; Azzi, A. Identification of a novel cytosolic tocopherol-binding protein:structure, specificity, and tissue distribution.

International Union of Biochemistry and Molecular Bialogy Life 1999, 48, 49-55.

193. Azzi, A.; Gysin, R.; Ricciarelli, R.; Villacorta, L,; Visanius, $T_{\text {; }}$ Zingg. J.-M. Regulation of gene and protein expression by vitamin $E$.

Free Radical Research 2002, 36, 30-35.

194. Ricciarelli, R., Zingg. J.; Azzi, A. The 80th anniversary of vitamin E: beyond its antioxidant propenties.

Biological Chemistry 2002, 383, 457-465.

195. Azzi, A.; Ricciarelli, R.; Zingg, J.M. Non-antioxidant molecular functions of alpha-tocopherol (vitamin E).

Federation of European Biochemical Societies letters 2002, 519, 8-10.

196. Aratri, E.; Spycher, S.; Breyer, In; Azzi, A. Modulation of alpha-tropomyasin expression by alpha-tocopherol in rat vascular smooth muscle cells.

Federation of European Biochemical Societies Letters 1999, 447, 91-94. 

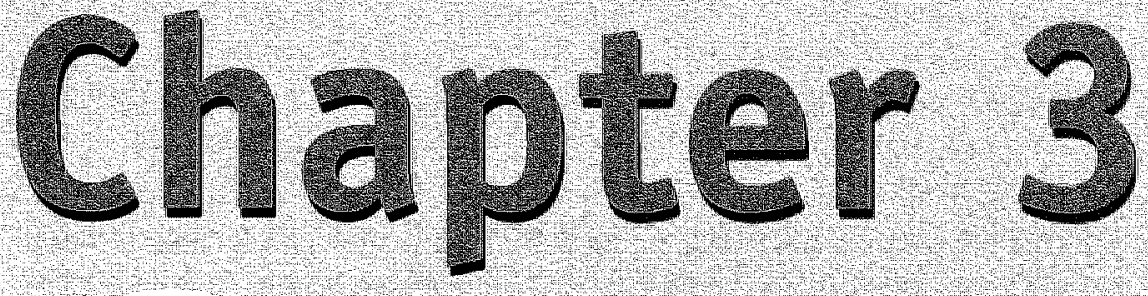

\title{
No reduction of $\alpha$-tocopherol quinone by glutathione in rat liver microsomes
}

\author{
Rachel I.M. van Haaften \\ Chris T.A. Evelo \\ Guido R.M.M. Haenen \\ and Aalt Bast
}

Biochemical Pharmacology 61

715-719 (2001) 


\section{Abstract}

The cell membrane is protected against lipid peroxidation by endogenous antioxidants such as vitamin $E$ ( $\alpha$-tocopherol). The oxidised form of $\alpha$-tocopherol ( $\alpha$ tocopherol quinone) does not have this antioxidant function. However, literature indicates that $\alpha$-tocopherol quinone can be reduced to $\alpha$-tocopherol in vivo and thereby will add to the total antioxidant potential [1]. We found that GSH (reduced glutathione) did not mediate the reduction of $\alpha$-tocopherol quinone, either directly in solution or in rat liver microsomes fortified with $\alpha$-tocopherol quinone. This renders GSH a less likely candidate for $\alpha$-tocopherol quinone reduction in vivo. In addition, $\alpha$-tocopherol quinone did not enhance the GSH-dependent protection against lipid peroxidation, either in control microsomes, or in vitamin $\mathrm{E}$ extracted microsomes. Indeed, $\alpha$-tocopherol quinone blocked the GSH-dependent protection against lipid peroxidation in the vitamin E-extracted microsomes. This indicates that $\alpha$-tocopherol quinone can act as a pro-oxidant. 


\section{Introduction}

Reactive oxygen species (ROS) play an important role in diseases like cancer and cardiovascular and pulmonary disorders. They are formed continuously e.g. by the cytochrome $\mathrm{P} 450$ system located in the microsomes (endoplasmic reticulum) in hepatocytes. Like all biomembranes, microsomes are susceptible to damage by ROS. In particular, polyunsaturated fatty acids in the membrane are vulnerable to lipid peroxidation. These polyunsaturated fatty acids are protected against peroxidation by antioxidants such as $\alpha$-tocopherol and reduced glutathione (GSH).

The lipid soluble $\alpha$-tocopherol functions as a chain-breaking antioxidant. Radicals that are formed during lipid peroxidation may abstract a hydrogen atom from the $\mathrm{OH}$-moiety of $\alpha$-tocopherol. In this way, radicals in the lipid bilayer are made inactive and the $\alpha$-tocopherol radicals are formed. The latter radical can be further oxidised to $\alpha$-tocopherol quinone, which does not function as an antioxidant because it lacks the $\mathrm{OH}$-moiety [2, 3]. Moore and Ingold have shown [1] that $\alpha$-tocopherol quinone is converted to $\alpha$-tocopherol in vivo. This implies that $\alpha$-tocopherol quinone may indirectly contribute to the antioxidant status in vivo. GSH protects against lipid peroxidation in cooperation with vitamin $E[2-7]$. It has been reported that $\alpha$-tocopherol is regenerated from the $\alpha$-tocopherol radical by a microsomal GSHdependent free radical reductase (inset in Figure 1.) $[2-4,8]$.

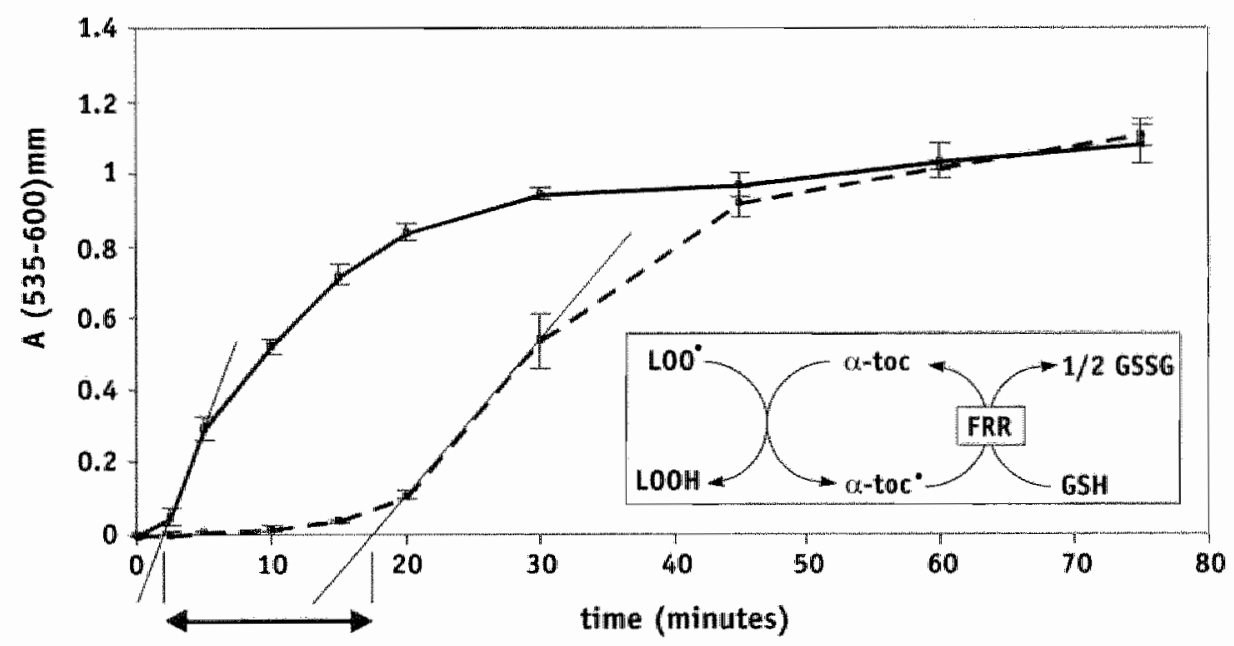

Figure 1. Influence of GSH (1 mM) on the time caurse of lipid peroxidation in cantrol microsomes with (-..) and without (- - $)$ addition of 65H. Lipid peroxidation was induced by ascorbic acid $(0.2 \mathrm{mM})$ and FeSO $(10 \mu \mathrm{M})$. Lag times, as given in Table 1 , were determined as shown in the figure. Results are shown as the means ( \pm S.E.M.) of three experiments. Inset: Interaction of $\alpha$-tocopherol $(\alpha-t o c)$ and $65 \mathrm{H}$ in the protection against lipid peroxidation. The $\alpha$-tocopherol radicals ( $\alpha$-toc) are regenerated to $\alpha$-tocopherol by GSH. This reaction is catalysed by a free radical reductase (FRR). 
In the present study, the recycling of $\alpha$-tocopherol from $\alpha$-tocopherol quinone by GSH was examined both after direct interaction and under conditions where $\alpha$ tocopherol quinone was present in the liver microsomal membrane. Liver microsomes were chosen since: (a) they contain an important radical-producing system; (b) the $\alpha$-tocopherol content is high; and (c) once the $\alpha$-tocopherol has been oxidised, the lipophilic $a$-tocopherol quinone is likely to be retanned within the microsomes. Moreover, the microsomes contain a free radical reductase that converts the $\alpha$ tocopherol radical to $\alpha$-tocopherol at the expense of GSH $[2-4,8]$. Possibly this or another microsomal enzyme might be involved in a GSH-dependent reduction of $\alpha$ tocopherol quinone to $\alpha_{-}$-tocopherol. The effect of $\alpha_{n}$-tocopherol quinone on the protection by GSH against lipid peroxidation was also studied.

\section{Materials and Methods}

\section{Chemicals}

GSH and $\alpha$-tocopherol quinone were obtained from ICN Biomedicals, and D- $\alpha$-tocopherol was obtained from Sigma. Alt other chemicals used were of analytical grade purity.

\section{Chemical reduction of $\alpha$-tocopherol quinone}

$\alpha$-Tocopherol quinone $(0.1 \mathrm{mM})$ was incubated with $\mathrm{GSH}(0.1,1$ and $10 \mathrm{mM})$ at $25^{\circ}$ in potassium phosphate buffer $(10 \mathrm{mM}, \mathrm{pH} 7.4$, total volume $0.6 \mathrm{~mL})$. The change of the absorption spectra over time was monitored to study the reduction of $\alpha$ tocopherol quinone to $\alpha$-tocopherol.

\section{Microsomes}

Microsomes were prepared from male Lewis rats (CPV, Maastricht University, Maastricht. The Netherlands), 200-250 g. After decapitation, the livers were removed and homogenised $(1: 2, w / v)$ in ice-cold potassium phosphate buffer $(50 \mathrm{mM}, \mathrm{pH} 7.4)$ containing $0.1 \mathrm{mM}$ EDTA. The homogenate was centrifuged at $10,000 \times \mathrm{g}(20 \mathrm{~min}$ at $4^{\circ} \%$. Subsequently, the supernatant was centrifuged at $10,000 \times 9\left(20 \mathrm{~min}\right.$ at $\left.4^{\circ}\right)$ and again at $65,000 \times \mathrm{g}\left(60 \mathrm{~min}\right.$ at $\left.4^{\circ}\right)$. The microsomal pellet was resuspended in the phosphate buffer $\left(2 \mathrm{~g}\right.$ tiver $/ \mathrm{mL}$ ) and stored at $-80^{\circ}$. Before use, the control microsomes were thawed and washed twice (centrifugation at $115,000 \times \mathrm{g}, 40 \mathrm{~min}$ ) with ice-cold Tris-HCl buffer $(50 \mathrm{mM}, \mathrm{pH} 7.4)$ containing $150 \mathrm{mM} \mathrm{KCl}$. $\alpha$-Tocopherol was extracted from the microsomes according to Maiorino et al. [9]. In short, the stored microsomes were thawed and mixed with 2 volumes of ice-cold acetone and shaken vigorously. After $5 \mathrm{~min}$, the microsomes were washed twice with centrifugation at $115,000 \times 9\left(40 \mathrm{~min}\right.$ at $\left.4^{\circ}\right)$. Care was taken to remove all the ace- 
tone, since it is known that acetone interferes with the method used to detect lipid peroxidation (i.e. acetone reacts with thiobarbituric acid). The pellet obtained after centrifugation of the microsomes was resuspended in ice-cold Tris-HCl buffer. $\alpha$-Tocopherol quinone was added to the microsomes after the extraction with acetone. The microsomes were mixed vigorously for $1 \mathrm{~min}$ and washed twice (centrifugation at $115,000 \times \mathrm{g}, 40 \mathrm{~min}$ at $4^{\circ}$ ) with ice-cold Tris- $\mathrm{HCl}$ buffer.

\section{Reduction of $\alpha$-tocopherol quinone in microsomes}

$\alpha$-Tocopherol quinone $(0.55 \mu \mathrm{M}$ final concentration) and an excess of GSH (1mM final concentration) was addied to microsomes $(2 \mathrm{~g}$ liver $/ \mathrm{mL}$ ) and shaken vigorously. The microsomes were incubated by shaking $\left(190 \mathrm{rpm}, 37^{\circ}\right)$, air being freely admitted, and the $\alpha$-tocopherol quinone and $\alpha$-tocopherol were determined using HPLC.

\section{Lipid peroxidation assay}

Microsomes (final concentration approximately $1 \mathrm{mg}$ protein $/ \mathrm{mL}$ ) were incubated at $37^{\circ}$ by shaking ( $\left.140 \mathrm{rpm}\right)$, air being freety admitted, in Tris- $\mathrm{HCl} / \mathrm{KCl}(50 \mathrm{mM} / 150$ $\mathrm{mM}, \mathrm{pH} 7.4)$. Ascorbic acid $(0.2 \mathrm{mM})$ and $\mathrm{GSH}(1 \mathrm{mM})$ were neutralised with $\mathrm{KOH}$ before addition. Reactions were started by adding a freshly prepared $\mathrm{FeSO}_{4}$ solution $(10 \mu M)$. Lipid peroxidation was assayed by measuring thiobarbituric acid (TBA)reactive material [2]. Mixing with ice-cold TBA-trichloroacetic acid (TCA) - HClbutylhydroxytoluene (BHT) solution $(2 \mathrm{~mL})$ stopped the reaction in an aliquot of the incubation mixture $(0.3 \mathrm{~mL})$. After heating $\left(15 \mathrm{~min}, 80^{\circ}\right)$ and centrifugation $(5 \mathrm{~min})$, the absorbance at 535 versus $600 \mathrm{~nm}$ was determined. The TBA-TCA-HCl solution was prepared by dissolving $1.68 \mathrm{~g} \mathrm{TCA}$ and $41.6 \mathrm{mg}$ TBA in $10 \mathrm{~mL} 0.125 \mathrm{M} \mathrm{HCl}$. BHT was dissolved in ethanal $(1.5 \mathrm{mg} / \mathrm{mL})$, and $1 \mathrm{~mL}$ of this solution was added to $10 \mathrm{~mL}$ TBA-TCA-HCl. The added chemicals did not interfere with the assay in the concentrations used.

\section{Determination of $\alpha$-tocopherol, $\alpha$-tocopherol quinone and protein}

$\alpha$-Tocopherol and $\alpha$-tocopherol quinone were extracted from the membrane to determine the concentration in the microsomes. The extraction was performed by adding $1 \mathrm{~mL}$ microsomes to $400 \mu \mathrm{L}$ water, $2 \mathrm{~mL}$ ethanol, $10 \mu \mathrm{L}$ internal standard ( $\alpha$ tocopherol-nicotinate, $200 \mu \mathrm{g} / \mathrm{mL}$ ). After shaking for $5 \mathrm{~min}, 3 \mathrm{~mL}$ hexane was added and the mixture was shaken again $(10 \mathrm{~min}$ ). The hexane layer was then evaporated and the residue was dissolved in $30 \mu \mathrm{L}$ iso-propylalcohol. The different products were quantified using HPLC (Nucleosil 100-5 C18 column, Hewlett Packard, eluted with $99 \%$ methanol; flow rate $2.0 \mathrm{~mL} / \mathrm{min}$ ) with diode array detection.

$\alpha$-Tocopherol and the $\alpha$-tocopherol-nicotinate where quantified using the absorption at $295 \mathrm{~nm}, \alpha$-tocopherol quinone using the absorption at $270 \mathrm{~nm}$. Microsomal protein was assayed according to Smith et al. [10], using BSA as standard. 


\section{Measurement of GSH}

The stability of reduced GSH during the incubation was verified according to the method developed by Ellman [11] by adding 5,5'-dithiobis(2-nitrobenzoic) acid (DTNB final concentration $0.6 \mathrm{mM}$ ) to $0.1 \mathrm{mM}$ GSH solution incubated in potassium phosphate buffer $(10 \mathrm{mM}, \mathrm{pH} 7.4)$ for up to $30 \mathrm{~min}$. Incubations were performed with and without the addition of $0.1 \mathrm{mM} \alpha$-tocopherol quinone. The reaction of GSH with DTNB was allowed to proceed for 5 min, after which the absorbance at $412 \mathrm{~nm}$ was determined. It should be noted that this assay only measures GSH and not GSSG, since glutathione reductase is not present.

\section{Results}

The possible reduction of $\alpha$-tocopherol quinone to $\alpha$-tocopherol by GSH was examined by adding different concentrations of GSH $(0.1,1$, and $10 \mathrm{mM})$ to an $\alpha$ tocopherol quinone solution $(0.1 \mathrm{mM})$ in buffer. The change in absorption spectra was examined to monitor the reaction. The $\alpha$-tocopherol quinone spectrum did not change within 30 min after addition of GSH, regardless of the GSH concentration, indicating that no reaction occurred.

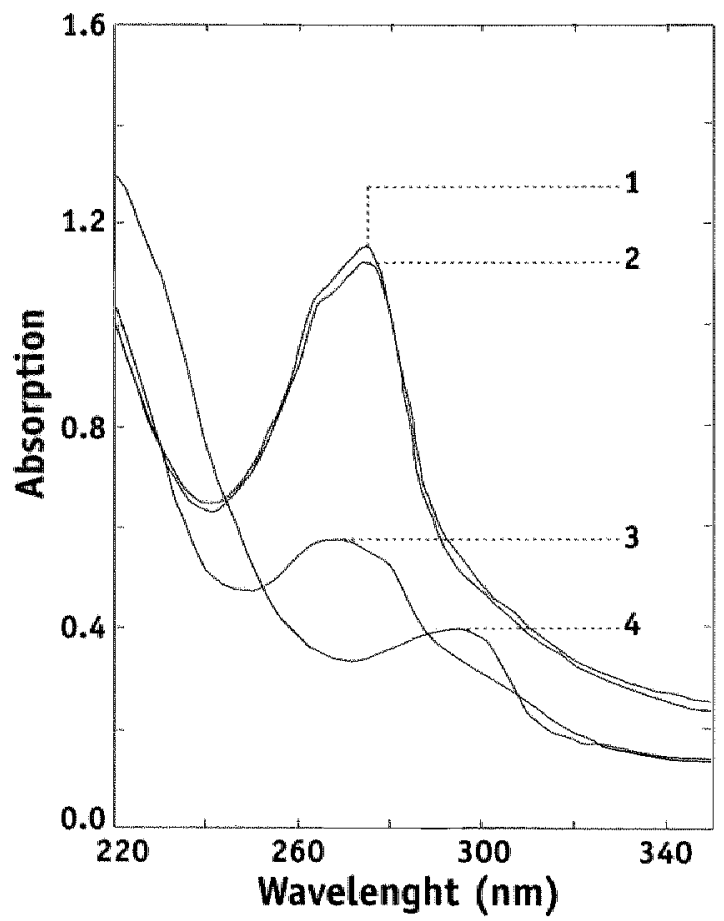

Figure 2. The UV absorption spec: tra of an o-tocopherol quinone solution $(0.1 \mathrm{~mm}$ ) (blank: spectrum 1) with the addition of GSH (0.1 mMl) (spectrum 2) or NaBH. (spectrum 3).

Spectrum 2 was examined $30 \mathrm{~min}$ after the addition of $65 \mathrm{H}$ and spectrum 31 min after the addition of $\mathrm{NaBH}_{4}$.

Spectrum 3 was depicted to show that a reduction of $\alpha$-tocopherol quinone is indeed passible.

Spectrum 4 shows the absorption spectrum of $\alpha$-tocopherol. 
Figure 2. shows an example of such a spectrum (the interaction between $0.1 \mathrm{mM}$ GSH and $0.1 \mathrm{mM} \alpha$-tocopherol quinone is depicted). In addition, no GSH consumption, measured with the non-enzymatic GSH assay, was observed during the 30-min incubation period, confirming that no reaction had indeed taken place. The strong reductant borohydride caused the reduction of $\alpha$-tocopherol quinone to $\alpha$-tocopherol hydroquinone, as is also observed in the change of the absorption spectrum. For comparison the spectrum of $\alpha$-tocopherol was also depicted.

To further examine the interaction of oxidised $\alpha$-tocopherol with GSH, rat liver microsomes were loaded with $\alpha$-tocopherol quinone $(0.55 \mu \mathrm{M})$ and the GSH (1 mM)induced formation of $\alpha$-tocopherol was monitored by HPLC (approximately 2000 times more GSH than $\alpha$-tocopherol quinone was present in the microsomes). The membrane concentrations of $\alpha$-tocopherol and of $\alpha$-tocopherol quinone were not altered by addition of GSH to microsomes fortified with $\alpha$-tocopherol quinone. Next, the endogenous vitamin $\mathrm{E}$ was removed from the microsomes by acetone extraction. After extraction, the $\alpha$-tocopherol concentration dropped from $0.23 \mathrm{nmol} \alpha$-tocopherol/mg protein to below the lower limit of detection (i.e. below $0.036 \mathrm{nmol} \alpha$ tocopherol/mg protein). Lipid peroxidation and the effect of GSH on this process were examined in both these extracted microsomes (with or without the addition of $\alpha$-tocopherol quinone) and in control unextracted microsomes (with or without the addition of $\alpha$-tocopherol quinone). Reduction of $\alpha$-tocopherol quinone by GSH is expected to increase the protective effect of GSH against lipid peroxidation. We studied whether such increased protection really occurred.

\begin{tabular}{|l|c|c|}
\hline \multirow{2}{*}{} & \multicolumn{2}{|c|}{ GSH-induced lagtime (min) } \\
\cline { 2 - 3 } & $\begin{array}{l}\text { Without } \alpha \text {-tocopherol } \\
\text { quinone addition }\end{array}$ & $\begin{array}{l}\text { With } \alpha \text {-tocopherol quinone } \\
(0.55 \mu M) \text { addition }\end{array}$ \\
\hline $\begin{array}{l}\text { Control microsomes } \\
\begin{array}{l}\alpha \text {-Tocopherol extracted } \\
\text { microsomes }\end{array}\end{array}$ & $\begin{array}{c}14.3 \pm 0.4(n=7) \\
\text { 6.5 }\end{array}$ & $\begin{array}{c}15.0 \pm 0.2(n=5) \\
0 \pm 0(n=4)\end{array}$ \\
\hline
\end{tabular}

Table 1. Lag time of microsomal lipid peroxidation induced by $1 \mathrm{mM} \mathrm{GSH}$.

Lipid peroxidation was induced by $10 \mu \mathrm{M} \mathrm{Fe}^{2+2 .}$ and $0.2 \mathrm{mM}$ ascorbate. The lag time induced by $1 \mathrm{mM}$ GSH was determined. Data are expressed as means \pm S.E.M. of at least four experiments. 
The results are listed in Table 1. In Figure 1., the time course of lipid peroxidation in control microsomes is depicted to explain how the lag times in Table 1 . were obtained. Protection by $1 \mathrm{mM}$ GSH against lipid peroxidation was clearly visible and resulted in a 14.3-min GSH-induced lag time in the control microsomes. In the extracted microsomes, protection against lipid peroxidation by GSH was reduced to 6.5 min compared to that in control microsomes. $\alpha$-Tocopherol quinone $(0.55 \mu \mathrm{M})$ addition alone had no effect on iron/ascorbate-induced lipid peroxidation. This again demonstrates that $\alpha$-tocopherol quinone has no antioxidant activity on its own. $\alpha$ Tocopherol quinone also has no effect on the GSH-dependent protection in control microsomes; whereas it completely blocked the GSH-dependent protection in the $\alpha$ tocopherol-extracted microsomes.

\section{Discussion}

$\alpha$-Tocopherol protects against lipid peroxidation. This protection is achieved via the scavenging of lipid peroxyl radicals by $\alpha$-tocopherol. The $\alpha$-tocopherol radicals thus formed can be regenerated in the membrane by cytosolic antioxidants such as vitamin $\mathrm{C}$ or GSH (inset in Figure 1.). Nevertheless, some of the $\alpha$-tocopherol radicals will not be captured by this recycling process and will be oxidised further to $\alpha$-tocopherol quinone, which has no antioxidant properties $[2,3]$.

Moore and Ingold [1] have shown that $\alpha$-tocopherol quinone is reduced to $\alpha$-tocopherol in man. They concluded that $\alpha$-tocopherol quinone might function as an antioxidant precursor. GSH is one of the likely candidates to serve as the reductant for $\alpha$-tocopherol quinone [5]. However, we found no reduction in $\alpha$-tocopherol quinone by GSH either directly in solution or in fortified microsomes (Figure 2.).

The presence of the cytochrome P-450 system in liver microsomes, which may serve as a potent source of free radicals, makes the $\alpha$-tocopherol present in these microsomes, prone to oxidation. There are several indications that the $\alpha$-tocopherol radical, that is formed first, can be regenerated to $\alpha$-tocopherol by a free radical reductase that uses GSH for its reducing equivalents $[2-4,8]$. As shown in this study, once the $\alpha$-tocopherol has been oxidised to $\alpha$-tocopherol quinone, GSH is not capable of recycling this oxidised form of $\alpha$-tocopherol (Figure 2.). Apparently, the conversion of $\alpha$-tocopherol quinone to $\alpha$-tocopherol observed by Moore et al. [1] was not due to direct interaction or to a GSH-dependent reaction with $\alpha$-tocopherol quinone in liver microsomes. The results of the lipid peroxidation experiments confirm that there is no significant conversion of $\alpha$-tocopherol quinone to $\alpha$-tocopheral by GSH in liver microsomes. If GSH had converted $\alpha$-tocopherol quinone to $\alpha$-tocopherol, the addition of $\alpha$-tocopherol quinone to $\alpha$-tocopherol extracted microsomes would have increased the GSH-dependent lag time. 
GSH-dependent protection against lipid peroxidation was clearly observed in control microsomes (Table 1.). A reduction in the $\alpha$-tocopherol level by extraction with acetone to a concentration below the limit of detection greatly reduced the $65 \mathrm{H}$ dependent protection against lipid peroxidation [12]. This was expected because the GSH-dependent protection functions in part through reduction of the $\alpha$-tocopherol radical, and lowering of $\alpha$-tocopherol levels decreases the efficiency of the protection against radicals involved in lipid peroxidation $[2,4,6,13]$. $\alpha$-Tocopherol quinone did not affect GSH-dependent protection in microsomes that contained $\alpha$ tocopherol (control microsomes), but it completely block GSH-dependent protection in $\alpha$-tocopherol depleted microsomes. This implies that $\alpha$-tocopherol quinone can be toxic to lipid membranes of the rat liver microsomes when the $\alpha$-tocopherol concentration is low. A possible explanation for this effect is that $\alpha$-tocopherol quinone competes with $\alpha$-tocopherol for binding to the microsomal labile free radical reductase, which catalyses the reaction as shown in the inset in Figure 1 . It has been demonstrated that this microsomal free radical reductase is not specific for $\alpha$-tocopherol and also interacts with $\alpha$-tocopherol-like components $[14,15]$. Thus $\alpha$-tocopherol quinone might block the interaction of $\alpha$-tocopherol with this enzyme. In this way, $\alpha$-tocopherol quinone would function as an $\alpha$-tocopherol antagonist. However, such an antagonistic effect of $\alpha$-tocopherol quinone is only discerned when $\alpha$-tocopherol levels are very low.

It has been shown previously that the GSH-dependent protection is drastically reduced in partly oxidised membranes $[2,3,12]$. One of the possible explanations for this reduction is the inactivation of the free radical reductase by intermediates that are formed during lipid peroxidation [3]. Vitamin E consumption and, as shown in this study, the formation of $\alpha$-tocopherol quinone may also contribute to the reduction of the GSH-dependent protection once the process of lipid peroxidation has started. The antagonistic effect of oxidised $\alpha$-tocopherol on 6 SH-dependent protection resembles that of oxidised glutathione, since this oxidised antioxidant also reduces the GSH-dependent protection [5].

In conclusion, GSH is not able to regenerate $\alpha$-tocopherol in rat liver microsomes once it has been oxidised to $\alpha$-tocopherol quinone. This implies that there is no positive effect of $\alpha$-tocopherol quinone on GSH-dependent protection against microsomal lipid peroxidation. In contrast, when the $\alpha$-tocopherol concentration is low, $\alpha$-tocopherol quinone may even reduce GSH-dependent protection, and thus act as a pro-oxidant. 


\section{References}

1. Moare, A.N.J.; Ingold, K.U. alpha-Tocopherol quinone is converted into vitamin E in mon.

Free Radical Biology \& Medicine 1997, 22, 931-934.

2. Haenen, G.R.M.M., Bast, A. Protection against lipid peraxidation by a microsomal glutathione-dependent labile factor.

Federation of European Biochemical Societies 1983, 159, 24-28.

3. Haenen, G.R.M.M.; Tai Tin Tsai, J.N.L.; Vermeulen, N.P.E.; Timmerman, H.; Bast, A. 4hydroxy-2,3-trans-nonenal stimulates microsomal lipid peroxidation by reducing the glutathione-dependent protection.

Archives of Biochemistry and Biophysics 1987, 259, 449-456.

4. Haenen, G.R.M.M.; Bastiaans, H.M.M.; Bast, A.: Mechanism of the glutathione-dependent protection against microsomal lipid peraxidation, in Oxygen Radicals.

Edited by Yoshikawa. Amsterdam, Exerpta Medica, 1992, pp 731-736.

5. Scholz, R.W.; Reddy, P.V; Wynn, M.K.; Graham, K.S.; Liken, A.D.; Gumpricht, E.; Reddy, C.C. Glutathione-dependent factors and inhibition of rat liver microsomal lipid peroxidation.

Free Radical Biology \& Medicine 1997, 23, 815-828.

6. Reddy, C.C.; Scholz, R.W.; Thomas, C.E.; Edward, J.M. Vitamin E dependent reduced glutathione inhibition of rat liver microsomal lipid peroxidation.

Life Sciences 1982, 31, 571-576.

7. Burk, R.F. Glutathione-dependent protection by rat liver microsomal protein against lipid peroxidation.

Biochemica et Biophysica Acta 1983, 757, 21-28.

8. McCay, P.B.; Brueggemann, G.; Lai, E. K.; Powell, S.R. Evidence that alpha-tocopherol functions gyclically to quench free radicals in hepatic microsomes.

Annals of The New York Acadeny of Sciences 1989, 570, 32-45.

9. Maiorino, M.; Coassin, M.: Ursini, $F_{n}$ : in Advances in the bioscience, vol 76.

Edited by Slater T.F. Oxford, Pergamon Press, 1989, pp 317-323.

10. Smith, P.K.; Krohn, R.I.; Hermanson, G. T,; Mallia, A. K.; Gartner, F.H.; Provenzano, M.D.; Fujimoto, E.K.; Goeke, N.M.; Olson, B.J.; Klenck, D.C. Measurement of protein using bicinchominic acid.

Aratytical Biochemistry 1985, 150, 76-85.

11. Ellinan, G.L. Tissue sulfhydryl groups.

Archives of Biochemistry and Biophysics 1959, 82, 70-77.

12. Bast, A.; Haenen, G.R.M.M.: Regulation of lipid peroxidation by glutathione and lipoic acid: Inwolvement of liver microsomal vitamin $E$ free radical reductase, in Antioxidants in therapy and preventive medicine, vol 264.

Edited by Auclair C., Plenum Press, 1990, pp 111-116.

13. Bast. A., Haenen, G.R.M.M.: Cytochrome $P$. 450 and vitamin E free radical reductase: formation of and protection against free radicals, in Free radiads, lipoproteins and membrane lipids.

Edited by Paoletti R., Plenum Press, 1990, pp 359-370.

14. Aarts, L.; Hee van der, R., Dekker, $I . ;$ Jang de, J.; Langemejjer, $H_{\text {, }}$; Bast, A. The widely used anesthetic agent propofol can replace à-tocopherol as an antioxidant.

Federation of European Biochemical Societies 1995, 357, 83-85. 
NO REDUCTION OF $\alpha$-TOCOPHEROL OUNONE BY GLTATHONE N WAT UNER MLCROSONES

15. Acker wan. F.A.A.; Schouten, 0; Hoenen, G.R.M.M.; Wijgh van der, W.J.F; Bast, A. Flavonoids can replace alpha-tocopherol as an antioxant.

Federation of European Biochemical Sacieties letters 2000, 473, 145-148. 


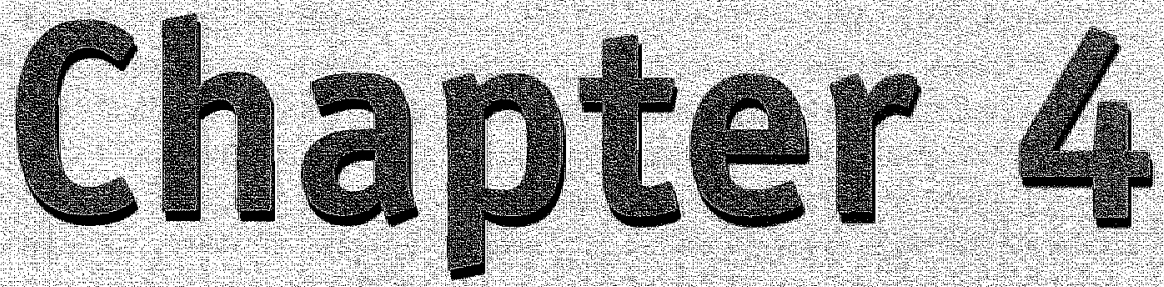

\section{$\alpha$-Tocopherol inhibits human glutathione S-transferase P1-1}

Rachel I. M. van Haaften Chris T.A. Evelo Guido R.M.M. Haenen and Aalt Bast

Biochemical and Biophysical Research Communications 280 $631-633$ (2001) 


\section{Abstract}

$\alpha$-Tocopherol is the most important fat-soluble, chain-breaking antioxidant. It is known that interplay between different protective mechanisms occurs. GSTs can catalyse glutathione conjugation with various electrophiles, many of which are toxic. We studied the influence of $\alpha$-tocopherol on the activity of the cytosolic P11 isoform of GST. $\alpha$-Tocopherol inhibits glutathione S-transferase P1- 1 in a concentration-dependent manner, with an $\mathrm{IC}_{50}$ value of $0.5 \mu \mathrm{M}$. At $\alpha$-tocopherol additions above $3 \mu \mathrm{M}$ there was no GST P1-1 activity left. $\alpha$-Tocopherol lowered the $V_{\max }$ values, but did not affect the $K_{m}$ for either CDNB or GSH. This indicates that the GST P11 enzyme is non-competitively inhibited by $\alpha$-tocopherol. An inhibition of GST P1-1 by $\alpha$-tocopherol may have far-reaching implications for the application of vitamin $E$. 


\section{Introduction}

A wide variety of protective systems prevent damage to cells by free radicals or electrophiles. $\alpha$-Tocopherol (vitamin E) is an important fat-soluble, chain-breaking antioxidant [1]. Apart from its antioxidant activity, $\alpha$-tocopherol possesses multiple other activities that do not depend on its ability to scavenge free radicals. $\alpha$ Tocopherol has for instance specific inhibitory effects on protein kinase $C$ activity, on the growth of certain cells and on the transcription of several genes. In addition $\alpha$-tocopherol activates the protein phosphatase $2 \mathrm{~A}$ and the expression of certain genes $[2,3]$.

An enzymatic line of defence is formed by the glutathione S-transferases (GSTs). GSTs are a family of isoenzymes encoded by at least five different gene families. Four (classes A, M, P and T) of the gene families encode the cytosolic GSTs, whereas the fifth encodes a microsomal form of the enzyme $[4,5]$. GSTs can catalyse glutathione conjugation with various electrophiles, many of which are toxic. GSTs are also able to covalently or non-covalently bind a variety of hydrophobic compounds that do not undergo metabolism. Binding of these non-substrate ligands to GST often inhibits the catalytic activity of GST [6].

It is known that interplay between different protective mechanisms can occur. $\alpha$ Tocopherol interacts with the activity of other antioxidants like GSH and vitamin C [7-10]. The P1-1-isoform of GST is the predominant form in human erythrocytes and in human placenta [11], and is very susceptible to oxidative stress [12]. With this in mind we assumed that antioxidants like $\alpha$-tocopherol might have a protective effect on GST P1-1. In the present study the effect of $\alpha$-tocopherol on GST P1-1 activity is examined.

\section{Materials and Methods}

\section{Chemicals}

RRR- $\alpha$-Tocopherol, 1-chloro-2,4-dinitrobenzene (CDNB) and glutathione S-transferase P1-1 (from human placenta) were obtained from Sigma, St. Louis, USA. Reduced glutathione (GSH) was obtained from ICN Biomedicals Inc., Costa Mesa, USA. All other chemicals were of analytical grade purity.

\section{Assay of glutathione S-transferase activity}

GST activity was measured as described by Mannervik and Guthenberg [13] with slight modifications. In short, the reaction of $1 \mathrm{mM}$ CDNB with $1 \mathrm{mM} \mathrm{GSH}$ in 100 $\mathrm{mM}$ potassium phosphate, $\mathrm{pH} 6.5$, at $37^{\circ} \mathrm{C}$ was monitored spectrophotometrically by recording the increase in absorbance at $340 \mathrm{~nm}$. Effects of various concentrations 
of $\alpha$-tocopherol (final concentration $0.25 \mu \mathrm{M}$ to $5 \mu \mathrm{M}$ ) on GST activity were determined. A stock solution of a-tocopherol was prepared in ethanol. The final concentration of ethanol in the incubation mixture was $1 \% \mathrm{v} / \mathrm{v}$; this concentration of ethanol had no effect on GST activity. The mixture of the GST enzyme $10.0095 \mathrm{U} / \mathrm{mL}$ in buffer) with o-tocopherol was incubated for $2 \mathrm{~min}$ at $37^{\circ} \mathrm{C}$ before activity measurement. A correction for the spontaneous reaction was made for the formation of the conjugate of GSH and CDNB in the absence of enzyme and in the presence of ethanol $(1 \%)$. Ethanol was added because $\alpha$-tocopherol was dissolved in ethanol.

To study the inhibitory mechanism substrate concentrations (CDNB or GSH) were varied, when CDNB was varied the GSH concentration was kept at $1 \mathrm{mM}$ and vice versa. In these experiments the concentration $\alpha$-tocopherol $(0.6 \mu \mathrm{M})$ was constant.

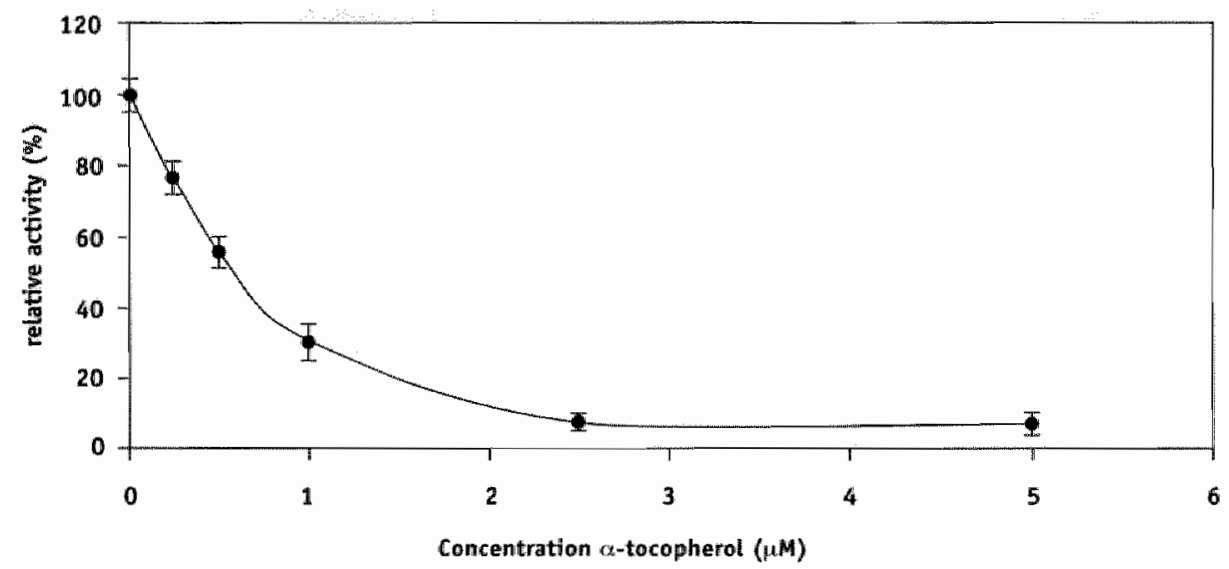

Figure 1. Effect of $\alpha$-tocopherol on the activity of GST P1-1.

The GST activity was measured by following the reaction between $1 \mathrm{mM}$ glutathiane and $1 \mathrm{mM} 1$-chloro-z" 4-dinitrobenzene in $100 \mathrm{mM}$ potassium phosphate, $\mathrm{pH} 6.5$, at $37^{\circ} \mathrm{C}$. The $1 C_{\text {s. }}$ value of $\alpha$-tocopherol is $0.5 \mu \mathrm{M}$. Each point denotes the mean \pm standard error of the mean of four experiments.

\section{Results}

As shown in Figure 1., the glutathione S-transferase activity was inhibited by $\alpha$ tocopherol in a concentration dependent manner. The concentration of $\alpha$-tocopherol giving $50 \%$ inhibition (IC $\mathrm{C}_{50}$ ) of GST P1-1 activity is $0.5 \mu \mathrm{M}$. With the addition of $3 \mu M \alpha$-tocopherol no GST activity could be detected anymore.

To obtain information on the nature of the inhibition. GST activity was measured with variable concentrations of either CDNB or GSH in the presence or absence of a 
fixed concentration $(0.6 \mu M)$ of $\alpha$-tocopherol. GST shows characteristic Michaelis Menten behavior towards both substrates. As depicted in Figures 2. and 3., $\alpha$-tocopherol lowered the $V_{\max }$ values, but did not affect the $K_{m}(\sim 1 \mathrm{mM})$ for either CDNB or GSH. This indicates that the GST P1-1 enzyme is non-competitively inhibited by $\alpha$ tocopherol.

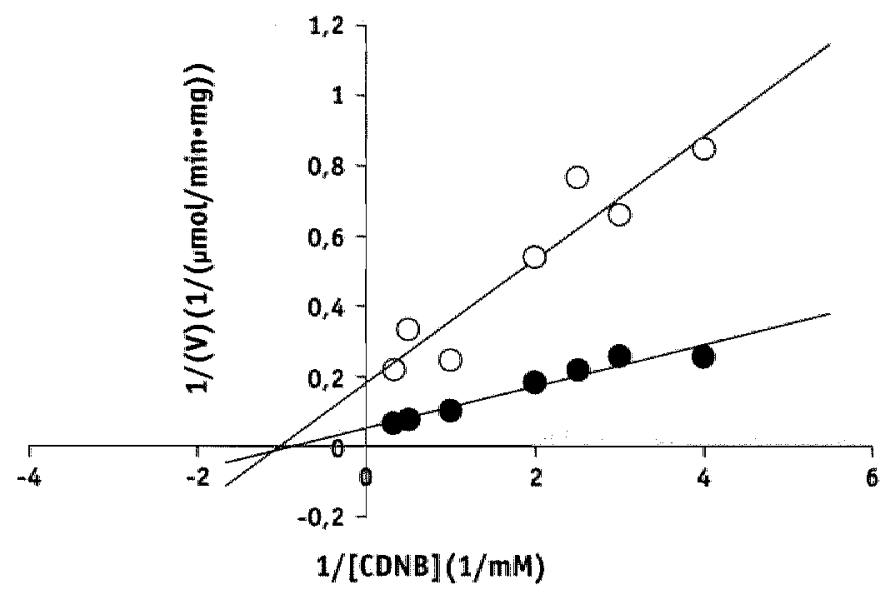

Figure 2. Lineweaver-Burk plot showing non-competitive imhibition of human placenta GST P1-1 isoenzyme towards CDNB by $0.6 \mu M \alpha$-tocopherol. The $K_{n \text { a }}$ and $V_{\text {nax }}$ (mean \pm standard error of the mean) for CONB $(\bullet)$ are respectively $1.11 \pm 0.35 \mathrm{mM}$ and $18.83 \pm 1.0(\mu \mathrm{mol} / \mathrm{min} \cdot \mathrm{mg})$. In the pre. sence of $\alpha$-tocopherol (o) these values are $0.96 \pm 0.24 \mathrm{mM}$ and $5.47 \pm 1.53(\mu \mathrm{mol} / \mathrm{min} \cdot \mathrm{mg})$.

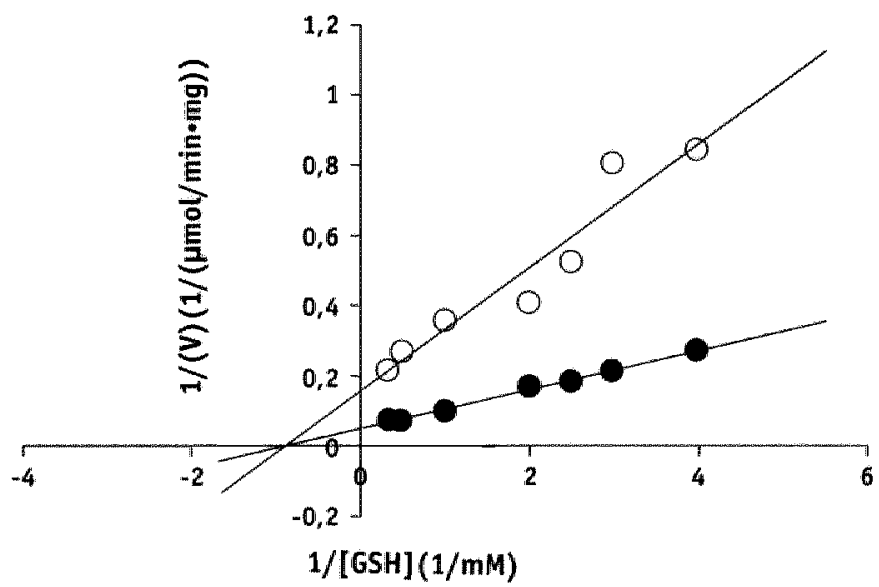

Figure 3. Lineweaver-Burk plot showing non-competitive inhibition of human placenta GST P1-1 isoenzyme toward's GSH by $0.6 \mu M \alpha$-tocopheral. The $K_{m}$ and $\mathbb{V}_{\text {san }}$ (mean \pm standard error of the mean) for $\mathrm{GSH}(\bullet)$ are respectively $1.00 \pm 0.53 \mathrm{mM}$ and $18.11 \pm 1.07(\mu \mathrm{mol} / \mathrm{min} \cdot \mathrm{mg})$. In the presence of $\alpha$-tocopherol (o) these values are $1.10 \pm 0.04 \mathrm{mM}$ and $6.26 \pm 0.87(\mu \mathrm{mol} / \mathrm{min} \cdot \mathrm{mg})$. 


\section{Discussion}

GSTs are a group of enzymes that catalyse the conjugation of GSH to electrophiles. In most cases this conjugation leads to the formation of products with a lower reactivity as the parent compound, and these products are rapidly removed by renal clearance, often as mercapturic acids [14]. The catalytic activity of the enzyme can be altered by 1) reversible unhibition (either competitive or non-competitive), 2) irreversible inhibition, 3) induction of GST, 4) GSH depletion (for example by adduct formation, consumption of GSH or inhibition of GSH synthesis).

Numerous compounds are known to inhibit the activity of the GST. These comprise endogenous substances as well as xenobiotics [15]. The P1-1 class of GST appears to be susceptible to oxidative effects. With this in mind we assumed that the antioxidant $\alpha$-tocopherol might have a protective effect on GST P1-1. Contrary to this expectation, the transferase activity is inhibited by $\alpha$-tocopherol in a concentration dependent manner (as shown in Figure 1.). When $0.5 \mu \mathrm{M} \alpha$-tocopherol is added to a solution of isolated GST P1-1, approximately half of the activity is left $\left(\mathrm{IC}_{50}\right.$ value of $\alpha$-tocopherol is $0.5 \mu \mathrm{M}$ ). When the inhibitory effect of $\alpha$-tocopherol is compared with that of other compounds, it can be concluded that $\alpha$-tocopherol is a very potent inhibitar of the P1-1 isoform of the GST. The inhibitory effect of $\alpha$-tocopherol is comparable to the effect of for example cibacron blue $\left(\mathrm{IC}_{50}\right.$ value is 0.5 $\mu \mathrm{M})$ and much higher than the inhibitory effect of for instance S-hexylglutathione $\left(\mathrm{IC}_{\mathrm{s0}}\right.$ value is $\left.20 \mu \mathrm{M}\right)$ or bromosulfothalein $\left(\mathrm{IC}_{50}\right.$ value is $\left.100 \mu \mathrm{M}\right)$ [16]. These compounds are all xenobiotics, while $\alpha$-tocopherol is present normally. Concentrations of $3 \mu \mathrm{M} \alpha$-tocopherol and higher completely black GST P1-1.

From Figures 2. and 3. it appears that the $K_{m}$ for CDNB or GSH is not changed by the addition of $\alpha$-tocopherol. This means that $\alpha$-tocopherol exhibits a non-competitive inhibition with respect to the substrates CDNB and GSH. Apparently $\alpha$-tocopherol does not compete for the binding sites of either GSH or CDNB it modifies. GST enough to fully inactivate the enzyme. Regarding the lipophilic nature of $\alpha$-tocopherol the most likely mechanism is through conformational changes due to volume increases and structural modifications of lipophilic regions that are present in the interface between the two monomers of the GST. Binding of compounds at this region is known to affect the activity of the GST enzyme [17]. The inhibitory effect of $\alpha$-tocopherol on GST is in line with the findings reported by Stone and Dratz [18]. They found that rats fed a diet deficient in vitamin $E$ have an increased activity of glutathione S-transferase in a variety of tissues.

The implications of the inhibition of GST P1-1 by $\alpha$-tocopherol are in theory far-reaching. It is known that GST P1-1 is present in the skin [19]. Henderson et al. showed that mice lacking the GST P1-1 have an increased risk for skin tumorigenesis [20]. Interestingly, Mitchel and McCann found that vitamin $\mathrm{E}$ is a complete tumor pro- 
moter in mouse skin [21]. The potent GST P1-1 inhibition by $\alpha$-tocopherol found in our study suggests that this promoter effect might be caused by GST PI-1 inhibition.

The vitamin $E$ concentration in several modern cosmetic products often exceeds the concentration needed to block GST P1-1. This urges to evaluate a possible inhibition of GST P1-1 in the skin as a consequence of the use of these cosmetic products. 


\section{References}

1. Acker wan, S.A.B.E.; Kaymans, L.M.H.; Bast. A. Malecular pharmacology of vitamin E:structural aspects of antioxidant activity.

Free Radical Biology \& Medicine 1993, 15, 311-328.

2. Azzi, A.; Stocker, A. Vitamin E: non-antioxidant roles.

Progress in lipid research 2000, 39, 231-255.

3. Traber, M.G.; Packer, L. Vitamin E: Beyond antioxidant function.

The American Joumal of Clinical Nutrition 1995, 62 (suppl), 15015-15095.

4. Mannervik, B. The isoenzymes of glutathione transferase.

Advances in enzymology and related areas of molecular biology 1985, 57, 357-417.

5. Uchida, $K$. Induction of glutathione S-transferase.

Mechanisms of ageing and development 2000, 116, 135-140.

6. Habig, W.H.; Pabst, M.J.; Jakoby, W.B. Glutathione S-transferases. The first enzymatic step in mercapturic acid formation.

The Journal of Biological Chemistry 1974, 249, 7130-7139.

7. Haenen, G.R.M.M.; Bast, A. Protection against lipid peraxidation by a microsomal glutathione-dependent labile factor.

Federation of European Biachemical Societies 1983, 159, 24-28.

8. McCay, P.B. Vitamin E: Interactions with free radicals and ascorbate.

Annual Review of Nutrition 1985, 5, 323-340.

9. Wijesundara, M.B.J.; Berger, S. The redox pair vitamin $E$ and vitamin C, a 13C-NMR study. Liebigs Annalen der Chemie 1994, 1239-1241.

10. Hamilton, I.M.J.; Gilmore, W. S.; Benzie, L.F.F.; Mulholland, C.W; Strain, J.J. Interactions between vitamins $C$ and $E$ in human subjects.

British Journal of Nutrition 2000, 84, 261-267.

11. Guthenberg, $C_{n}$; Manmewik, B. Glutathione S-transferase (transferase pi) from human placenta is identical or closely related to glutathione S-transferase (transferase $p$ ) from enythrocytes.

Biachimica et Biophysica Acta 1981, 661, 255-260.

12. Neefjes, V.M.; Evelo, C.T.; Boars, L.G.; Blanco, C.E. Eythrocyte glutathione 5 transferase as a marker of oxidative stress at birth.

Archives of disease in childhoad 1999, 81, F130-F133.

13. Mannervik, B.; Guthenberg, C. Glutathione transferase (Human placenta).

Methods in enzymology 1981,77, 231-235.

14. Welie van, R. T.; Dijck wan, R.G.; Vermeulen, N.P., Sittert van, N.J. Mercapturic acids, protein adducts, and DNA adducts as biomarkers of electrophilic chemicals.

Critical Reviews in Toxicology 1992,22, 271-306.

15. Bladeren van, P.J.; Ommen van, B. The inhibition of glutathione 5-transferases: mechanisms, toxic consequences and therapeutic benefits.

Pharmacology and therapeutics 1991, 51, 35-46.

16. Mannervik, B.; Danielson, U.H. Glutathione transferases-Structure and catalytic activity. CRC. Critical Reviews in Biochemistry 1988, 23, 283-337,

17. Ricci, G.; Lo-Bello, M.; Caccurni, A.M.; Pastore, A.: Nuccetelli, M.; Parker, M.W.; Federici, 6. Site-directed mutagenesis of human glutathione transferase P1-1. Mitutation of Cys47 induces a positive cooperativety in glutathione transferase P1-1.

The Journal of Biological Chemistry 1995, 270, 1243-1248. 
18. Stone, W.L.; Dratz, E.A. Increased glutathone-S-transferase activity in antioxidant-deffcient rats.

Biochimica et Biophysica Acta 1980, 631, 503-506.

19. Singhal, S.S.; Saxena, M.; Awasthi, S.; Mukhtor, H.; Zaidi, S.I.; Ahmad, H.; Awasthi, Y.C. Glutathione S-transferases of human skin: qualitative and quantitative differences in men and women.

Biochimica et Biophysica Acta 1993, 1163, 266-272.

20. Henderson, C.J.; Smith, A.G.; Ure, J.; Brown, K.; Bacon, E.J.; Wolf, C.R. Increased skin tumorigenesis in mice lacking pi class glutathione S-transferases. Proceedings of the National Academy of Sciences of the United States of America 1998, 95, 5275.5280.

21. Mitchel, R.E.; McCann, R. Vitamin E is a complete tumor promoter in mouse skin.

Carcinogenesis 1993, 14, 659-662. 


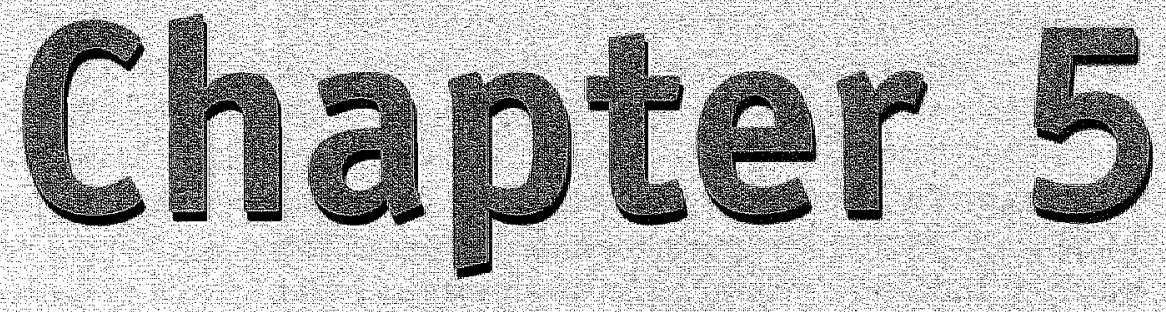

\section{Inhibition of human glutathione S-transferase P1-1 by tocopherols and $\alpha$-tocopherol derivatives}

Rachel I.M. van Haaften Chris T.A. Evelo John Penders Miguel P.F. Eijnwachter Guido R.M.M. Haenen and Aalt Bast

Biochimica et Biophysica Acta 1548 23-28 (2001) 


\section{Abstract}

$\alpha$-Tocopherol inhibits glutathione S-transferase P1-1 (GST P1-1) [1]. In various cosmetic and dietary products $\alpha$-tocopherol is added as a tocopherol ester. Therefore we have studied the effect of various tocopherol derivatives on GST P1-1 activity. It was found that GST P1-1 is inhibited, in a concentration dependent manner, by these compounds. Of the compounds tested, the tocopherols were the most potent inhibitors of GST P1-1; the concentration giving $50 \%$ inhibition ( $\mathrm{IC}_{50}$ ) is $<1 \mu \mathrm{M}$. The esterified tocopherols and $\alpha$-tocopherol quinone also inhibit the GST P1-1 activity at a very low concentration: for most compounds the $\mathrm{IC}_{30}$ was below $10 \mu \mathrm{M}$. RRR- $\alpha$ tocopherol-acetate lowered the $V_{\text {max }}$ values, but did not affect the $K_{m}$ for either 1chloro-2,4-dinitrobenzene or GSH. This indicates that the GST P1-1 enzyme is noncompetitively inhibited by RRR- $\alpha$-tocopherol-acetate. The potential implications of GST P1-1 inhibition by tocopherol and $\alpha$-tocopherol derivatives are discussed. 


\section{Introduction}

Glutathione S-transferases (GSTS) are a family of phase II detoxification enzymes that catalyse the conjugation of glutathione (GSH) to electrophiles. Numerous compounds are known to inhibit the GST activity. Recently, we reported that $\alpha$-tocopherol is a potent inhibitor of the P1-1 isoform of GST [1].

Vitamin $\mathrm{E}$ is a generic name for all tocol and tocotrienol derivatives. The antioxidant activity is the most studied biological activity of these compounds discovered thus $\mathrm{far}_{\text {, }}$ although other activities have also been found $[2,3]$.

The tocopherols can be viewed as consisting of a chroman head consisting of two rings (one phenolic and one heterocyclic) and a phytyl tail. The phytyl tail has three chiral centers (at positions 2, $4^{\prime}$ and $8^{\prime}$ ), making a total of eight stereoisomeric forms possible (Figure 1.). The phytyl chain of naturally occurring tocopherols ( $\alpha$-, $\beta-, \gamma$, and $\delta$-tocopherol) has the RRR configuration. A synthetic tocopherol usually is a mixture of approximately equal amounts of the eight stereoisomers (RRR, RRS, RSR, RSS, SRR, SRS, SSR and SSS). This mixture is denoted as all-rac-tocopherol. [4]. In the antioxidant activity of tocopherol, the free aromatic hydroxyl group plays an essential role: the tocopherol can donate its phenolic hydrogen to lipid free radicals. Sequestration of this group inhibits the antioxidant activity but also makes the molecule less vulnerable to oxidation [4]. Therefore forms of $\alpha$-tocopherol have been developed in which the free hydroxyl group has been blocked, e.g. by esterification of this alcoholic group with acetate or succinate. In vivo, the ester is saponified by an esterase revealing the antioxidant activity.

The aim of this study is to investigate whether tocopherols and $\alpha$-tocopherol derivatives, other than $\alpha$-tocopherol, can inhibit GST P1-1.

\section{Materials and Methods}

\section{Chemicals}

The compounds tested were: RRR- $\alpha$-tocopherol, all-rac- $\alpha$-tocopherol, RRR- $\delta$-tocopherol, RRR- $\alpha$-tocopherol quinone, all-rac- $\alpha$-tocopherol phosphate, RRR- $\alpha$-tocopherol succinate, all-rac- $\alpha$-tocopherol nicotinate, RRR- $\alpha$-tocopherol acetate, allrac- $\alpha$-tocopherol acetate, arachidonic acid and trolox (6-hydroxy-2,5,7,8-tetramethyl-chroman-2-carboxylic acid). All compounds were purchased from Sigma (St. Louis, MO, USA), except RRR- $\alpha$-tocopherol-quinone. This compound was synthesised from RRR- $\alpha$-tocopherol by oxidation with ferric chloride, according to Cohen et al. [5]. 1-Chloro-2,4-dinitrobenzene (CDNB) and GST P1-1 (from human placenta) were also obtained from Sigma. GSH was obtained from ICN Biomedicals (Costa Mesa, CA, USA). All other chemicals were of analytical grade purity. 


\section{Assay of glutathione S-transferase activity}

GST activity was measured as described by Mannerwik and Guthenberg [6] with slight modifications. In short, the reaction of $1 \mathrm{mM}$ CDNB with $1 \mathrm{mM}$ GSH in 100 mM potassium phosphate, $\mathrm{pH} 6.5$, at $37^{\circ} \mathrm{C}$ was monitored spectrophotometrically by recording the increase in absorbance at $340 \mathrm{~nm}$. Effects of various concentrations of test compound on GST activity were determined. A stock solution of test compound was prepared in ethanol. The final concentration of ethanol in the incubation mixture was $1 \% \mathrm{~V} / \mathrm{v}^{\text {; }}$ this concentration of ethanol had no effect on GST activity. The mixture of the GST enzyme $(0.0095 \mathrm{U} / \mathrm{ml}$ in buffer) with test compound was incubated for $2 \mathrm{~min}$ at $37^{\circ} \mathrm{C}$ before activity measurement. A correction for the spontaneous formation of the conjugate of GSH and CDNB in the absence of enzyme and in the presence of ethanol (1\%) was made. To study the inhibitory mechanism of RRR- $\alpha$-tocopherol acetate, substrate concentrations (CDNB or GSH) were varied. When CDNB was varied the GSH concentration was kept at $1 \mathrm{mM}$ and vice versa. In these experiments the concentration RRR- $\alpha$-tocopherol-acetate was kept constant at $12.5 \mu \mathrm{M}$.

\section{Results and discussion}

All compounds tested (Figure 1.), except trolox and arachidonic acid, were found to inhibit human GST P1-1 activity towards CDNB at relatively low concentrations. An example of an inhibition curve at increasing concentration of test compound is given in Figure 2. for RRR- $\alpha$-tocopherol acetate.

Figure 1. (see page 87) Chemical structures of the compounds tested with the corresponding $I C_{S 0}$ values.

The three chiral centers in the phytyl tail are indicated with * in $\alpha$-tocopherol. of $\alpha$-tocopherol and $\alpha$-tocopherol-acetate both the RRR and the all-rac forms are tested. $I C_{\text {so }}$ walues indicate means ( \pm S.E.M.J of three independent experiments each performed in duplicate. 


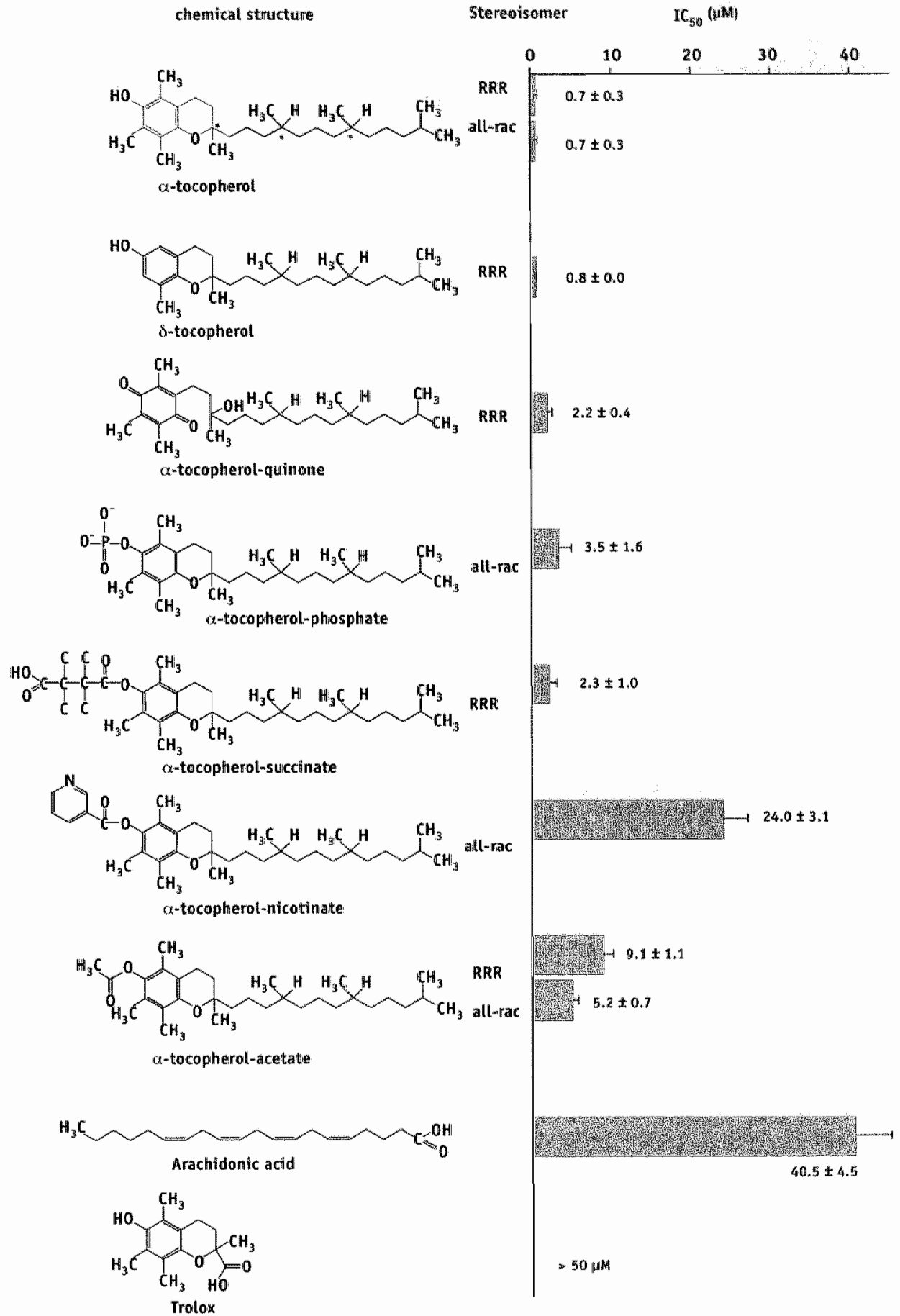




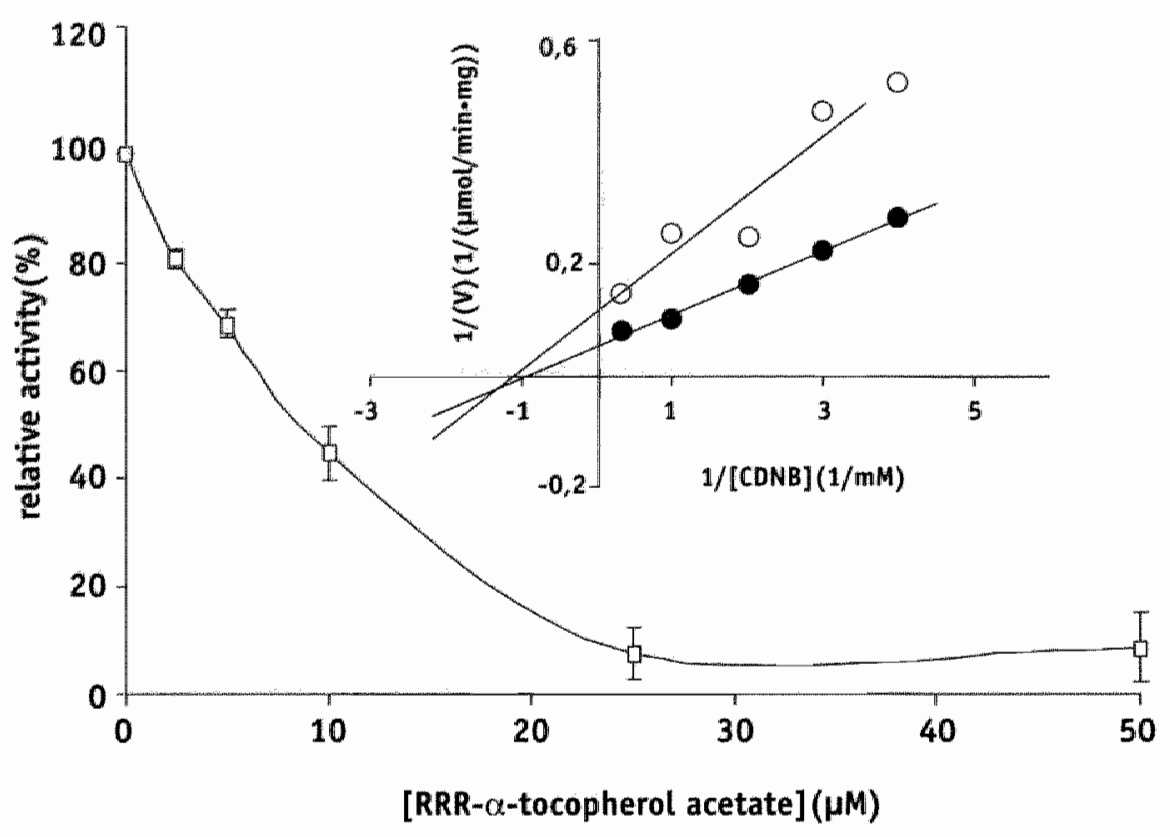

Figure 2. Effect of $R R R-\alpha$-tocopherol acetate on the activity of GST P1-1.

The GST activity was measured by following the reaction between $1 \mathrm{mM}$ glutathione and $1 \mathrm{mM}$ 1-chloro2.4-dinitrobenzene in $100 \mathrm{mM}$ potassium phosphate, pH 6.5 at $37^{\circ} \mathrm{C}$. Each point denotes the mean ( $\$$ S.E.M.) of three independent experiments each performed in triplicate.

Insert: Lineweaver-Burk plot showing non-competitive inhibition of human placenta GST P1-1 isoenzyme towards CDNB by $12.5 \mu M$ RRR- $\alpha$-tocopherol acetate. The $K_{m}$ and $V_{m a x}$ (mean \pm range) of two independent experiments performed in triplicate for CDNB (*) are respectively $1.13 \pm 0.23 \mathrm{mM}$ and $19.71 \pm 3.49 \mu \mathrm{mal} / \mathrm{min} \cdot \mathrm{mg}$. In the presence of RRR- $\alpha$-tocopherol-acetate $(0)$ these values are 0.94 $\pm 0.06 \mathrm{mM}$ and $9.05 \pm 1.45 \mathrm{\mu mol} / \mathrm{min} \cdot \mathrm{mg}$.

The data in Figure 1 . show that both $\alpha$-tocopherol and $\delta$-tocopherol are very potent inhibitors of the P1-1 isoform of GST. The IC ${ }_{s,}$ of $\alpha$-tocopherol and $\delta$-tocopherol are $0.7 \mu \mathrm{M}$ and $0.8 \mu \mathrm{M}$ respectively, indicating that there is practically no difference in potency between the $\alpha$ and the $\delta$ isoform. These two isoforms of tocopherol differ in the methylation pattern in the phenolic ring of the chroman head (Figure 1.) [4]. From this it can be concluded that methylation at positions 5 and 7 in the chroman head of tocopherol has no influence on the GST P1-1 inhibitory capacity. From the results it also appears that sequestration of the hydroxyl group in the chroman head of the tocopherol molecule by acetate, succinate, phosphate or nicotinate lowers the GST P1-1 inhibitory capacity, although the compounds are still potent inhibitors (Figure 1.). Figure 1. also shows that the oxidation product of $\alpha$ tocopherol, $\alpha$-tocopherol quinone $\left(\mathrm{IC}_{50}\right.$ is $\left.2.2 \mu \mathrm{M}\right)$, is also active but has a lower 
inhibitory effect than the parent compound. The inhibitory potency of trolox was low; even at $50 \mu \mathrm{M}$ no substantial inhibition of GST P1-1 activity was observed. This molecule has the same chroman ring as $\alpha$-tocopherol, however the phytyl chain is replaced by a negatively charged carboxylate group (Figure 1.). Based on these results we can conclude that the free aromatic hydroxyl group is not essential, while the phytyl tail probably has a major contribution to GST P1-1 inhibition. Thus other structural elements play a role in GST inhibition than in free radical scavenging in which the free hydroxyl group is important.

The $\mathrm{IC}_{50}$ values of the acetate esters of RRR- $\alpha$-tocopherol and all-rac- $\alpha$-tocopherol are $9.1 \mu \mathrm{M}$ and $5.2 \mu \mathrm{M}$ respectively. This implies that at least one stereoisomer of the all-rac- $\alpha$-tocopherol acetate molecule inhibits GST P1-1 activity with higher potency than the RRR- $\alpha$-tocopherol acetate. So the sterical orientation in the phytyl. tail of the $\alpha$-tocopherol acetate molecule seems to be important for the GST P1-1 inhibitory capacity. However, the RRR- $\alpha$-tocopherol and the all-rac- $\alpha$-tocopherol exhibit the same GST P1-1 inhibitory capacity; the $\mathrm{IC}_{50}$ of the RRR- $\alpha$-tocopherol and the all-rac- $\alpha$-tocopherol are $0.70 \mu \mathrm{M}$ and $0.74 \mu \mathrm{M}$ respectively. This indicates that the mean inhibitory capacity of all $\alpha$-tocopherol stereoisomers is identical to that of RRR- $\alpha$-tocopherol. In vivo, RRR- $\alpha$-tocopherol has a greater bioavailability compared to the other stereoisomers [7] and the effect of this isomer might therefore still be the most important when a racemic mixture is given.

From the results it also appears that arachidonic acid inhibits the GST P1-1 activity with an $\mathrm{IC}_{s 0}$ value of $40.5 \mu \mathrm{M}$, much higher than for the tocopherols. So not all compounds with a long hydrophobic group inhibit the GST P1-1 activity at relatively low concentrations. Arachidonic acid is known to be a potent inhibitor of other GST isoenzymes. Mitra et al. [8] used a crude GST fraction from rat liver and found an $\mathrm{IC}_{50}$ of $17 \mu \mathrm{M}$, which is lower than the $\mathrm{IC}_{50}$ we found for GST P1-1 in this study.

For the compound RRR- $\alpha$-tocopherol acetate the nature of the inhibition was also studied. GST activity was measured with variable concentrations of either CDNB (insert Figure 2.) or GSH (data not shown) in the presence of a fixed concentration RRR- $\alpha$-tocopherol acetate. RRR- $\alpha$-tocopherol acetate lowered the $V_{\max }$ values, but did not affect the $K_{\mathrm{rij}}$ (approx. $1 \mathrm{mM}$ ). This means that RRR- $\alpha$-tocopherol acetate, like RRR- $\alpha$-tocopherol [1] exhibits a non-competitive inhibition with respect to the substrates CDNB and GSH.

The most probable mechanism of GST inhibition by tocopherols, $\alpha$-tocopherol derivatives and arachidonic acid is the induction of conformational changes of the enzyme. These conformational changes could be caused by volume increases and structural modifications of lipophilic regions that are present in the interface between the two monomers of the GST. Binding of a compound to this region can change the activity of the enzyme [9]. 
In conclusion, of all tested compounds the tocopherols were the most potent inhibitors of GST P1-1. However the esterified tocopherols and the oxidised product also inhibit the GST P1-1 activity at a very low concentration (all $\alpha$-tocopherol esters except all-rac- $\alpha$-tocopherol nicotinate exhibit an $\mathrm{IC}_{s o}$ value lower than $10 \mu \mathrm{M}$ ). Mitchell and McCann [10] found that all-rac- $\alpha$-tocopherol is a complete tumor promoter in mouse skin and Henderson et a!. [11] showed that mice lacking the GST P1-1 have an increased risk for skin tumorigenesis. These results together with the fact that GST P1-1 is present in the skin [12] might be explained by the potent GST P1-1 inhibition.

When vitamin $E$ is added to a product, e.g. a cosmetic product, mostly a tocopherol ester is used. This is due to the better chemical stability of the ester compared to the free tocopherol [13]. Most cosmetic products, containing a tocopherol ester, are applied to the skin. GST P1-1 is present mainly in many cells in the upper layers of the epidermis [14]. To estimate the maximal concentration of the tocopherol ester in the skin after application of a cosmetic product we assume that i) all the tocopherol ester is transferred to the epidermis and ii) the concentration in the epidermis is one tenth of the concentration in the cosmetic product. Indeed, Klain found that $4 \mathrm{~h}$ after dermal application of ${ }^{16} \mathrm{C}$-labeled vitamin $\mathrm{E}$, to human skin grafted athymic nude mice; the epidermis contained the most radioactivity. He suggested that the skin can act as a reservoir for vitamin E [15]. Metabolism, elimination, distribution or accumulation due to frequent application of the cosmetic product is not taken into account in this estimation. Based on these assumptions it can be calculated that to reach a concentration of $10 \mu \mathrm{M}$ of the tocopherol ester in the epidermis, a concentration inhibiting GST P1-1 more than $50 \%, 0.0005 \% \mathrm{w} / \mathrm{v}$ tocopherol ester in the cosmetic product would be sufficient. The concentration in most tocopherol ester containing cosmetic products exceeds this value by far. Concentrations up to $1 \%$ can be found; even products containing pure vitamin $\mathrm{E}$ are sold. This indicates that application of a tocopherol ester containing product on the skin probably results in a substantial inhibition of GST P1-1. Therefore, a potential tumor promoter effect may also be ascribed to $\alpha$-tocopherol esters; however, further research is needed to substantiate this hypothesis. 


\section{References}

1. Haaften van, R.I.M.; Evelo, C.T.A.; Haenen, G.R.M.M.; Bast. A. Alpha-tocopherol inhibits human glutathione S-transferase pi.

Biochemical and Biophysical Research Communications 2001, 280,631-633.

2. Azzi, A.; Stocker, A. Vitamin E: non-antioxidant roles.

Progress in lipid research 2000, 39, 231-255.

3. Traber, M.G., Packer, L. Vitamin E: Beyond antioxidant function.

The American Joumal of Clinical Nutrition 1995, 62 (suppl), 15015-15095.

4. Kamal-Eldin, A.; Appelqvist, L.A. The chemistry and antioxidant properties of tocopherols and tocotrienols.

Lipids 1996, 31, 671-701.

5. Cohen, M.; Lopresti, R.A.; Neukom, C. Studies on the total synthesis of $(2 R, 4 R, 8 R)$ $\alpha$-tocopherol (vitamin E). Stereaspecific cyclizations leading to optically active chromans. Journal of Organic Chemistry 1981, 46, 2445-2450.

6. Mannervik, B.; Guthenberg, C. Glutathione transferase (Human placenta). Methods in enzymology 1981, 77, 231-235.

7. Ferslew, K.E.; Acuff, R.V.; Daigneault, E.A.: Woolley, T.W.; Stanton, P.E., Jr. Pharmacokinetics and bioavailability of the RRR and all racemic stereoisomers of alpha-tocopherol in humans after single oral administration.

Journal of clinical pharmacology 1993, 33, 84-88.

8. Mitra, A.; Govindwar, S.; Kulkarmi, A.P. Inhibition of hepatic glutathione-S-transferases by fatty acids and fatty acid esters.

Toxicology 1991, 58, 135-141.

9. Ricci, G.; Lo-Bello, M.; Caccurri, A.M.; Pastore, A.; Nuccetelli, M.; Parker. M.W.; Federici, G. Site-directed mutagenesis of human glutathione transferase P1-1. Mutation of Cys47 induces a positive cooperativety in glutathione transferase P1-1.

The Journal of Biological Chemisty 1995, 270, 1243-1248.

10. Mitchel, R.E.; MCCann, R. Vitamin $E$ is a complete turnor promoter in mouse skin. Carcinogenesis 1993, 14, 659-662.

11. Henderson, C.J.; Smith, A.G.; Ure, J.; Brown, K.; Bacon, E.J.; Wolf, C.R. Increased skim tumorigenesis in mice lacking pi class giutathione S-transferases. Proceedings of the National Academy of Sciences of the United States of America 1998, 95, 5275-5280.

12. Singhat, 5.5.; Saxena, M.; Awasthr, S.; Mukhtar, H.; Zaidi, S.I.; Ahmad, H., Awasthi, Y.C. Glutathione S-transferases of human skin: qualitative and quantitative differences in men and women.

Biachimica et Biophysica Acta 1993, 1163, 266-272.

13. Cheeseman, K.H.; Holley, A.E.; Kelly, F.J.; Wasil, M.; Hughes, L.; Burton, G. Biokinetics in humans of RRR-alpha-tocopherol: the free phenol, acetate ester, and succinate ester forms of vitamin $E$.

Free Radical Biology \& Medicine 1995, 19, 591-598.

14. Shimizu, $K_{\text {.; }}$ Toriyama, $F_{\text {; }}$ Yoshida, $H$. The expression of placental-type glutathione Stransferase (GST-pi) in human cutaneaus squamous cell carcinoma and normal human skin. Virchows Archiv 1995, 425, 589-592.

15. Klain, G.J. Dermal penetration and systemic distribution of 14C.Labeled vitamin $E$ in human skin grafted athymic nude mice.

Int J Vitam Nutr Res 1989, 59, 333-337. 

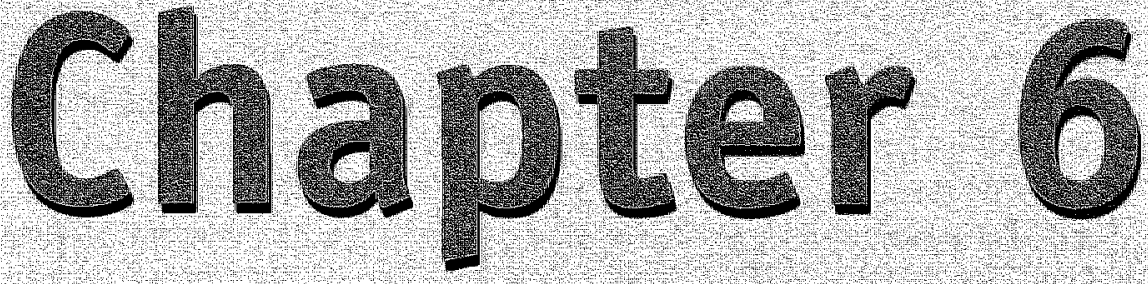

\title{
Tocotrienols inhibit human glutathione S-transferase P1-1
}

\author{
Rachel I.M. van Haaften \\ Guido R.M.M. Haenen \\ Chris T.A. Evelo \\ and Aalt Bast
}

IUBMB Life 54 81-84 (2002) 


\section{Abstract}

Tocopherols and tocotrienols are food ingredients that are believed to have a positive effect on health. The most studied property of both groups of compounds is their antioxidant action. Previously we have found that tocopherols and diverse tocopherol derivatives can inhibit the activity of human glutathione S-transferase P1-1 (GST P1-1). In this study we found that GST P1-1 is also inhibited, in a concentration-dependent manner, by $\alpha$ - and $\gamma$-tocotrienol. The concentration giving $50 \%$ inhibition of GST P1-1 is $1.8 \pm 0.1 \mu \mathrm{M}$ for $\alpha$-tocotrienol and $0.7 \pm 0.1 \mu \mathrm{M}$ for $\gamma$-tocotrienol. This inhibition of GST P1-1 is noncompetitive with respect to both substrates CDNB and GSH.

We also examined the 3D structure of GST P1-1 for a possible tocopherol/tocatrienol binding site. The enzyme contains a very hydrophobic pit-like structure where the phytyl tail of tocopherols and tocotrienols could fit in. Binding of tocopherol and tocotrienol to this hydrophobic region might lead to bending of the 30 structure. In this way tocopherols and tocotrienols can inhibit the activity of the enzyme; this inhibition can have far-reaching implications for humans. 


\section{Introduction}

Vitamin $E$ is the generic name for both tocopherol and tocotrienol derivatives. Tocopherols and tocotrienols both consist of a common chromanol head (with two rings: one phenolic and one heterocyclic) and a 16-carbon tail attached at the 2position. The tocotrienols differ from the tocopherols only in the tait. Tocopherols have a saturated phytyl side chain, whereas the tail of tocotrienols is unsaturated and forms an isoprenaid chain [1-3]. Tocotrienols and tocopherols are further divided into several vitamers $(\alpha, \beta, \delta$ and $\gamma)$ depending on the number and position of methyl groups on the chroman head (Figure 1.) [1-3].<smiles></smiles><smiles>[R]c1c(C)c2c(c([R])c1O)CC[C@@](C)(CC/C=C(/C)CC/C=C(\C)CCC=C(C)C)O2</smiles>

\begin{tabular}{|c|cc|}
\hline & $\mathrm{R}_{1}$ & $\mathrm{R}_{2}$ \\
\hline$\alpha$ & $\mathrm{CH}_{3}$ & $\mathrm{CH}_{3}$ \\
$\beta$ & $\mathrm{CH}_{3}$ & $\mathrm{H}$ \\
$\gamma$ & $\mathrm{H}$ & $\mathrm{CH}_{3}$ \\
$\delta$ & $\mathrm{H}$ & $\mathrm{H}$ \\
\hline
\end{tabular}

Figure 1. Molecular structure of tocopherols and tocotrienols. The naturally occurring vitamers, $\alpha, \beta$, $\gamma$ and $\delta_{x}$ have methylation patterns as indicated.

They are both used as food additives. The natural sources of tocopherol mainly consist of nuts and common vegetable oils (i.e., wheat germ, sunflower) [4]. Tocotrienols are minor plant constituents, with a relative high abundance in cereal grains (i.e., oat, barley, and rye) and certain vegetable oils (i.e., palm oil and rice bran oil) [4].

Both tocopherols and tocotrienols are well recognised for their antioxidative effect. It has been stated that, in vitro, the tocotrienols are more potent antioxidants than the tocopherols [3]. Aside from their function as antioxidants, tocotrienols are reported to reduce plasma cholesterol levels and lipid-and nonlipid-related risk factors for cardiovascular disease [4].

Tocopherols and diverse tocopherol derivatives can inhibit the activity of glutathione S-transferase P1-1 (GST P1-1) [5, 6]. This detoxification isoenzyme is the most prominent GST in erythrocytes and is also present in human skin $[7,8]$. In this study we examined the effect of two vitamers of tocotrienol on the activity of GST P1-1. 


\section{Materials and Methods}

\section{Chemicals}

Tocotrienols were a gift from BASF (Stuttgart, Germany); 1-chloro-2, 4-dinitrobenzene (CDNB) and glutathione S-transferase $\mathrm{P} 1-1$ (from human placenta) were obtained from Sigma, St. Louis, Missouri, USA. Reduced glutathione (GSH) was obtained from ICN Biomedicals Inc, Costa Mesa, USA. All other chemicals were of analytical grade purity.

\section{Assay of glutathione S-transferase activity}

GST activity was measured as described by Mannervik and Guthenberg [8] with slight modifications. In short, the reaction of $1 \mathrm{mM}$ CDNB with $1 \mathrm{mM}$ GSH in 100 $\mathrm{mM}$ potassium phosphate, $\mathrm{pH} 6.5$, at $37^{\circ} \mathrm{C}$ was monitored spectrophotometrically by recording the increase in absorbance at $340 \mathrm{~nm}$. Effects of various concentrations. of $\alpha$ - and $\gamma$-tocotrienol (final concentration $0.25 \mu \mathrm{M}-5 \mu \mathrm{M}$ ) on GST activity were determined. A stock solution of tocotrienol was prepared in ethanol. The final concentration of ethanol in the incubation mixture was $1 \% \mathrm{v} / \mathrm{v}$; this concentration of ethanol had no effect on GST activity. The mixture of the GST enzyme $(0.0095 \mathrm{U} / \mathrm{mL}$ in buffer) with tocotrienol was incubated for 2 minutes at $37^{\circ} \mathrm{C}$ before activity measurement. A correction for the spontaneous reaction was made for the formation of the conjugate of GSH and CDNB in the absence of enzyme and in the presence of ethanol (1\%). Ethanol was added as control because tocotrienol was dissolved in ethanol. To study the inhibitory mechanism, substrate concentrations (CDNB or GSH) were varied. When CDNB was varied, the GSH concentration was kept at $1 \mathrm{mM}$ and vice versa, the concentration tocotrienol was constant $(1 \mu \mathrm{M})$.

\section{D structure evaluation}

The PDB file for human GST P1-1 with GSH bound (PDB ID: 7GSS [9]) was downloaded from the PDB database <http://www.rcsb.org/pdb> [10]) and examined with Rasmol (version 2.6, <http://www.umass.edu/microbio/rasmols). Hydrophobic amino acids were color-coded light gray (green in full. color version) using the Rasmol "color hydrophobic light gray (green in full color version)" setting. The G-site of GST P1-1 was previously identified by Reinemer et al. [11]. The nonhydrophobic aminoacids in this region were color coded black (blue in full color version).

\section{Results}

Both $\alpha$ - and $\gamma$-tocotrienol inhibited the GST P1-1 activity in a concentration dependent manner (Figure 2.). The concentration giving 50\% inhibition of the GST P1-1 activity $\left(\mathrm{IC}_{\mathrm{s}_{0}}\right)$ is $1.8 \pm 0.1 \mu \mathrm{M}$ for $\alpha$-tocotrienol and $0.7 \pm 0.1 \mu \mathrm{M}$ for $\gamma$-tocotrienol. 


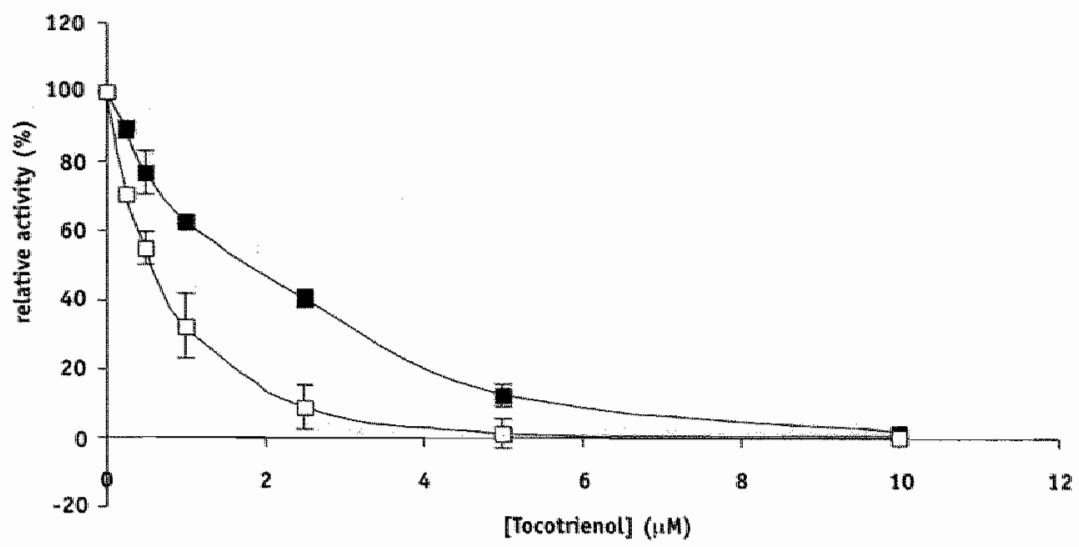

Figure 2. Effect of $\alpha$-tocotrienol ( $\sim$ ) and $\gamma$-tocotrienol ( 0 ) on the activity of GST P1.1. The IC $\mathrm{S}_{\text {si: }}$ walues are $1.8 \pm 0.1 \mu \mathrm{M}$ for $\alpha$-tocotrienol and $0.7 \pm 0.1 \mu \mathrm{M}$ for $\gamma$-tocotrienol. Each point denotes the mean \pm standard error of the mean of three experiments.

The nature of the inhibition of $\gamma$-tocotrienol was studied by making Lineweaver-Burk plots for both the substrates CDNB and GSH. GST activity was measured with variable concentrations of either CDNB (Figure 3.) or GSH (data not shown) in the presence of a fixed concentration $(1 \mu \mathrm{M})$ of $\gamma$-tocotrienol. GST showed characteristic MichaelisMenten behavior towards both substrates (Figure 3.). As depicted in Figure 3., $\gamma$ tocotrienol lowered the $\mathrm{V}_{\max }$, but did not change the $\mathrm{K}_{\mathrm{m}}$ for CDNB. The same results are obtained for GSH.

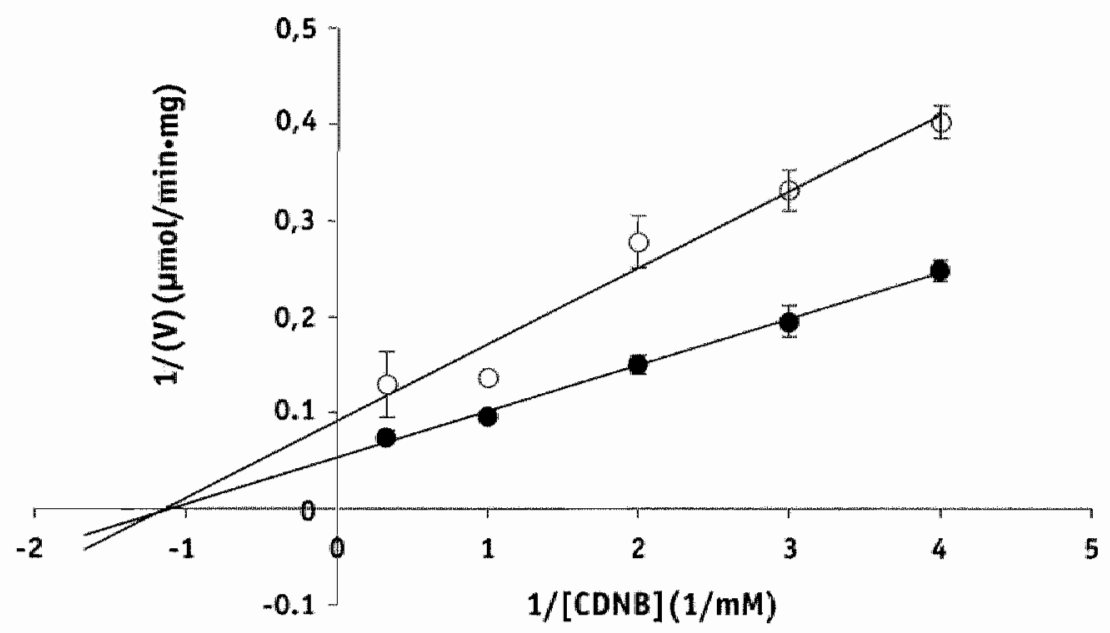

Figure 3. Lineweaver-Burk plot showing noncompetitive inhibition of human GST P1-1 towards CONB by $1 \mu M$ Y-tocotrienol. The $K_{m}$ and $V_{\max }$ (mean \pm standard error of the mean) for CDNB ( $)$ are respectively $1.1 \pm 0.01 \mathrm{mM}$ and $20.7 \pm 2.5\left(\mu \mathrm{mal} \cdot \mathrm{min}^{-1} \cdot \mathrm{mg}^{2}\right)$. In the presence of $\gamma$-tocotrienol (o) these values are $1.3 \pm 0.1 \mathrm{mM}$ and $14.6 \pm 1.2\left(\mathrm{mmol} \cdot \mathrm{min}^{-1} \cdot \mathrm{mg}^{-13}\right)$. 
Three-dimensional evaluation of the GST P1-1 protein structure revealed that there are surprisingly few hydrophobic amino acids present in the contact region of the two monomers. The hydrophilic amino acids in the contact region are color coded dark grey (orange in full color version) in Figure 4 . The figure is shown in full color on the cover of this thesis. Further evaluation of possible hydrophobic binding locations for tocopherols and tocotrienols revealed that each monomer contains a region consisting of two $\alpha$-helix fragments (15-22 and 68-78), with hydrophobic amino acids all on one side and folded towards each other, and a third hydrophobic two-amino acid fragment (150-151) that also folds to the same region (white [purple in full color version] fragment in Figure 4.). This region is very close to the GSH binding site (G-site) (black [blue in full color version] part in Figure 4 . is hydrophilic part of 6 -site); the minimum distance between a $65 \mathrm{H}$ member atom and the nearest atom in the region is only $6.5 \AA$.

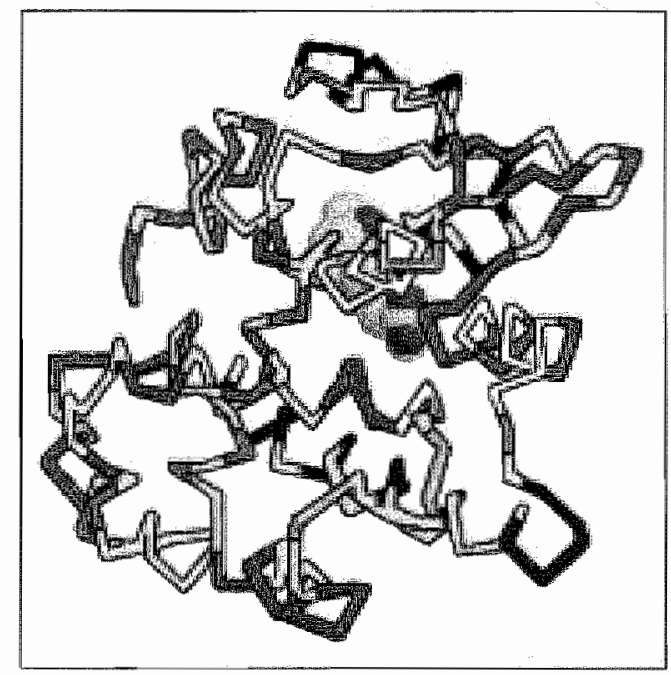

Figure 4. Threedimensional structure of human GST P1-1 with GSH bound. (The figure is shown in full color on the cover of this thesis.) 6SH is shown as a ball-structure. The hydrophobic parts are light gray (green in full color version) and the hydrophilic parts are gray (white in full color version). The black part (blue in full color version) is the hydrophilic part of the glutathione binding site. The dark groy part (orange in full color version) depicts the hydrophilic amino acids at the interface between the two monomers of the human GST P1-1. The hydrophobic region to which tocopherots and tocotrienols are proposed to bind is white (purple in full color version).

The Rasmol script file for the GST monomer that we used to generate the structure above and another script that will generate the dimeric structure are available on < http://www.bigcat.unimaas.nl/publications/thesis/vanHaaften/index.html > 


\section{Discussion}

Comparable to tocopherol and $\alpha$-tocopherol derivatives, tocotrienols inhibit the activity of GST P1-1 in a concentration-dependent manner. The $\mathrm{IC}_{\mathrm{s} 0}$ of the tocotrienols ( $\alpha$-tocotrienol $1.8 \mu \mathrm{M}$ and $\gamma$-tocotrienol $0.7 \mu \mathrm{M}$ ) are in the same range of the $\mathrm{IC}_{50}$ of the tocopherols ( $\alpha$-tocopherol $0.7 \mu \mathrm{M}$ and $\delta$-tocopherol $0.8 \mu \mathrm{M}$ ) [6]. So the tocopherols and the tocotrienols have a comparable potency to inhibit the GST P1-1 activity. The antioxidant activity of tocopherols and tocotrienols is also comparable, since the group that displays the central antioxidant activity, i.e., the chromanol head, is identical. Both tocopherols and tocotrienols scavenge the chain propagating peroxyl radical in the process of peroxidation of lipids [3]. Although it has been reported that, in vitro, the tocotrienols are more potent antioxidants than the tocopherols, tocotrienols have a lower bioavailability after oral ingestion [3].

The inhibition of GST P1-1 by tocotrienols is, similar to the inhibition by tocopherols [5], noncompetitive with respect to both substrates CDNB and GSH.

We have previously suggested that the probable mechanism of GST inhibition by tocopherols and tocopherol derivatives is the induction of conformational changes of the enzyme. These conformational changes could be caused by volume increases and structural modifications of lipophilic regions that are present in the interface between the two monomers of the GST enzyme [12].

The three-dimensional evaluation of the GST structure showed that binding of tocopherols or tocotrienals in the contact region of the two monomers is unlikely because a large hydrophilic fragment of amino acids is present in this region (dark grey [orange in full color version] part in Figure 4.). However, a very hydrophobic pit-like structure, where the phytyl tail of tocopherols and tocotrienols could fit in, is present just below the G-site. It is likely that binding of hydrophobic tocopherol or tocotrienol occurs preferentially in this hydrophobic region.

Several groups found that GST P1-1 can bind various hydrophobic compounds that can induce significant conformational changes of the protein. This resulted in a marked reduction of enzyme activity. The amino acid sequences involved in the binding of these hydrophobic compounds are residues 141-156 [13-15]. It appeared that binding of a hydrophobic compound (e.g., 1-amina-8-naphtalene sulfonic acid) results in noncompetitive inhibition (toward substrates, GSH and CDNB) of the GST activity [15]. The pit-like structure described in this study (Figure 4.) contains an overlapping region (residues 150-151) with the hydrophobic binding region described in earlier studies (residues 141-156). Our three-dimensional structure analyses showed that sequences $150-151$ within the sequences $141-156$ are the most important for the binding of tocopherols/tocotrienols. These two amino acids are hydrophobic and 
are the only amino acids that have the right orientation in the sequence 141-156 to interact with lipophilic compounds. Together with the amino acids in sequences 15-22 and 68-78 the amino acids in sequence 150-151 form the pit-like structure in GST P1-1, where the tail of tocopherol and tocotrienol fits im. Binding of tocopherols and tocotrienols to this region might lead to the bending of the $3 D$ structure by pushing the three hydrophobic regions apart resulting in distorting the G-site and possibly the hydrophobic-site (H-site).

Although the tocopherols and tocotrienols share the same mechanism of inhibition of GST P1-1, their retention in the body is different. The $\alpha$-tocopherol transfer protein ( $\alpha$-TTP) binds to $\alpha$-tocopherol with high affinity and specificity. This protein enhances transfer of $\alpha$-tocopherol between membranes and determines the level of plasma and tissue $\alpha$-tocopherol in the different organs. The affinity of $\alpha$-tocotrienol for $\alpha$-TTP is only $12 \%$ of that of $\alpha$-tocopherol [16]. Due to this lower affinity of $\alpha$-tocotrienol compared to $\alpha$-tocopherol and due to lower intake of $\alpha$-tocotrienol compared to $\alpha$-tocopherol, the concentration of $\alpha$-tocopherol in most organs is much higher than the concentration of $\alpha$-tocotrienol [17].

Less than $2 \%$ of the total amount of vitamin $E$ in most vital tissues consists of tocotrienol. Surprisingly, dietary tocotrienols specifically accumulate in the skin [18] because up to $13 \%$ of total vitamin $E$ in skin consists of tocotrienol [17]. Vitamin $E$ in the skin has multiple important functions besides the antioxidant function. For example, skin has been suggested to be an important storage site for vitamin $E$ [19] and vitamin $\mathrm{E}$ has a regulatory role in maintaining the barrier function of the skin [17]. It is known that the skin also contains a relatively high amount of GST P1-1 [20]. GST P1-1 detoxifies a wide variety of xenobiotics including (+)-anti-7,8-dihydroxy-9,10-epoxy-7,8,9,10-tetrahydrobenzo[a]pyrene ((+)-anti-BPDE) [21].

This compound is a well-known mutagenic, tumorigenic and carcinogenic compound. Tocotrienols may reduce the defence against this noxious compound. This can have far-reaching consequences in human health. 


\section{References}

1. Kamal-Eldin, A.; Appelqvist, L.A. The chemistry and antioxidant properties of tocopherols and tocotrienols.

Lipids 1996, 31, 671-701.

2. Komiyama, K.; Iizuka, K.; Vamaaka, M.; Watanabe, $H_{\text {; }}$ Tsuchya, $N_{\text {.; }}$ Unezawa, I. Studies on the biological activity of tocotrienals.

Chemical and Pharmaceutical Bulletin 1989, 37, 1369-1371.

3. Packer, L.; Weber, S.U.; Rimbach, G. Molecular aspects of alpha-tocotrienol antioxidant action and cell signalling.

Journal of Nutrition 2001, 131, 369s-373s.

4. Theriault, A.; Choo, J.T.; Wang, Q.; Gapor, A.; Adeli, K. Tocotrienol: a review of its therapeutic potential.

Clinical Biachermistry 1999, 32, 309-319.

5. Haaften van, R.I.M.; Evelo, C.T.A.; Haenen, G.R.M.M.; Bast, A. Alpha-tocopherol inhibits human glutathione S-transferase pi.

Biachemical and Biophysical Research Communications 2001, 280, 631-633'.

6. Haaften van, R.I.M.; Evelo, C.T.A.; Penders, J.: Eijnwachter, M.P.F.; Haenen, G.R.M.M.; Bast. A. Inhibition of human glutathione S-transferase P1-1 by tocopherols and alphotocopherol derivatives.

Biochimica et Biophysica Acta 2001, 1548, 23-28.

7. Guthenberg, C.; Mannenik. B. Glutathione S-transferase (transferase pi) from human placenta is identical or closely related to glutathione S-transferase (transferase p) from erythrocytes.

Biochimica et Biophysica Acta 1981, 661, 255-260.

8. Mannervik, B.; Guthenberg, C. Glutathione transferase (Human placenta). Methods in enzymology 1981, 77, 231-235.

9. Oakley, A.J.; Bello, M.L.; Battistani, A.; Ricci, G.; Rossjohn, J., Villar, H. O.; Parker, M.W. The structures of human glutathione transferase $P_{1-1}$ in complex with glutathione and various inhibitors at high resolution.

Journal of Molecular Biolegy 1997, 274, 84-100.

10. Berman, H.M.; Westbrook, J.; Feng. Z., Gillitand, G.; Bhat, T.N.; Weissig, H.; Shindyalov, I.N.; Bourne, P.E. The Protein Data Bank.

Nucleic Acids Research 2000, 28, 235-242.

11. Reinemer, P.; Dir, H.W.; Ladenstein, R.: Huber, R.; Lo Bello, M., Federici, G.; Parker, M.W. Three-dimensional structure of class pi glutathione S-transferase from human placenta in complex with S-hexylglutathione at $2.8 \mathrm{~A}$ resolution.

Joumal of molecular biology 1992, 227, 214-226.

12. Ricci, G.; Lo-Bello, M.; Caccurri, A.M.; Pastore, A.; Nuccetelli, M.; Parker, M.W.; Federici, G. Site-directed mutagenesis of human glutathione transferase P1-1. Mutation of Cys47 induces a positive cooperativety in glutathione transferase $P_{1-1}$.

The Journal of Biological Chemistry 1995, 270, 1243-1248.

13. Nishihira, J.; Ishibashi, T.; Sakai, M.; Tsuda, S.; Hikichi, K. Identification of the hydrophobic ligand-binding region in recombinant glutathione S-transferase $P$ and its binding effect on the conformational state of the enzyme.

Archives of Biochemistry and Biophysics 1993, 302, 128-133.

14. Nishihira, J.; Ishibashi, T.; Sakai, M.; Nishi, S.; Kumazaki, T. Identification of the fatty 
acid binding site on glutathrone 5-transferose P by immobilization to fatty acid-linked sepharose.

Biochemical and Biophysical Research Communications 1993, 190, 823-831.

15. Nishihira, J., Ishibashi, T., Sakai, M.: Nishi, S, Kondo. H, Makita. A. Identification of the fatty acid binding site on giutothione S-transferase $P$.

Biochemical and Biophysical Research Communications 1992, 189, 197-205.

16. Hosomi, A.; Arita, M.; Sato, Y.; Kiyose, C.; Ueda, T.; Igarashi, 0.; Arai, $H$.; Inoue, $K$. Affinity for alpha-tocopherol transfer protein as a determinant of the brological activities of vitamin $E$ anologs.

Federation of European Biochemical Societies 1997, 409, 105-108.

17. Podda, M.; Weber, C.; Traber, M.G.; Packer, L. Simultaneous determination of tissue tacopherols, tocotrienals, ubiquinols, and ubiquinones.

Joumal of Lipid Research 1996, 37, 893-901.

18. Ikeda, 5. ; Niwa, $T_{\text {.; }}$ Yamashita, $K$. Selective uptake of dietary tocotrienols into rat skin. Jounal of Nutritional Science and Vitaminology 2000, 46, 141-143.

19. Shiratori, T. Uptake, storage and excretion of chylomicra-bound $3 \mathrm{H}$-alpha-tocopherol by the skin of the rat.

Life Sciences 1974, 14, 929-935.

20. Singhal, 5.S.; Saxena, M.; Awasthi, S.; Mukhtar, H.; Zaidi, S.I.; Ahmad, H.; Awasthi, $Y C_{\text {. Glutathione S-transferases of human skin: qualitative and quantitative differences }}$ in men and women.

Biachimica et Biophysica Acto 1993, 1163, 266-272.

21. Mannervik, $B$. The isoenzymes of glutathione transferase.

Advances in enzymology and related areas of molecular biology $1985,57,357-417$. 

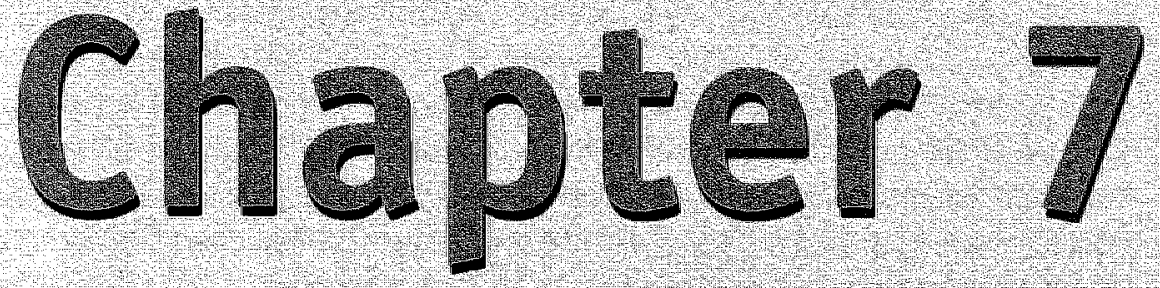

\section{Inhibition of various glutathione S-transferase isoenzymes by RRR- $\alpha$-tocopherol}

Rachel I.M. van Haaften Guido R.M.M. Haenen Peter J. van Bladeren Jan J.P. Bogaards Chris T.A. Evelo and Aalt Bast

Toxicology in vitro (2003) 


\section{Abstract}

The activity of human cytosolic glutathione S-transferases (GSTs) can positively or negatively be changed by various compounds. It is for instance known that RRR- $\alpha-$ tocopherol inhibits GST P1-1 [1]. The effect of RRR- $\alpha$-tocopherol on the other isoenzymes of GST in purified forms of the isoenzymes and in human liver cytosol (GST $M$ and GST A) and lysate of human erythrocytes (GST P) is studied. It is found that all isoenzymes (purified enzymes and enzymes present in homogenates) are inhibited, in a concentration-dependent way, by RRR- $\alpha$-tocopheroL. GST $P$ is in both cases inhibited with the highest potency compared to the other isoenzymes.

It also appeared that the purified GST P1-1 isoenzyme is non-competitively inhibited by RRR- $\alpha$-tocopherol. The $\mathrm{IC}_{50}$ values of RRR- $\alpha$-tocopherol for the purified isoenzymes of GST are much lower compared to the $\mathrm{IC}_{50}$ values for human lysate and human liver cytosol. This is probably due to binding of RRR-o-tocopherol to proteins, e.g. albumin and hemoglobin, with higher affinity than to GST; so more RRR$\alpha$-tocopherol is needed to inhibit the enzyme. However, the inhibition of GSTs by RRR-a-tocopherol can still be of physiological relevance, because due to dermal application of cosmetic products very high concentrations vitamin $E$ can be reached in the skin, where GST P1-1 is present. RRR- $\alpha$-tocopherol might also be a good lead compound for the development of a new class of inhibitors of GST that can be used as adjuvant in cancer therapy. 


\section{Introduction}

The human body protects itself against harmful compounds by different mechanisms. An important line of defence is formed by the glutathione S-transferases (GSTs). These enzymes represent a major group of phase II metabolism enzymes, which catalyse the conjugation of glutathione with various electrophiles [2, 3]. In most cases the electrophile becomes less toxic but in some cases the electrophile is activated. Multiple cytosolic and membrane-bound GST isoenzymes are known in humans, each of which displays distinct catalytic as well as binding properties. On the basis of their substrate specificity and kinetic characteristics the cytosolic isoenzymes can be classified into four major classes, A (alpha), M (mu), P (pi) and $T$ (theta). All cytosolic isoenzymes are dimers of two subunits. Within the mu and alpha classes several distinct GST subunits, denoted with Arabic numerals, have been characterised and a high degree of heterogeneity has been documented among the GSTs of these two classes in human tissues $[2,4]$. The cytosolic isoforms are differentially expressed in the different organs in the human body. It is also possible that one organ expresses more than one isoform of GST. The human liver for example expresses the alpa and the mu form of GST and the mu isoform of the enzyme is expressed in for example the adrenal gland, the kidney, the testis and the liver. Human erythrocytes, only express the pi isoform of the enzyme $[3,4]$. The pi class isoenzyme appears the most widely distributed GST isoenzyme and is the most abundant form found in many tissues $[3,4]$, and is the GST isoenzyme mostly expressed in tumour cells [5]. GST M1 is expressed in only $60 \%$ of human individuals. It has been reported that people lacking the GST M1 have a higher risk of developing lung cancer $[3,6]$.

The activity of the human glutathione S-transferase enzymes can be influenced by multiple compounds. In previous studies we have found that different forms of vitamin $\mathbb{E}$ (tocopherols, tocotrienols and different esters of tocopherol) can inhibit the activity (GSH conjugation) of purified GST P1-1 [1,7].

In the present study, the effect of RRR- $\alpha$-tocopherol (the form of vitamin $E$ most abundantly present in humans and the vitamer with the highest potency in inhibiting GST P1-1) on the activity of various purified GST isoenzymes is compared. Also the effect of RRR- $\alpha$-tocopherol on GST activity in lysate of human red blood cells and cytosol of human liver is studied. As stated above, in red blood cells only the pi isoform of GST is present and in human liver both the mu and the alpha isoform of GST are the most prominent forms. 


\section{Materials and Methods}

\section{Chemicals}

RRR- $\alpha$-tocopherol; 1-chloro-2,4-dinitrobenzene (CDNB), hemoglobin and albumin were obtained from Sigma, St. Louis, USA. Reduced glutathione (GSH) was obtained from ICN Biomedicals Inc., Costa Mesa, USA. Purified human glutathione S-transferases (GST A1-1 (98\%), GST A2-2 (94\%), GST M1a-1a (100\%) and GST P1-1(98\%)) were a gift of TNO Nutrition and Food Research, Zeist, The Netherlands. The specific activities with CDNB of these isoenzymes are respectively $123 \mathrm{U} / \mathrm{mg}, 64 \mathrm{U} / \mathrm{mg}, 262$ $\mathrm{U} / \mathrm{mg}$ and $53 \mathrm{U} / \mathrm{mg}$. All other chemicals were of analytical grade purity.

\section{Human lysate}

Human blood, from a healthy female volunteer (25 years), was collected in an EDTAtube. After centrifugation at $3000 \mathrm{rpm}\left(10 \mathrm{~min}\right.$ at $\left.4^{\circ} \mathrm{C}\right)$ the plasma was removed from the erythrocytes. The erythrocytes were washed three times with an equal volume cold phosphate buffered salt (PBS). These washed erythrocytes are lysed with ice cold milliQ water. After 10 minutes on ice, the solution is mixed vigorously and centrifuged at $5000 \mathrm{rpm}\left(10 \mathrm{~min}\right.$ at $4^{\circ} \mathrm{C}$ ) (supernatant is lysate). Before measuring the glutathione S-transferase activity the human lysate was diluted 60 times with $100 \mathrm{mM}$ potassium phosphate, $\mathrm{pH} 6.5$.

\section{Human liver cytosol}

Cytosal was prepared from a small piece of human liver (purchased from a male patient) with hepatoma. The part next to the removed tumour has been used in this experiment. After removal, the piece of liver was homogenised $(1: 2, w / v)$ in ice cold potassium phosphate buffer ( $50 \mathrm{mM}, \mathrm{pH} 7.4)$ containing $0.1 \mathrm{mM}$ EDTA. The homogenate was centrifuged at $10000 \times \mathrm{g}\left(20 \mathrm{~min}\right.$ at $\left.4^{\circ} \mathrm{C}\right)$. Subsequently the supernatant was centrifuged at $10000 \times \mathrm{g}\left(20 \mathrm{~min}\right.$ at $\left.4^{\circ} \mathrm{C}\right)$ and again at $65000 \times \mathrm{g}(60 \mathrm{~min}$ at $4^{\circ} \mathrm{C}$ ). The supernatant was collected and stored at $-80^{\circ} \mathrm{C}$. Before use the cytosol was thawed and diluted 6000 times with $100 \mathrm{mM}$ potassium phosphate, $\mathrm{pH} 6.5$.

\section{Assay of glutathione S-transferase activity}

GST activity was measured as described by Mannervik and Guthenberg [8] with slight modifications. In short, the reaction of $1 \mathrm{mM}$ CDNB with $1 \mathrm{mM} \mathrm{GSH}$ in purified enzyme (in $100 \mathrm{mM}$ potassium phosphate, $\mathrm{pH}$ 6.5) or in the diluted human liver cytosol or lysate of erythrocytes was monitored spectrophotometrically by recording the increase in absorbance at $340 \mathrm{~nm}$ at $37^{\circ} \mathrm{C}$. Effects of various concentrations of RRR- $\alpha$-tocopherol on GST activity were determined. A stock solution of $\alpha$-tocopherol was prepared in ethanol. The final concentration of ethanol in the incubation mixture was $1 \% \mathrm{v} / \mathrm{v}$; this concentration of ethanal had no effect on GST activity. 
The mixture of the purified GST enzyme $(0.4 \mu \mathrm{g}$ protein $/ \mathrm{mL}$ buffer $)$ or the human liver cytosol or lysate of erythrocytes with RRR- $\alpha$-tocopherol was incubated for 2 minutes at $37^{\circ} \mathrm{C}$ before activity measurement. A correction for the spontaneous reaction between GSH and CDNB in the absence of enzyme and in the presence of ethanol $(1 \%)$ was made. Ethanol was added because $\alpha$-tocopherol was dissolved in ethanol. The $\mathrm{IC}_{50}$ of the purified enzyme is normalised on enzyme activity.

To study the inhibitory mechanism of RRR- $\alpha$-tocopherol on the glutathione S-transferase P1-1 activity (of the purified enzyme), substrate concentrations (CDNB or GSH) were varied. When CDNB was waried the GSH concentration was kept at $1 \mathrm{mM}$ and vice versa. In these experiments the concentration RRR- $\alpha$-tocopherol was kept constant at $0.6 \mu \mathrm{M}$.

The effect of the combined addition of RRR- $\alpha$-tocopherol with two proteins, hemoglobin and albumin, on the activity of purified human glutathione S-transferase P11 enzyme was also studied. Effects of a fixed concentration RRR- $\alpha$-tocopherol with a fixed concentration of hemoglobin or albumin were determined. The mixture of purified human glutathione S-transferase P1-1 enzyme $(0.0095 \mathrm{U} / \mathrm{ml}$ in $100 \mathrm{mM}$ potassium phosphate buffer $\mathrm{pH}$ 6.5) with RRR- $\alpha$-tocopherol and albumin or hemoglobin was incubated for 2 min at $37^{\circ} \mathrm{C}$ before activity measurement. A correction for the spontaneous reactions between GSH and CDNB in the absence of enzyme and in the presence of ethanoL, RRR- $\alpha$-tocopherol, hemoglobin or albumin was made.

\section{Results}

\section{Purified isoenzymes}

All purified isoenzymes tested are inhibited by RRR- $\alpha$-tocopherol in a concentration dependent manner.

The concentrations RRR- $\alpha$-tocopherol giving $50 \%$ inhibition (IC $\mathbb{C}_{30}$ ) of GST activity are depicted in Figure 1. The IC $C_{90}$ of RRR- $\alpha$-tocopherol varies for the different isoenzymes of GST investigated. The IC $\mathrm{C}_{50}$ of RRR- $\alpha$-tocopherol on GST P1-1 is the lowest compared to the other isoenzymes tested ( $\mathrm{IC}_{50}$ is $\left.0.6 \pm 0.06 \mu \mathrm{M}\right)$. The concentration of RRR- $\alpha$-tocopherol needed to inhibit the activity of GST A1-1 (IC 5 is $0.9 \pm 0.08$ $\mu \mathrm{M})$ and GST M1a-1a (IC $\mathrm{S}_{\mathrm{s}}$ is $\left.1.2 \pm 0.06 \mu \mathrm{M}\right)$ is higher compared to that of GST P11. The catalytic activity of GST A2-2 (IC $3.5 \pm 0.06 \mu \mathrm{M})$ is inhibited by RRR- $\alpha$ tocopherol with a much lower potency compared to the other isoenzymes tested. 


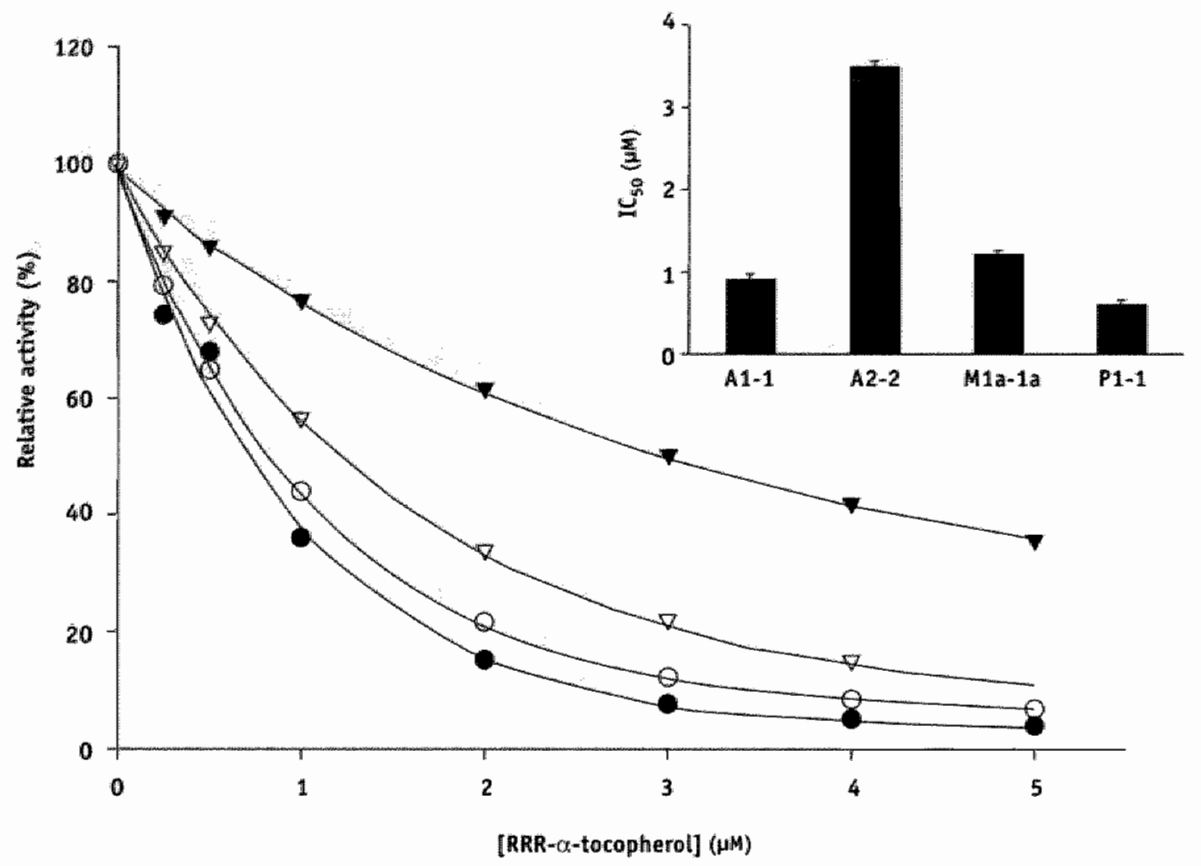

Figure 1. Effect of RRR- $\alpha$-tocopherol on the activity of different purified glutathione S-transferase isoforms. The GST activity was measured by following the reaction between $1 \mathrm{mM}$ glutathione and 1 $m M 1$-chloro-2,4-dinitrobenzene at $37^{\circ} \mathrm{C}$. Insert: $1 C_{s, 0}$ values indicate means ( \pm S.E.M.) of three independent experiments each performed in duplicate.

For the GST P1-1 isoenzyme the nature of the inhibition by RRR- $\alpha$-tocopherol was studied. GST activity was measured with variable concentrations of either GSH (Figure 2.) or CDNB (data not shown) in the presence of a fixed concentration of RRR$\alpha$-tocopherol. From Figure 2. it appears that RRR- $\alpha$-tocopherol lowers the $V_{\text {max }}$ values (from $18 \mu \mathrm{mol} / \mathrm{min} \cdot \mathrm{mg}$ to $5 \mu \mathrm{mol} / \mathrm{min} \cdot \mathrm{mg}$ (enzyme concentration is $0.0002 \mathrm{U} / \mathrm{ml}$ )), but does not affect the $K_{\mathrm{m}}(0.9 \mathrm{mM})$. A similar type of inhibition is obtained with CDNB as substrate. In the Eadie-Hofstee plot (insert in Figure 2.) two parallel lines are observed with and without the addition of $0.6 \mu \mathrm{M} R R R-\alpha$-tocopherol. This confirms that RRR- $\alpha$-tocopherol exhibits a non-competitive inhibition on GST P1-1 with respect to the substrates GSH and CDNB.

\section{Human liver cytosol and lysate of erythrocytes}

As shown in Figure 3. RRR- $\alpha$-tocopherol also inhibits the glutathione S-transferase activity in human liver cytosol and in lysate of human erythrocytes in a concentration dependent manner. The $\mathrm{IC}_{50}$ of GST activity in erythrocyte lysate is $103 \pm 17 \mu \mathrm{M}$ and in human liver cytosol $281 \pm 4 \mu \mathrm{M}$. 
In Figure 4., the effect of the addition of hemoglobin or albumin to an incubation of RRR- $\alpha$-tocopherol with purified GST P1-1 is depicted. When the purified GST P11 enzyme is incubated wit $2 \mu M$ RRR- $\alpha$-tocopherol the activity of the GST P1-1 is diminished to $16 \%$. When albumin or hemoglobin is included in the incubation with purified enzyme, $2 \mu M$ RRR- $\alpha$-tocopherol far less diminished (to $98 \%$ and $90 \%$ respectively) the GST activity.

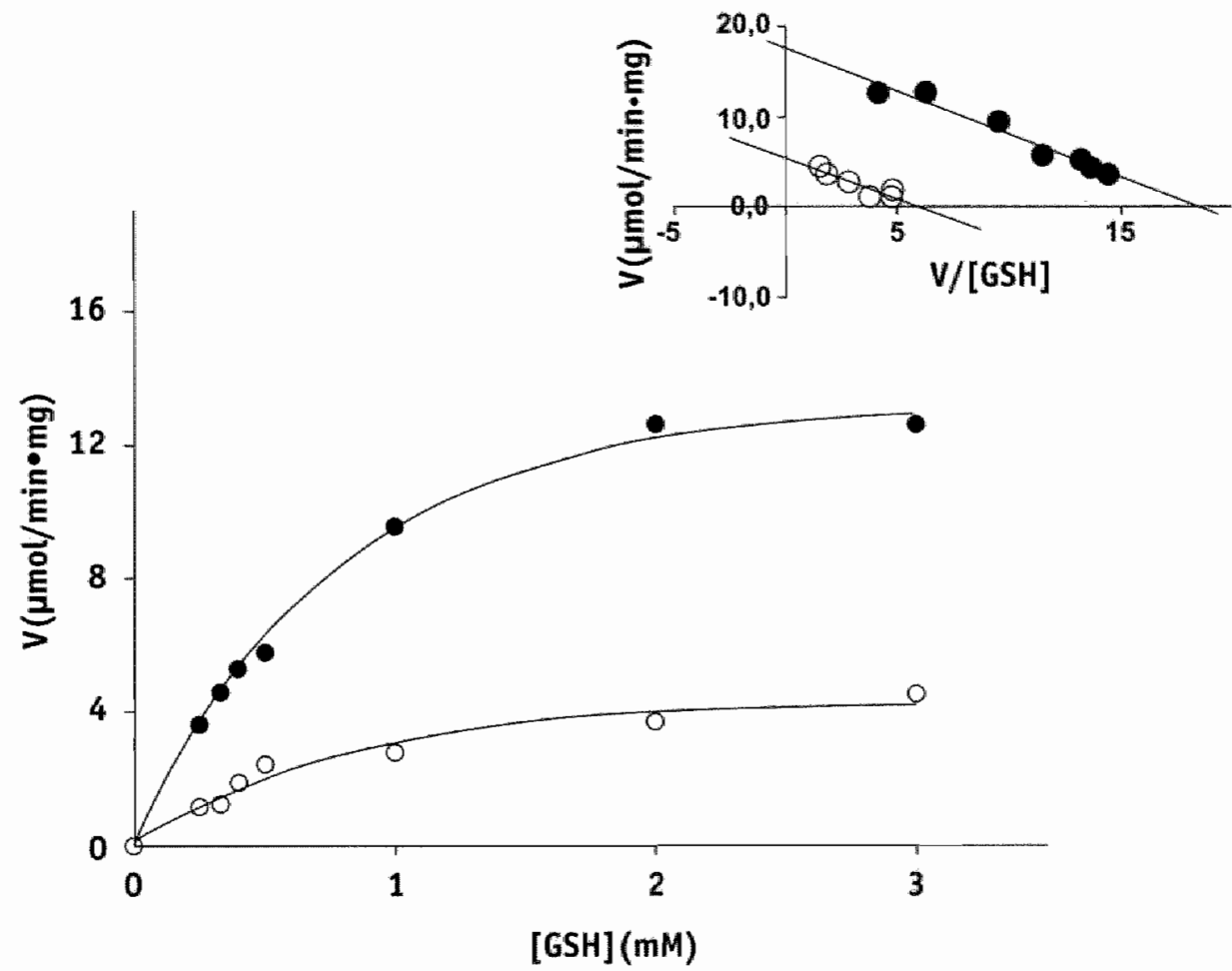

Figure 2. Effect of RRR- $\alpha$-tocopherol on the activity of GST $P_{1-1}$. The $K_{\text {tid }}$ and $V_{\text {inati }}$ for GSH in the incubation without $R R R$ - $\alpha$-tocopherol $(\bullet)$ are respectively $0.9 \mathrm{mM}$ and $18 \mu \mathrm{mol} / \mathrm{min} * \mathrm{mg}$. In the presence of $0.6 \mu M$ RRR-a-tocopherol ( $O$ ) these values are $0.9 \mathrm{mM}$ and $5 \mu \mathrm{mol} / \mathrm{min} \cdot \mathrm{mg}$. Insert: Eadie-fiafstee plot showing non-competitive inhibition of human GST P1-1 isoenzyme towards GSH by RRR-O-tocopherol. The experiments are performed at an emzyme concentration of $0.002 \mathrm{U} / \mathrm{ml}$. The data points are the mean of two independent experiments performed in triplicate. 


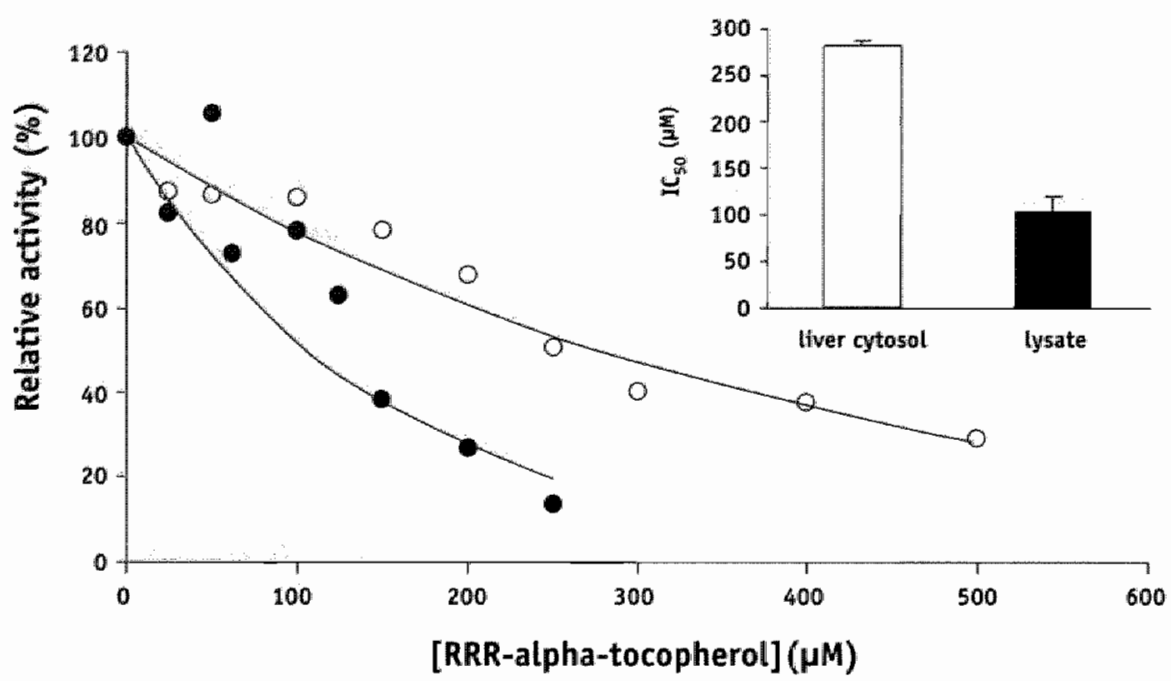

Figure 3. Effect of RRR- $\alpha$-tocopherol an the activity of glutathione S-transferase in human lysate ( $\bullet$ and in human biver cytosol (0). The GST activity was measured by following the reaction between 1 $m$ glutathione and $1 \mathrm{mM} 1$-chloro-2, 4 -dinitrobenzene at $37^{\circ} \mathrm{C}$. The $I C_{50}$ values for $R R R-\alpha$-tacopherol (insert) are $103( \pm 17) \mu M$ in the human lysate and 281 ( \pm 4$) \mu M$ in the human liver cytosol. $I C_{\text {sia }}$ values indicate means ( \pm S.E.M.) of three independent experiments each performed in duplicate.

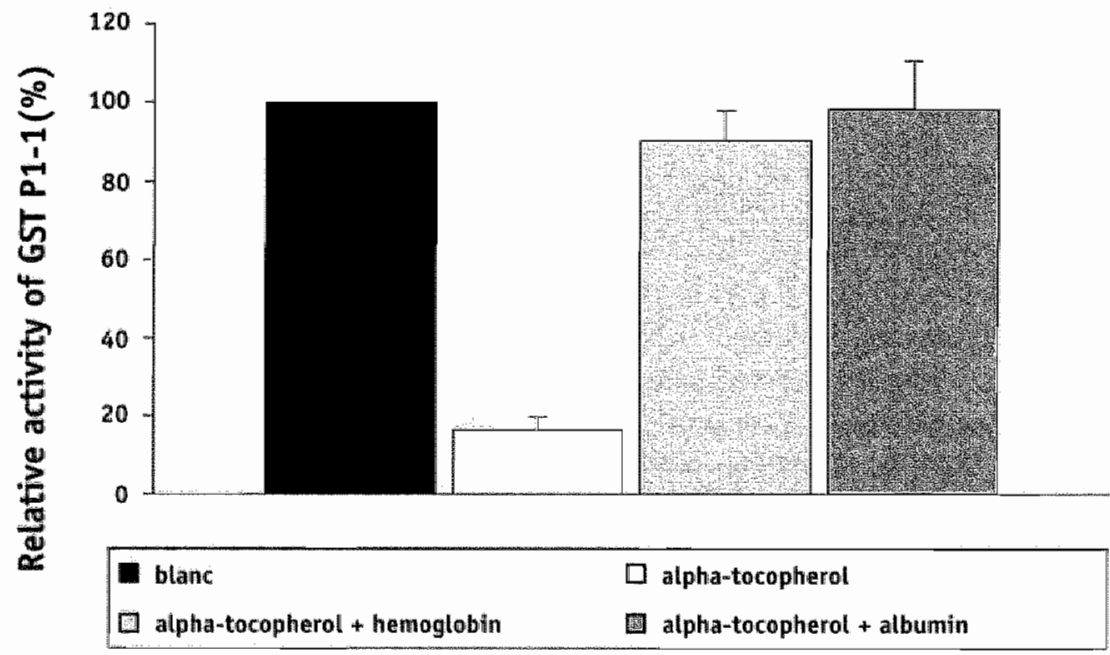

Figure 4. Effect of the addition of hemoglobin or albumin to an incubation of $R R R$ - $\alpha$-tocopheral with purified GST P1-1. In the blank incubation the GST P1-1 activity is set at 100\%. Addition of $2 \mu \mathrm{M}$ $R R R-Q$-tocopherol diminished the GST activity to $16 \pm 3 \%$. After addition of hemoglobin or albumin the GST activity is only diminished to $90 \pm 7 \%$ and $98 \pm 12 \%$ respectively. The values indicate means ( \pm S.E.M.) of three independent experiments each performed in duplicate. 


\section{Discussion}

GST isoenzymes are differentially expressed in different tissues. The pi isoform is for example expressed in red blood cells, placenta and skin. The alpha and mu isoforms are expressed in the liver. In the present study the effect of RRR- $\alpha$-tocopherol on different purified GST isoenzymes is studied. To test the effect of RRR- $\alpha$-tocopherol on different GST isoenzymes in human homogenates we used human red blood cell lysate and cytosol of human liver.

It is found that purified human GST A1-1, A2-2, M1a-1a and P1-1 are inhibited, in a concentration dependent way, by RRR- $\alpha$-tocopherol. The concentration of RRR- $\alpha$ tocopherol needed to inhibit the isoenzyme with $50 \%$ is not the same for the different isoenzymes. The IC $C_{50}$ of RRR- $\alpha$-tocopherol on GST P1- 1 is the lowest compared to the other isoenzymes tested. The $\mathrm{IC}_{50}$ of GST A1-1 and GST M1a-1a are higher compared to GST P1-1 and the $I_{50}$ of GST A2-2 is the highest of all isoenzymes tested. The IC $\mathrm{IC}_{50}$ of RRR- $\alpha$-tocopherol on GST A1-1 is approximately 4 times lower than on GST A2-2. Compared to previous described inhibitors of GST, RRR- $\alpha$-tocopherol has a high potency $[1,9]$. For the most sensitive GST isoenzyme (GST P1-1) the nature of the inhibition by RRR- $\alpha$-tocopherol was found to be non-competitive. From this study it also appeared that RRR- $\alpha$-tocopherol can inhibit glutathione Stransferase activity in human homogenates containing different isoforms of the enzyme. The inhibition by RRR- $\alpha$-tocopherol is concentration dependent. GST P1-1, present in lysate of human erythrocytes, is inhibited with an $\mathrm{IC}_{50}$ value of $103 \mu \mathrm{M}$ and the GST present in human liver cytosol (a combination of mu and alpha) is inhibited with an $\mathrm{IC}_{50}$ value of $281 \mu \mathrm{M}$. The $\mathrm{IC}_{50}$ of RRR- $\alpha$-tocopherol is lower for the GST present in human erythrocytes ( $p$ i isoform) than for the GST present in human liver cytosol (a combination of mu and alpha isoforms). These results are in accordance with the results of the experiments with the purified isoenzymes of GST, which show that the GST P isoform is inhibited with a lower IC $_{50}$ compared to the mu and alpha isoforms of human GST.

The $\mathrm{IC}_{50}$ values of the experiment with the purified isoenzymes of GST are much lower compared to the $\mathrm{IC}_{30}$ values of the experiment with human lysate and human liver cytosol. This difference can probably be explained by binding of RRR- $\alpha$-tocopherol to proteins, e.g. albumin and hemoglobin, with higher affinity than to GST; more RRR- $\alpha$-tocopherol is needed to inhibit the enzyme.

The inhibition of glutathione S-transferase can have opposite effects. On the one hand the inhibition of the enzyme can have toxic consequences, because the detoxification activity of the enzyme is decreased. Electrophilic compounds are not well detoxified and can do harm to DNA, proteins and lipids which can result in multiple diseases including cancer and neurodegenerative disorders. Inhibition of GST 
can in principle have the same consequence as GST deficiency because in both cases the catalytic activity of the enzyme is not executed. From literature it is known that approximately $40 \%$ of the human population is deficient for the GST M1 $[3,6]$. Experimental studies have reported that people lacking the GST M1 null phenotype have a higher risk of developing lung, bladder and larynx cancer [10, 11]. Therefore inhibition of GST M1 by RRR- $\alpha$-tocopheral is expected to increase the risk of developing various types of neoplastic disease. Genetically determined deficiency of the alpha and pi classes GSTs appears to be extremely rare [3], suggesting a pivotal role of these isoenzymes.

On the other hand it can be positive to inhibit the detoxification activity of the GST enzyme. Overexpression of certain GST isoenzymes in tumour cells contributes to resistance against cytostatic drugs through GSH conjugation of the active metabolites [12-14]. Therefore, compounds are being developed that inhibit GST activity and can be used as adjuvant in cancer therapy [12]. In this respect GST P1-1 is of interest since this is the class of GST overexpressed in various tumours [5]. The inhibitors of GST that have been discovered thus far have little effect on GST P1-1 [5]. As shown in this study RRR- $\alpha$-tocopherol has the highest potency for inhibition of GST P1-1. The inhibitors of GST that have been reported are ethacrynic acid and GSH-derived structures [13]. These inhibitors are highly lipophilic. A potent inhibitor of cytosolic GST in vivo has to enter the cell, so it has to be lipaphilic or utilise a carrier system for uptake. Because the GSH-conjugates are very hydrophilic and highly charged they cannot pass the lipophilic membrane of the cells and enter the cell [12]. RRR- $\alpha$-tocopherol is very lipophilic and can pass the cell membrane.

The previously reported inhibitors of GST activity exert their action by binding to the hydrophobic pocket of the active site of GST (H-site) [12]. We have reported previously that RRR- $\alpha$-tocopherol probably binds to a lipophilic pit-like structure in GST P1-1. Binding of RRR- $\alpha$-tocopherol to this site induces a conformational change of the GST molecule and in this way the activity of the enzyme is diminished [15]. RRR- $\alpha$-tocopherol uses a new mechanism for GST inhibition and possibly RRR- $\alpha$ tocopherol can be used as lead compound for developing of good GST P1-1 inhibitors in vivo.

Although the isoenzymes of GST in human homogenates are inhibited by RRR- $\alpha$ tocopherol with less potency compared to purified isoenzymes (probably due to the presence of other proteins), the inhibition of GSTs by RRR- $\alpha$-tocopherol can still be of physiological relevance. A Lot of products contain relatively high concentrations vitamin E. In cosmetic products, which are applied to the skin in which GST P1-1 is present, up to $5 \%$ vitamin $\mathbf{E}$ can be found. Even products comtaining pure vitamin $E$ are sold. Dermal application of these cosmetic products will increase vitamin $E$ levels in the skin [16]. These levels can be high enough to inhibit GST activity. 


\section{References}

1. Haaften van, R.I.M.; Evelo, C.T.A. Haenen, G.R.M.M.; Bast, A. Alpha-tocopheral inhibits human glutathione S-transferase pi.

Biochemical and Biophysical Research Communications 2001, 280, 631-633.

2. Mannervik, $B$. The isoenzymes of glutathione transferase.

Advances in enzymology and related areas of molecular bialogy 1985, 57, 357-417.

3. Board, P.; Coggan, M.; Jahnston, P.; Ross, V; Suzuki, T.; Webb, G. Genetic heterogeneity of the human glutathione transferases: a complex of gene families.

Pharmacology and Therapeutics 1990, 48, 357-369.

4. Awasthi, Y.C.; Sharma, R.; Singhat, S.S. Human glutathione S-transferases.

The International journal of biachemistry 1994,26, 295-308.

5. Ouwerkerk Mahadevan, S.; Mulder, G.J. Inhibition of glutathione conjugation in the rat in wivo by analogues of glutathione conjugates.

Chemico-Biological Interactions 1998, 111-112, 163-176.

6. Bladeren van. P.J.; Ammen van, B. The inhibition of glutathione S-transferases: mechanisms, toxic consequences and theropeutic benefits.

Pharmacology and therapeutics 1991, 51, 35-46.

7. Haaften van, R.I.M.; Evelo, C.T.A.; Penders, J.; Eijnwachter, M.P.F.; Haerien, G.R.M.M.; Bast, A. Inhibition of human glutathione S-transferase P1-1 by tocopherols and alphatocopherol derivatives.

Bioctimica et Biophysica Acta 2001, 1548, 23-28.

8. Mannervik, B.; Guthenberg, C. Glutathione transferase (Human placenta).

Methods in enzymology 1981, 77, 231-235.

9. Mannervik, B.; Danielson, U.H. Glutathione transferases-Structure and catalytic activity. Critical Reviews in Biochemistry and Molecular Biology 1988, 23, 283-337.

10. Lafuente, A.; Pujol, F.; Carretero, P.; Villa, J.P.; Cuchi, A. Human glutathione S-transferase mu (GST mu) deficiency as a marker for the susceptibility to bladder and larynx cancer among smokers.

Cancer Letters 1993, 68, 49-54.

11. Poppel van, G.; Vogel de, N.; Bladeren van, P.J.; Kok, F.J. Increased cytogenetic damage in smokers deficient in glutathione S-transferase isozyme mu.

Carcinogenesis 1992, 13, 303-305.

12. Burg, D.; Hameetman, L.; Filippov, D.V.; wan der Marel, G.A.; Mulder, G.J. Inhibition of glutathione S-transferase in rat hepatocytes by a glycine-tetrazole modified S-alkyl-GSH analogue.

Bioorganic and Medicinal Chemistry Letters 2002, 12, 1579-1582.

13. Mulder, G.J.; Ouwerkerk Mahadewan, S. Modulation of glutathione conjugation in vivo: how to decrease glutathione conjugation in vivo or in intact cellular systems in vitro. Chemico-Biological Interactions 1997, 105, 17-34.

14. Morgan, A.S.; Ciaccio, P.J.; Tew, K.D.; Kauwar, L.M. Isazyme-specific glutathione S-transferase inhibitors potentiate drug sensitivity in cultured human tumor cell lines. Cancer Chemotherapy and Pharmacology 1996, 37, 363-370.

15. Haaften van, R.I.M.; Haenen, G.R.M.M.; Evelo, C.T.A.; Bast, A. Tocotrienols inhibit human glutathione S-transferase P1-1.

IUBMB Life 2002, 54, 81-84.

16. Fiume, M.Z. Final report on the safety assessment of tocopherol, tocopheryl acetate, 
tocopheryl linoleate, tocopheryl linoleate/ aleate, tocopheryl nicotinate, tocopheryl succinate, dioleyl tacopheryl methylsitanol, potassium ascorbyl tocopheryl phosphate, and tocophersolan.

Internotional Joumal of Toxicology 2002, 21, 51-116. 

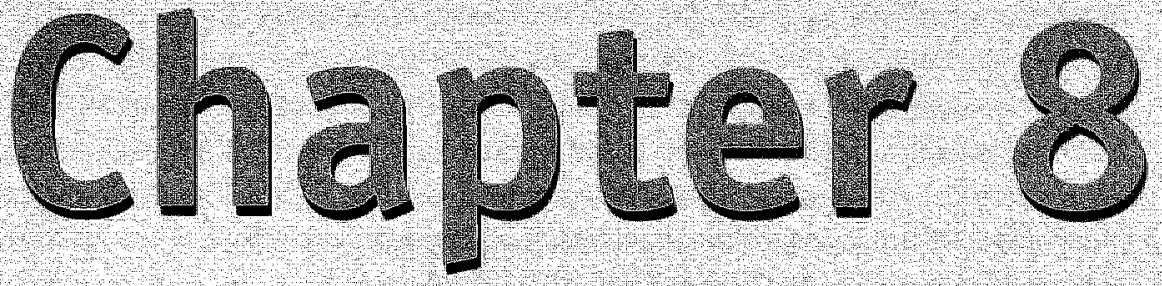

\section{Hypochlorous acid is a potent inhibitor of GST P1-1}

Rachel I.M. van Haaften Gertjan J.M. den Hartog Chris T.A. Evelo Guido R.M.M. Haenen and Aalt Bast

Chemico-Biological Interactions 138

$77-83$ (2001) 


\section{Abstract}

Glutathione S-transferase is a phase II detoxification enzyme that can be inactivated by $\mathrm{H}_{2} \mathrm{O}_{2}$. During oxidative stress various other reactive oxygen species are generated that are more reactive than the relatively stable $\mathrm{H}_{2} \mathrm{O}_{2}$. Hypochlorous acid $(\mathrm{HOCl})$ is a powerful oxidant which is highly reactive towards a range of biological substrates. We studied the influence of $\mathrm{HOCl}$ on the activity of GST P1-1. HOCl inhibits purified glutathione $S$-transferase $P 1-1$ in a concentration dependent manner with an $\mathrm{IC}_{5 a}$ value of $0.6 \mu \mathrm{M}$, which is more than 1000 times as low as $\mathrm{IC}_{50}$ reported for $\mathrm{H}_{2} \mathrm{O}_{2}$. $\mathrm{HOCl}$ lowered the $\mathrm{V}_{\max }$ value, but did not affect the $\mathrm{K}_{\mathrm{m}}$ for CDNB. Our results show that $\mathrm{HOCl}$ is a potent, non-competitive inhibitor of GST P1-1. The relevance of this effect is discussed. 


\section{Introduction}

Glutathione S-transferases are a superfamily of phase II detoxification enzymes, which can catalyse the conjugation of glutathione with various electrophiles. The superfamily consists of at least five gene families of which four (alpha, mu, pi and theta) encode the cytosolic GSTs, whereas the fifth encodes a microsomal form of the enzyme [1-3]. In humans the pi-isoform of the enzyme occurs mostly in red blood cells and placenta [4] and has been shown to be especially vulnerable to oxidative stress $[5,6]$. It is known that GST P1-1 is inactivated in human erythrocytes by $\mathrm{H}_{2} \mathrm{O}_{2}[7]$.

The inhibition of GST by oxidative stress seems to be specific for GST P1-1. It is shown that GST P1-1 can be inactivated by $\mathrm{H}_{2} \mathrm{O}_{2}$, whereas. GST $M$ is not sensitive for inactivation with $\mathrm{H}_{2} \mathrm{O}_{2}$. In fact, GST M can even be activated by reactive oxygen species [8]. During oxidative stress various other reactive oxygen species are generated that are more reactive than the relatively stable $\mathrm{H}_{2} \mathrm{O}_{2}$. Hypochlorous acid $(\mathrm{HOCl})$ is a powerful oxidant generated by the neutrophil enzyme myeloperoxidase from $\mathrm{H}_{2} \mathrm{O}_{2}$ and chloride ions and it plays a role in the bactericidal function. It is highly reactive toward a range of biological substrates $[9,10]$. In the present study the effect of HOCl on GST P1-1 activity is examined.

\section{Materials and Methods}

\section{Chemicals}

1-Chloro-2,4-dinitrobenzene (CDNB), lipoic acid, sodium hypochlorous acid and glutathione S-transferase P1-1 (from human placenta) were obtained from Sigma, St. Louis, USA. Reduced glutathione (GSH) was obtained from ICN Biomedicals Inc., Costa Mesa, USA and hydrogen peroxide $\left(\mathrm{H}_{2} \mathrm{O}_{2}\right)$ from Merck, Darmstadt, Germany. All other chemicals were of analytical grade purity.

\section{Assay of glutathione S-transferase activity}

GST activity was measured as described by Mannervik and Guthenberg [11] with slight modifications. In short, the reaction of $1 \mathrm{mM}$ CDNB with $1 \mathrm{mM} \mathrm{GSH}$ in the presence or absence of GST was monitored spectrophotometrically by recording the increase in absorbance at $340 \mathrm{~nm}$. Measurements were performed at $\mathrm{pH} 6.5$ to reduce the spontaneous reaction for the formation of the conjugate of GSH and CDNB.

\section{Incubations}

Purified enzyme

Effects of various concentrations of $\mathrm{HOCl}$ (final concentration $0.2-1 \mu \mathrm{M}$ ) on acti- 
vity of purified GST P1-1 $(0.02 \mathrm{U} / \mathrm{ml})$ were determined. The GST enzyme was incubated in $100 \mathrm{mM}$ potassium phosphate $\mathrm{pH} 6.5$ or $7.4\left(37^{\circ} \mathrm{C}\right)$ with or without lipoic acid. After preincubation (1 min), HOCl was added and the reaction was allowed to proceed for 305 before the activity of GST P1-1 was determined. The effect of $\mathrm{H}_{2} \mathrm{O}_{2}$ on the activity of purified GST P1-1 was determined in the same way.

To study the inhibitory mechanism of $\mathrm{HOCl}$ on GST P1-1, substrate concentrations (CONB or GSH) were varied. When CDNB was varied, the GSH concentration was kept at $1 \mathrm{mM}$ and vice versa. In these experiments the concentration $\mathrm{HOCl}(0.75 \mu \mathrm{M})$ was constant.

Additionally, the reversibility of GST P1-1 inactivation by $\mathrm{HOCl}$ was studied. The GST was treated with $1 \mu \mathrm{M} \mathrm{HOCl}$ at $37^{\circ} \mathrm{C}$ at pH 7.4. After $30 \mathrm{~s}, 1 \mathrm{mM} \mathrm{GSH}$ was added and the mixture was incubated again for $5 \mathrm{~min}$ at $37^{\circ} \mathrm{C}$. Subsequently the GST activity was measured. This activity was compared to the GST activity observed when GSH was added after the incubation of 5 min, just before the addition of CDNB.

\section{Lysate of human erythrocytes}

Effects of various concentrations $\mathrm{HOCl}$ (final concentration $0-75 \mu \mathrm{M}$ ) on GST aCtivity in the lysate of human erythrocytes were also determined with the method described above. The lysate was prepared by mixing $1 \mathrm{ml}$ frozen blood from a male volunteer with $1 \mathrm{ml}$ cold water and $2 \mathrm{ml}$ cold $100 \mathrm{~m} M$ potassium phosphate $\mathrm{pH} 7.4$. This solution was mixed vigorously and centrifuged for $10 \mathrm{~min}$ at $13,000 \mathrm{rpm}$ at $4^{\circ} \mathrm{C}$. The supernatant was diluted 45 times. The incubation of the lysate with HOCl was performed at $\mathrm{pH} 7.4$, and the activity of GST was determined with GSH and CDNB as substrate after the $\mathrm{pH}$ was adjusted to $\mathrm{pH} 6.5$.

\section{Results}

As shown in Figure 1., the glutathione S-tramsferase activity was imhibited by $\mathrm{HOCl}$ in a concentration dependent manner. The concentrations of $\mathrm{HOCl}$ giving $50 \%$ inhibition ( $\mathrm{IC}_{50}$ ) of GST P1-1 activity were $0.6 \mu \mathrm{m}$ for both $\mathrm{pHs} . \mathrm{H}_{2} \mathrm{O}_{2}$ in a concentration of $1 \mathrm{mM}$ inhibited the GST P1-1 activity only $15 \%$. 


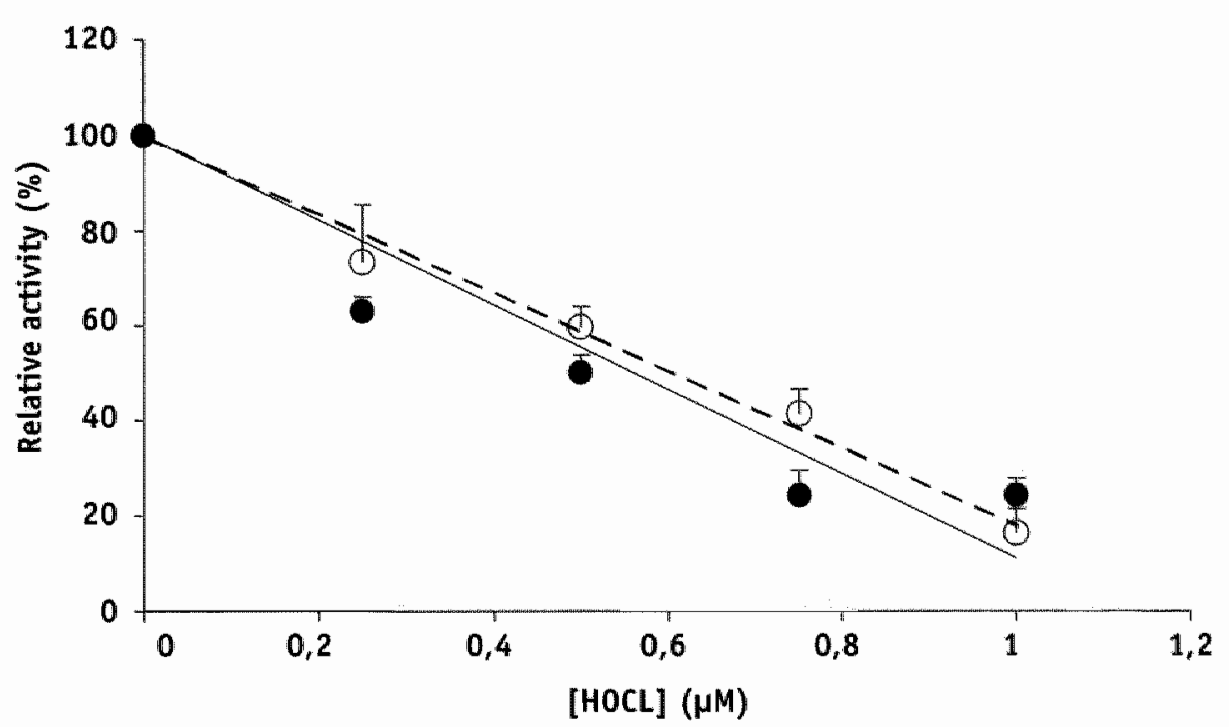

Figure 1. Inactivation of isolated GST P1-1 by HOCl. The inactivation was performed at pH 7.4 (dashed line, $\bullet$ ) ar pH 6.5 (solid line, O). The $I C_{s 0}$ values of $H O C$ are $0.56 \mu \mathrm{M}$ and $0.61 \mu \mathrm{M}$ at $\mathrm{pH} 6.5$ and 7.4, respectively. The concentration of the enzyme was $0.017 \mathrm{U} / \mathrm{ml}$. Each point denotes the means $( \pm S . E . M$.$) of three experiments.$

In the lysate of human erythrocytes $(\mathrm{pH} 7.4)$ the $\mathrm{IC}_{50}$ value of $\mathrm{HOCl}$ was $44 \pm 4 \mu \mathrm{M}$. A HOCl scavenger such as lipoic acid [12] can prevent the effect of HOCl on GST P11 (Figure 2.). The inhibition of GST P1-1 by $\mathrm{HOCl}$ was not reversible by addition of GSH to the HOCl inactivated enzyme (data not shown).

To obtain information on the nature of the inhibition of G5T P1-1 by HOCL, GST activity of the purified enzyme with or without pre-treatment of $\mathrm{HOCl}(0.75 \mu \mathrm{M})$, was measured with variable concentrations of either CDNB or GSH. GST shows characteristic Michaelis Menten behaviour towards both substrates. The Lineweaver-Burk plot of the substrate CDNB is depicted in Figure 3. As shown also in this figure, $\mathrm{HOCl}$ lowered the $V_{\text {snax }}$, but did not affect the $K_{\text {in }}$ for either CDNB or GSH. This indicates that the GST P1-1 enzyme is non-competitively inhibited by $\mathrm{HOCl}$. 


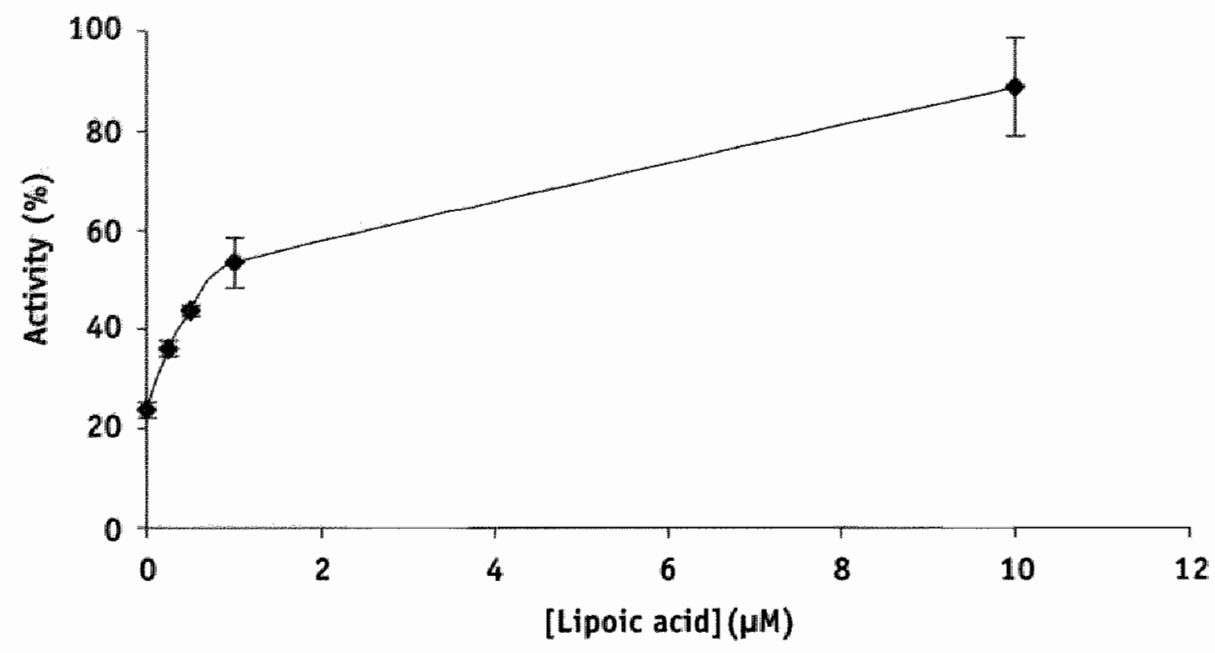

Figure 2. Protection by lipoic acid against the inhibition of GST P1-1 by HOCl. The concentration of enzyme and $\mathrm{HOCl}$ were respectively $0.034 \mathrm{U} / \mathrm{m}$ and $1.8 \mu \mathrm{M}$. Each point denotes the means ( \pm S.E.M.) of four measurements.

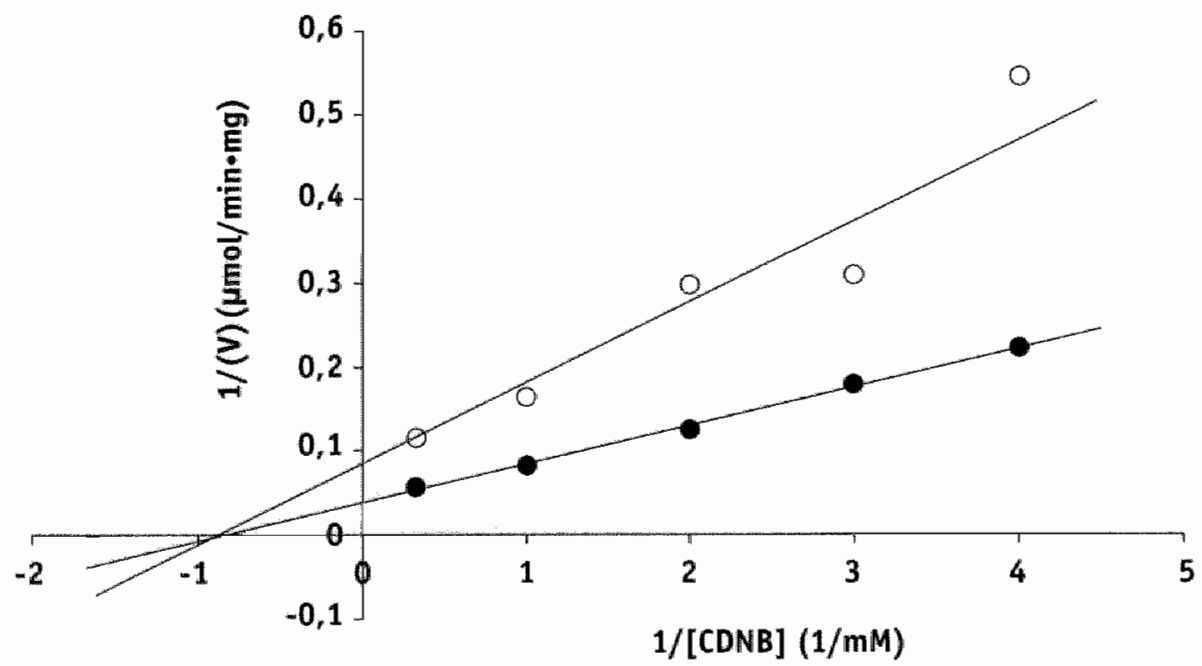

Figure 3. Lineweaver-Burk plot showing non-competitive inhibition of human placenta GST P1-1 isoenzyme towards CONB by $0.75 \mu \mathrm{MHOCl}$. The $K_{m a}$ and $V_{\max }$ of the enzyme for CONB ( $\bullet$ ) are respectiveby $1.2 \mathrm{mM}$ and $26 \mu \mathrm{mol} / \mathrm{min} \cdot \mathrm{mg}$. After $\mathrm{HOCl}$ treatment (O) these walues are $1.1 \mathrm{mM}$ and 11 fmol/min $\bullet \mathrm{mg}$. The concentration enzyme used was $0.017 \mathrm{U} / \mathrm{ml}$. Each points denotes the means ( \pm S.E.M.) of four measurements. 


\section{Discussion}

GSTs can conjugate numerous electrophilic compounds, many of which are toxic, to GSH. In most cases, this conjugation leads to detoxification of the compounds [13]. The catalytic activity of the enzyme can be altered by different mechanisms. It is known that GST $\mathrm{P}_{1}-1$ can be inhibited by $\mathrm{H}_{2} \mathrm{O}_{2}$ [7].

This study confirmed the inhibition of GST $\mathrm{P} 1-1$ by $\mathrm{H}_{2} \mathrm{O}_{2}$. However, a relatively high concentration of $\mathrm{H}_{2} \mathrm{O}_{2}(1 \mathrm{mM})$ inhibited the enzyme $15 \%$. The potency of $\mathrm{HOCl}$ to inhibit the enzyme is much higher. When $\mathrm{HOCl}$ was added to a solution of isolated GST P1-1, the $\mathrm{IC}_{50}$ value was $0.6 \mu \mathrm{M}$ (Figure 1.). Higher potency of $\mathrm{HOCl}$ compared to $\mathrm{H}_{2} \mathrm{O}_{2}$ was also found for other important biological effects such as induction of apoptosis via caspase 3 [14]. For induction of apoptosis the activity of $\mathrm{HOCl}$ exceeded even that of peroxynitrite [14].

It was shown that the inactivation of GST by $\mathrm{HOCl}$ is non-competitive and not reversible by GSH. The HOCl scavenger lipoic acid can protect against the inactivation of GST by HOCL. Lipoic acid contains an intramolecular S-S bridge in a ring in which some strain exists. By scavenging $\mathrm{HOCl}$ the lipoic acid is converted into a sulphoxide [12].

Human GST contains 4 cysteine residues at positions 14, 47, 101 and 169. Disulphide formation between cysteine residues at positions 47 and 101 was found to be critical for the inactivation of GST P1-1. This results in steric hindrance which is the most probable cause for the inactivation [15]. It is known that $\mathrm{HOCl}$ also shows a high reactivity towards thiol groups $[12,16,17]$. Probably $\mathrm{HOCl}$ inhibits the GST P1-1 activity by oxidation of a cysteine residue.

In erythrocytes GST P1-1 is the isoenzyme with the highest activity with respect to CDNB [18]. To inhibit the activity of GST in lysate of human erythrocytes, a much higher concentration $\mathrm{HOCl}$ was needed compared with purified GST P1-1 (IC Falues $_{s_{0}}$ were $44 \mu \mathrm{M}$ and $0.6 \mu \mathrm{M}$, respectively). The higher $\mathrm{IC}_{5 \bar{j}}$ value in the lysate can be explained by the presence of GSH and thiol containing proteins that also can react with $\mathrm{HOCl}$.

One of the major targets of $\mathrm{HOCl}$ in vivo is $\alpha 1$-antiproteinase ( $\alpha 1-\mathrm{AP}$ ). The $\mathrm{HOCl}$ mediated oxidation of this protein is an essential step in the etiology of lung emphysema [12]. A competition experiment, where $\alpha 1-A P$ and GST P1-1 are mixed, revealed that $H O C L$ first inactivates GST P1-1 before reacting with $\alpha 1-A P$ [19]. This indicates that the inactivation of GST P1-1 by HOCl is of physiological relevance.

Beside the transferase activity of GST P1-1, another function has been reported recently. As a guardian of Jun $\mathrm{N}$-terminal Kinase (JNK) in normally growing cells, GST P1-1 may serve as a sensor of intramolecular changes in redox potential. that 
are elicited by various forms of stress [20]. Phosphorylation of Jun by JNK has been implicated in changes in the cell cycle, DNA repair or apoptosis [18]. It is tempting to speculate that $\mathrm{HOCl}$ is one of the important triggers in this system since $\mathrm{HOCl}$ is a much more potent inhibitor of GST P1-1 than the other stressors (i.e. $\mathrm{H}_{2} \mathrm{O}_{2}$ ) studied thus far. Together with the proclaimed role of $\mathrm{HOCl}$ in activation of caspase 3 [14], elevation of $p 53$ levels [21], induction of the expression of apurinic endonuclease [22] and the activation of NF-KB [23], this points toward a pivotal function of $\mathrm{HOCl}$ in (patho-) physiology.

\section{Acknowledgements}

We are grateful to Marjolein Hemelt and Karlien v. d. Hout for their help with the experiments. 


\section{References}

1. Mannervik, B. The isoenzymes of glutathione transferase.

Advances in enzymology and related areas of molecular brology $1985,57,357-417$.

2. Hayes, J.D.; Pulford, D.J. The glutathione S-transferase supergene family: regulation of GST and the contribution of the isoenzymes to cancer chemoprotection and drug resistance.

Critical reviews in biochemistry and molecular biology 1995, 30, 445-600.

3. Uchida. K. Induction of glutathione S-transferase.

Mechanisms of ageing and dewelopment 2000,116, 135-140.

4. Guthenberg, C; Mannerwik, B. Glutathone S-transferase (transferase pi) from human placenta is identical ar closely related to glutathione S-transferase (transferase tho) from eythrocytes.

Biachimica et Biophysica Acta 1981, 661, 255-260.

5. Neefjes, V.M.; Evela, C.T.; Baars, L.G.; Blanco, C.E. Eyythrocyte glutathione 5 transferase as a marker of oxidative stress at birth.

Archives of disease in childhood 1999, 81, F130-F133.

6. Spooren, A.A.M.G.; Evelo, C.T.A. Only the glutathione dependent antiaxidant enzymes are inhibited by haematotoxic hydroxylamines.

Human \& Experimental Toxicology 1998, 17, 554.559.

7. Shen, H.X.; Tamai, K.; Satoh, K.; Hatayama, I.; Tsuchida, S.; Sato, K. Modulation of class Pi glutathione transferase activity by sulfhydryl group madification.

Archives of Biochemistry and Biophysics 1991, 286, 178-182.

8. Murata, $T_{. ;}$Hatayama, I.: Satoh, K.; Tsuchida, $S_{. ;}$Sato, K. Activation of rat glutathione transferases in class mu by active oxygen species [published erratum appears in Biochem Biophys Res Commun 1990 Dec 31;173(3):1382].

Biachemical and Biophysical Research Communications 1990, 171, 845-851.

9. Hampton, M.B.; Kettle, A.J.; Winterbourn, C.C. Inside the neutrophil phagosome: oxidants, myeloperoxidase, and bacterial killing.

Blood 1998, 92, 3007-3017.

10. Pullar, J.M.; Winterboum, C.C. Vissers, M.C. LOss of GSH and thiol enzymes in endo. thelial cells exposed to sublethal concentrations of hypochlorous acid.

The American joumal of physiology 1999, 277, H1505-H1512.

11. Mannervik, B.. Guthenberg, C. Glutathione transferase (Human placenta). Methods in enzymology 1981, $77,231-235$.

12. Haenen, G.R.; Bast, A. Scavenging of hypochlorous acid by lipoic acid. Biochemical Pharmacology 1991, 42, 2244-2246.

13. Eaton, 0.L.: Bammler, T.K. Concise review of the glutathione S-transferases and their significance to toxicology.

Taxicological sciences 1999, 49, 156-164.

14. Vissers, M.C.M.; Pullar, J.M.; Hampton, M.B. Hypochlarous acid causes caspase activation and apoptosis ar growth arrest in human endathelial cells.

Biochemical Journal 1999, 344, 443-449.

15. Mannervik, B.; Danielson, U.H. Glutathione transferases-Structure and catalytic activity. Critical Reviews in Biochemistry and Molecular Biology 1988, 23, 283-337.

16. Winterbourn, C.C. Comparative reactivities of various biological compounds with myeloperoxidase-hydrogen peraxide-chloride, and similarity of the oxidant to hypochlorite. 
Biochimica et Biophysica Acta $1985,840,204-210$.

17. Carr, A.C.; Winterbourn, C.C. Oxidation of neutrophil glutathione and protein thials by myeloperaxidase-derived hypochloraus acid".

Biochemical Journal 1997, 327, 275-281.

18. Fazi, A.: Accorsi, A.; Piatti, E.; Magnani, M. Cell age dependent decay of human erythrocytes glutathione S-transferase.

Mechanisms of ageing and development 1991, 58, 255-266.

19. den Hartog, G.J.M.; Haenen, G.R.M.M.; Vegt, E.; van der Vijgh, W.J.F.; Bast, A. Efficacy of hypochlorous acid scavenging by sulfur containing compounds. Antioxidant activity of glutathione disulfide?

Biological Chemistry 2002, 383, 709-713.

20. Adler, W.; Vin, Z; Fuchs, 5.Y.; Benezra, M., Rosano, L.; Tew, K.D.; Pincus, M.R.; Sardana, M.; Henderson, C.J.; Wolf. C.R.; Davis, R.J.; Ronai, Z Regulation of JNK signaling by GSTp.

The EMBO journal 1999, 18, 1321-1334.

21. Vile, G.F.; Rothwell, L.A.; Kettle, A.J. Hypochloraus acid activates the tumor suppressor protein 053 in cultured human skin fibroblasts.

Archives of Biachemistry and Biophysics 1998, 359, 51-56.

22. Grosch, S.; Fritz, G.; Kaina, B. Apurinic endonuclease (Ref-1) is induced in mammalian cells by axidative stress and involved in clastogenic adaptation.

Cancer Research 1998, 58, 4410-4416.

23. Schoonbroodt, S.; Legrand-Poels, S.; Best-Belpomme, M.; Piette, J. Activation of the NF$\kappa B$ transcription factor in a T-lymphocytic cell line by hypochloraus acid.

Biochemical Journal 1997, 321, 777-785. 


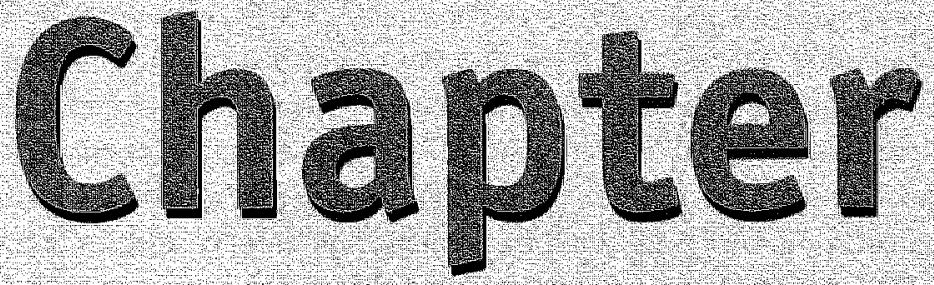

\section{Summary and General discussion}




\section{Summary and General discussion}

The human body has several lines of defence, e.g. antioxidants, enzymes and metal chelators, to cope with reactive oxygen species and electrophiles. Antioxidants do not work in isolation but form an intricate network. This thesis focuses on the interaction of two different defence mechanisms: vitamin $\mathrm{E}$ and glutathione-dependent enzymes. Specifically the interplay between vitamin $E$ or $\alpha$-tocopherol quinone and free radical reductase; the reduction of $\alpha$-tocopherol quinone by glutathione; and the effect of different forms of vitamin $E$ on glutathione S-transferase activity is explored.

In chapter 2 of this thesis an overview on vitamin $E$ and glutathione (-dependent enzymes) is presented. Together with other antioxidants (enzymatic and nonenzymatic) these two compounds form a barrier against damaging species. The uptake of the different forms of vitamin $E$ and of glutathione is discussed and the different functions of vitamin $E$ and glutathione (-dependent enzymes) are reported.

Radicals are able to oxidise polyunsaturated fatty acids in the membranes of cells. Products which are formed during this process can inhibit cell growth and display genotoxic activity. Vitamin $E$ cam inhibit this process of lipid peroxidation by scavenging lipid peroxyl radicals that propagate chains in nonenzymatic lipid peroxidation [1]. $\alpha$-Tocopherol is the form of vitamin $E$ mostly present in the human body due to the presence of $\alpha$-tocopherol transfer protein in the liver which selectively sorts out RRR- $\alpha$-tocopherol for uptake in the body [2]. Because of the higher bioavailability of $\alpha$-tocopherol compared to all other vitamin $E$ vitamers its antioxidant effect is superior to the other vitamin $E$ vitamers in the defence aganst lipid peroxidation. It should be realised that once $\alpha$-tocopherol scavenges the lipid peroxidation radical, it becomes a radical itself.

Next to $\alpha$-tocopherol, GSH is also a potent inhibitor of lipid peroxidation. The GSHdependent protection is vitamin $E$ dependent and proceeds via a free radical reductase, an enzyme which is able to regenerate $\alpha$-tocopherol radical to $\alpha$-tocopherol. However not all $\alpha$-tocopherol radicals are regenerated in this way, some radicals are oxidised further and form $\alpha$-tocopherol quinome. It has been demonstrated that $\alpha$ tocopherol quinone can be reduced to $\alpha$-tocopherol in humans [3]. However, this reduction is not due to a direct reaction with GSH (chopter 3). The reduction does occur neither directly in solution nor in microsomes in which the free radical reductase enzyme is present. Chapter 3 deals also with the interaction of $\alpha$-tocopherol and $\alpha$-tocopherol quinone with glutathione in the process of lipid peroxidation. As described in earlier studies, $\alpha$-tocopherol inhibits the process of lipid peroxidation 
via GSH-dependent protection. $\alpha$-Tocopherol quinone does not affect this GSHdependent protection in the presence of adequate levels of $\alpha$-tocopherol. However, when $\alpha$-tocopherol levels are reduced, $\alpha$-tocopherol quinone completely blocks the GSH-dependent protection against lipid peroxidation.

This indicates that $\alpha$-tocopherol quinone acts as a weak $\alpha$-tocopherol antagonist for the free radical reductase. In this way $\alpha$-tocopherol quinone can work as a prooxidant when $\alpha$-tocopherol levels are low.

Glutathione S-transferases also protect the human body against damaging activities of, for instance, reactive oxygen species and various electrophiles. They catalyse the glutathione conjugation of various compounds [4]. The pi isoform of GST is especially vulnerable to oxidative stress [5]. Since $\alpha$-tocopherol is able to protect against radicals, it was expected that it would have a protective effect on GST P1-1. In chapter 4 it was demonstrated, however, that $\alpha$-tocopherol is a very potent inhibitor of GST P1-1 compared with other known inhibitors of GST P1-1, i.e. S-hexylglutathione and bromosulfothalein [6]. $\alpha$-Tocopherol does not compete for the binding sites of either GSH or CDNB on GST P1-1; it inhibits the activity in a noncompetitive manner.

When vitamin $E$ is used as supplement or is added to a product, e.g. cosmetic product, the molecule is frequently made less vulnerable to oxidation by sequestration of the hydroxyl group in the chroman head, that is essential for its antioxidant function [7]. Chapter 5 describes the effect of some tocopherol derivatives on activity of GST P1-1. Although sequestration of the free hydroxyl group in tocopherol lowers the capacity to inhibit GST P1-1, all tested tocopherols and tocopherol derivatives inhibit human GST P1-1 in a concentration-dependent manner at relatively low concentrations. The water-soluble vitamin $E$ analogue trolox, with the same chroman head as $\alpha$-tocopherol, has a poor inhibitory effect on GST P1-1. Also arachidonic acid, a long fatty acid resembling the tail of $\alpha$-tocopherol, does not have a high inhibiting effect on GST P1-1. The inhibition of the ester RRR- $\alpha$-tocopherol acetate was noncompetitive, indicating that the type of inhibition of the esters is identical to that of the free tocopherols. Based on these results it can be concluded that not just the tail or the head of tocopherol is important for GST P1-1 inhibition, but a combination of the head and the tail of the molecule. It also can be concluded that other structural elements play a role in GST P1-1 inhibition than in free radical scavenging. Chapter 5 also describes the most probable mechanism of GST inhibition by tocopherols and tocopherol derivatives. The hypothesis is that these compounds induce conformational changes of the enzyme due to structural modifications of lipophilic regions present in the interface between the two monomers of GST. Binding of a compound to this region can change the activity of the enzyme [8]. 
In chapter 6 the inhibition of GST P1-1 by tocotrienols is described. Tocotrienols inhibit GST P1-1 activity with comparable potency to that of tocopherols. The inhibition was also non-competitive with respect to both substrates CDNB and GSH. The hypothesis for the mechanism of GST inhibition by tocopherols and tocopherol derivatives described in chapter 5 is verfified in chapter 6 . Three-dimensional evaluation of the GST P1-1 protein structure revealed that there are surprisingly few lipophilic amino acids present in the contact region of the two monomers. Binding of tocopherol, tocatrienal or tocopheral derivatives in this region is very unlikely. However, a very hydrophobic pit-like structure, where the lipophilic tail of tocopherols and tocotrienols could fit in, is present just below the G-site in the molecule. It is likely that tocopherols and tocotrienols preferentially bind to this region and in this way change the conformation of the enzyme. The activity of the enzyme will be inhibited in this way. The region described in this chapter contains overlapping regions with a hydrophobic binding region described in earlier studies [ $9-11]$.

GST is a superfamily of multiple isoenzymes. The three major cytosolic isoemzymes are alpha, mu and pi. The alpha and mu class isoenzymes are predominantly expressed in the liver and the kidney and the pi isoenzyme in the skin and red blood cells. In chapter 7 we discussed the effects of RRR- $\alpha$-tocopherol on the activity of purified isoenzymes of GST. Also the effects of RRR- $\alpha$-tocopherol on GST activity in human liver cytosol and human red blood cell lysate are discussed. All the purified isoenzymes tested (GST A1-1, A2-2, M1a-1a and P1-1) are imhibited, in a concentration-dependent manner, by RRR- $\alpha$-tocopheroL. GST P1-1 is inhibited with the highest potency. The $\mathrm{IC}_{50}$ of GST A1-1 and GST M1a-1a are higher compared to GST P1-1; the $\mathrm{IC}_{50}$ of GST A2-2 is the highest of all isoenzymes tested.

It also appeared that RRR- $\alpha$-tocopherol inhibits GST activity in human tissues containing different isoforms of the enzyme. This inhibition by RRR- $\alpha$-tacopherol is also concentration-dependent. The $\mathrm{IC}_{\mathrm{s} \text { : }}$ value for GST $\mathrm{P}$, present in lysate of human erythrocytes is much lower compared to the $\mathrm{IC}_{\mathrm{s}_{0}}$ value for the mixture of GST $M$ and GST A, present in human liver cytosol. These results are in accordance with the results of the purified isoenzymes. However, the absolute $I C_{50}$ values are higher for the human sources of the isoenzymes compared to these values for purified isoenzymes. A possible explanation for this difference in $I_{S_{0}}$ values is that the potency of RRR- $\alpha$-tocopherol to inhibit GST activity is drastically reduced when proteins, e.g. albumin or hemoglobin are present. Probably RRR- $\alpha$-tocopherol binds to the protein with higher affinity than to the GST enzyme.

As already mentioned, GST P1-1 is especially vulnerable to oxidative stress. It is known that GST P1-1 is inactivated in human erythrocytes by $\mathrm{H}_{2} \mathrm{O}_{2}$ [12]. Numerous 
reactive oxygen species are known to be more reactive than the relative stable $\mathrm{H}_{2} \mathrm{O}_{2}$. $\mathrm{HOCl}$ is a powerful oxidant generated by the neutrophil enzyme myeloperoxidase from $\mathrm{H}_{2} \mathrm{O}_{2}$ and chloride ions. It is highly reactive towards a range of biological substrates [13]. In chapter 8 the effect of this highly reactive oxygen species, $\mathrm{HOCl}$, on GST P1-1-activity is presented. The results show that GST P1-1 is inhibited by $\mathrm{HOCl}$ with a very high potency compared to $\mathrm{H}_{2} \mathrm{O}_{2}$. The inhibition of GST P1-1 by $\mathrm{HOCl}$ is concentration-dependent, noncompetitive and not reversible by $6 \mathrm{SH}$. It was also shown that the $\mathrm{HOCl}$ scavenger, lipoic acid, can protect against the inactivation of GST P1-1 by HOCl. Human GST P1-1 contains four cysteine residues of which two, cys-47 and cys-101, are critical for the activity [6]. Probably $\mathrm{HOCl}$ inhibits the activity of the enzyme by oxidation of such a cysteine residue, because it is known that $\mathrm{HOCl}$ shows high reactivity towards thiol groups [14, 15]. To inhibit GST in lysate of human erythrocytes (major form of GST is GST P1-1), higher concentrations of $\mathrm{HOCl}$ are needed to inhibit the enzyme compared with purified GST P1-1. This can be explained by the presence of GSH and thiol containing proteins that also can react with $\mathrm{HOCl}$.

\section{Implications}

The effects of multiple forms of vitamin $E$ on GSH-dependent enzymes can have numerous implications, which can be advantageous or disadvantageous for humans. As described in chapter $3, \alpha$-tocopherol quinone can act as a pro-oxidant in the GSH-dependent protection against lipid peroxidation, in conditions where the $\alpha$ tocopherol concentration is low. Another disadvantageous effect of $\alpha$-tocopherol is the indirect carcinogenic action performed by inhibition of GST P1-1 activity (chopter 4). In addition to the use of vitamin $E$ as food ingredient or a supplement, several modern cosmetic products contain relatively high concentrations witamin $E$. It is known that GST P1-1 is present in humar skin [16]. In view of this it is of importance that mice lacking the GST P1-1 have an increased risk for skin tumorigenesis [17] and that vitamin $E$ has been shown to be a complete tumour pramoter in mouse skin [18]. The potent GST P1-1 inhibition by $\alpha$-tocopherol found in our study (chapter 4) suggests that this promater effect might be caused by GST P'1-1 inhibition. Most cosmetic products contain vitamin $\mathrm{E}$ in an esterified form of tocopherol. These esterified products are also potent inhibitors of GST P1-1. Also tocotrienols can indirectly be carcinogenic compounds in this way (chapter 6).

Chapter 5 describes a risk assessment for dermal application of vitamin $\mathrm{E}$ containing products. Based on the assumptions made, it can be concluded that to reach a concentration of $10 \mu \mathrm{M}$ of the esterified vitamin $\mathrm{E}$ vitamer in the epidermis, a concen- 
tration inhibiting GST P1-1 more than $50 \%, 0.0005 \% \mathrm{w} / \mathrm{v}$ tocopherol ester in the product would be sufficient. In cosmetic products up to $1 \%$ vitamin $E$ can be found. This indicates that application of such a vitamin $E$ containing product to the skin probably results in a substantial inhibition of GST P1-1, with possible disadvantageous effects.

In some cases the inhibition of GST can however be advantageous (chapter $7 / 8$ ). Tumour cells express certain isoenzymes, especially GST P1-1, which contributes to resistance against cytostatic drugs through GSH conjugation of the active metabolites $[19,20]$. Inhibition of GST activity can increase the potency of chemotherapeutics. Therefore, compounds are being developed that inhibit GST activity and can be used as adjuvant in cancer therapy. Possibly, vitamin $E$ can be useful as inhibitor of glutathione conjugation in cancer therapy.

It is also known that GST P1-1 functions as a guardian of JNK in normally growing cells. GST P1-1 may serve as a sensor of intramolecular changes in redox potential that are elicited by various forms of stress [21]. Chapter 8 shows that $\mathrm{HOCl}$ can inhibit GST P1-1 activity, what makes HOCl such a form of stress. These forms of stress alter the conformation of GST P1-1 which triggers the phophorylation of Jun by JNK. This can result in changes in cell cycle, DNA repair or apoptosis. Overphosphorylation of Jun can increase cell proliferation and eventually apoptosis (chapter 2/8). Inhibition of GST P1-1 by vitamers of vitamin $E$ also gives conformational changes in the GST molecule (chapter 6 ), albeit other changes than the changes induced by HOCl. Probably vitamin E also can act as guardian of JNK. 


\section{References}

1. Haenen, G.R.M.M.; Bast, A. Protection against lipid peraxidation by a microsomal glutathione-dependent labile factor.

Federation of European Biochemical Societies 1983, 159, $24-28$.

2. Burton, G.W.: Traber, M.G. Vitamin E: antioxidant activity biokinetics, and bioavailability. Annual Review of Nutrition 1990, 10,357-382.

3. Moore, A.N.J., Ingold, K.U. alpha-Tocopherol quinone is converted into vitamin E in man. Free Radical Biology \& Medicine 1997, 22, 931-934.

4. Habig, W.H.; Pabst, M.J.; Jakoby, W.B. Glutathione S-transferases. The first enzymatic step in mercapturic acid formation.

The Journat of Biological Chemistry 1974, 249, 7130-7139.

5. Neefjes, V.M.; Evelo, C.T.; Baars, L.G.; Blanco, C.E. Eythrogyte glutathione 5 transferase as a marker of oxidative stress at birth.

Archives of disease in childhood 1999, 81, F130-F133.

6. Mannervik, B.; Danielson, U.H. Glutathione transferases-Structure and catalytic activity. Critical Reviews in Biochemistry and Molecular Biology 1988, 23, 283-337.

7. Kamal-Eldin, A.; Appelqvist, L.A. The chemistry and antioxidant properties of tocopherols and tocotrienals.

Lipids 1996, 31, 671-701.

8. Ricci, G.; Lo-Bello, M.; Caccurn, A.M.; Pastore, A., Nuccetelli, M.; Parker, M.W.; Federici, G. Site-directed mutagenesis of human glutathione transferase P1-1. Mutation of Cys47 induces a positive cooperativety in glutathione transferase P1-1.

The Joumal of Bialogical Chemistry 1995, 270, 1243-1248.

9. Nishihira . J.; Ishibashi, T.; Sakai, M.; Nishi, S.; Kumazaki, T. Identification of the fatty acid binding site on glutathione S-transferase $P$ by immobilization to fatty acid-linked sepharase.

Biochemical and Biophysical Research Communications 1993, 190, 823-831.

10. Nishihira, J.; Ishibashi, $T_{.}$S Sakai, M.; Tsuda, S.; Hikichi, K. Identification of the hydrophabic ligand-binding region in recombinant glutathione S-transferase $P$ and its binding effect on the conformational state of the enzyme.

Archives of Biachemistry and Biophysics 1993, 302, 128-133.

11. Nishihira, J.; Ishibashi, T.; Sakai, M.; Nishi, S.; Kondo, H., Makita. A. Identification of the fatty acid binding site on glutathione S-transferase $P$.

Biochemical and Biophysical Research Communications 1992, 189, 197-205.

12. Shen, H.X.; Tamai, K.; Satoh, K.; Hatayama, I.; Tsuchida, S.; Sato, K. Madulatian of class Pi glutathione transferase activity by sulfhydryl group modification.

Archives of Brachemisty and Biophysics 1991, 286, 178-182.

13. Hampton, M.B.; Kettle, A.J.; Winterbourn, C.C. Inside the neutrophil phagosome: oxidants, myeloperoxidase, and bacterial killing.

Blood 1998, 92, 3007-3017.

14. Winterbourn, C.C. Comparative reactivities of various biological compounds with myeloperoxidase-hydrogen peroxide-chloride, and similarity of the oxidant to hypochlorite. Biochimica et Biophysica Acta 1985, 840, 204-210.

15. Haenen, G.R.; Bast, A. Scavenging of hypochlorous acid by lipoic acid. Biochemical Pharmacology 1991, 42, 2244-22466.

16. Singhal, 5.S.; Saxena, M.; Awasthi, S.; Mukhtar, H.: Zaidi, S.I.; Ahmad, H.; Awasthi, 
Y.G. Glutathione S-transferases of human skim: qualitative and quantitative differences in men and women.

Biocthimica et Biophysico Acta 1993, 1163, 266-272.

17. Henderson, C.J.; Smith, A. G.; Ure, J.; Brown, K.; Bacon, E.J.; Wolf, C.R. Increased skin tumorigenesis in mice lacking pi class glutathione S-transferases.

Proceedings of the National Academy of 5 ciences of the United States of America 1998, $95,5275-5280$.

18. Mitchel, R.E.: McCann, R. Vitamin E is a complete tumor promater in mouse skin. Carcinogenesis 1993, 14, 659-662.

19. Margan, A. S.; Ciaccio, P.J.; Tew, K.D., Kawvar, L.M. Isozyme-specific glutathione S-transferase inhibitors potentiate drug sensitivity in cultured human tumor cell lines. Cancer Chemotherapy and Pharmacalogy 1996, 37, 363-370.

20. Mulder, G.J.; Ouwerkerk Mahadewan. 5. Madulation of glutathione conjugation in vivo: how to decrease glutathione conjugation in vivo or in intact cellular systems in vitro. Chemico-Biological Interactions 1997, 105, 17-34.

21. Adler, V., Yin, Z.; Fuchs, 5.Y.; Benezra, M.; Rosario, L.; Tew, K.D.; Pincus, M. R.; Sardana, M.; Henderson, C.J.; Wolf, C.R.; Davis, R.J.; Ronai, Z. Regulation of JNK signaling by GSTp.

The EMBO journal 1999, 18, 1321-1334. 


\section{Samenvatting}




\section{Samenvatting}

Het menselijk lichaam heeft verschillende enzymatische en niet-enzymatische beschermingsmechanismen om het hoofd te kunnen bieden aan reactieve zuurstof deeltjes en electrofielen. De niet-enzymatische antioxidanten werken niet alleen, maar vormen een ingewikkeld netwerk. Ook werken ze in samenhang met de enzymatische beschermingsmechanismen. Dit proefschrift concentreert zich op de interactie tussen twee verschillende beschermingsmechanismen: vitamine E en glutathion-afhankelijke enzymen. Met name de interactie tussen vitamine $E$, of $\alpha$-tocoferol quinon, en vrij radicaal reductase; de reductie van $\alpha$-tocoferol quinon door glutathion; en het effect van verschillende vormen van vitamine $E$ op glutathion $S$-transferase activiteit is onderzocht.

In hoofdstuk 2 van dit proefschrift wordt een overzicht van vitamine $E$ en glutathion (-afhankelijke enzymen) gegeven. Samen met andere enzymatische en non-enzymatische antioxidanten vormen deze twee componenten een barrière tegen schadelijke deeltjes. De opname van de verschillende vormen van vitamine $E$ en glutathion wordt besproken en de verschillende functies van vitamine $\mathrm{E}$ en glutathion (-afhankelijke enzymen) zijn weergegeven.

Radicalen zijn in staat om meervoudig onverzadigde vetzuren in de membranen van cellen te oxideren. Producten die gevormal worden tijdens dit proces kunnen de celgroei remmen en genotoxische activiteit uitoefenen. Vitamine $E$ kan dit proces van lipide peroxidatie remmen door het wegvangen van lipide peroxyl radicalen die de kettingreactie van non-enzymatische lipide peroxidatie propageren. $\alpha$-Tocoferol is de vorm van vitamine $E$ die het meest aanwezig is in het menselijk lichaam door de aanwezigheid van $\alpha$-tocoferol transfer eiwit in de lever, dat selectief RRR- $\alpha$-tocoferol bindt voor opname in het lichaam. Door de hogere biologische beschikbaarheid van $\alpha$-tocoferol in vergelijking met alle andere vitamine $E$ vitameren, is het antioxidant effect in de bescherming tegen lipide peroxidatie van $\alpha$-tocoferol superieur aan de andere vitamine $\mathrm{E}$ vitameren. Opgemerkt moet worden dat $\alpha$-tocoferol zelf een radicaal wordt wanneer het een lipide peroxyl radicaal wegvangt.

Naast $\alpha$-tocoferol is ook GSH een potente remmer van lipide peroxidatie. De GSHafhankelijke bescherming is vitamine $\mathrm{E}$ afhankelijk en verloopt via een vrij radicaal reductase; een enzym dat in staat is om $\alpha$-tocoferol te regenereren uit $\alpha$-tocoferol radicaal. Echter niet alle radicalen worden op deze manier geregenereerd, enkele radicalen oxideren verder en vormen $\alpha$-tocoferol quinon. Het is aangetoond dat mensen $\alpha$-tocoferol quinon kunnen reduceren naar $\alpha$-tocoferol. Deze reductie is echter niet het gevolg van een directe reactie met GSH (hoofdstuk 3). De reductie 
gebeurt niet rechtstreeks in oplossing en ook niet in lever microsomen waarin het vrij radicaal reductase enzym aanwezig is. In hoofdstuk 3 wordt ook de interactie van $\alpha$-tocoferol en $\alpha$-tocoferol quinon met glutathion in het proces van lipide peroxidatie beschreven. Zoals besproken in eerdere studies remt $\alpha$-tocoferol het proces van lipide peroxidatie via GSH-afhankelijke bescherming. $\alpha$-Tocoferol quinom beïnvloedt deze GSH-afhankelijke bescherming niet in de aanwezigheid van adequate gehaltes $\alpha$-tocoferol. Wanneer het $\alpha$-tocoferol gehalte echter is afgenomen。 voorkomt $\alpha$-tocoferol quinon de GSH-afhankelijke bescherming tegen lipide peroxidatie volledig. Dit suggereert dat $\alpha$-tocoferol quinon werkt als een $\alpha$-tocoferol antagonist voor het vrij radicaal reductase. Op deze manier kan, indien de $\alpha$-tocoferol gehaltes laag zijn, $\alpha$-tocoferol quinon als een pro-oxidant werken.

Glutathion S-transferases beschermen het menselijk lichaam ook tegen schadelijke effecten van, bijvoorbeeld, reactieve zuurstof deeltjes en verschillende electrofielen. Ze katalyseren de conjugatie van glutathion met verschillende componenten. De pi isovorm van GST is gevoelig voor oxidatieve schade. Aangezien $\alpha$-tocoferol in staat is om de mens te beschermen tegen radicalen, werd verwacht dat $\alpha$-tocoferol een beschermend effect zou hebben op GST P1-1. In hoofdstuk 4 wordt echter aangetoond dat $\alpha$-tocoferol, in vergelijking met andere bekende remmers van GST P11 , zoals $S$-hexylglutathion en bromosulfothaleine, een zeer potente remmer van GST P1-1 is. $\alpha$-Tocoferol competeert niet voor de bindingsplaatsen van GSH of CDNB in GST P1-1, maar remt de activiteit op een non-competitieve manier.

Wanneer vitamine $\mathrm{E}$ wordt gebruikt als supplement of wordt toegevoegd aan een product (bijvoorbeeld een cosmetisch product) wordt het molecuul vaak minder gevoelig gemaakt voor oxidatie door afscherming van de hydroxyl groep in de chromaan groep. Deze groep is essentieel voor de antioxidant functie. Hoofdstuk 5 beschrijft het effect van enkele tocoferol derivaten op de activiteit van GST P1-1. Hoewel afscherming van de vrije hydroxyl groep in tocoferol de capaciteit om GST P1-1 te remmen verlaagt, remmen alle geteste tocoferolen en tocoferol derivaten humaan GST P1-1 op een concentratie-afhankelijke manier bij relatief lage concentraties. Het wateroplosbare vitamine $\mathrm{E}$ analoog trolox, dat dezelfde chromaan groep heeft als $\alpha$-tocoferol, heeft een geringe remming op GST P1-1. Het vetzuur, arachidonzuur, dat lijkt op de staart van $\alpha$-tocoferol, heeft ook geen sterk remmend effect op GST P1-1. De remming van de ester RRR- $\alpha$-tocoferol acetaat is non-competitief; hetgeen suggereert dat de remming van de esters op vergelijkbare wijze verloopt als die van de vrije tocoferolen. Gebaseerd op deze resultaten kan worden geconcludeerd dat niet alleen de phytyl staart of de chromaan groep van tocoferol, maar een combinatie van beide structuren in het molecuul, belangrijk is voor GST P1-1 remming. Ook kan worden geconcludeerd dat bij GST P1-1 remming andere moleculaire structuur kenmerken een rol spelen dan bij vrije radicaal scavenging. 
In hoofdstuk 5 wordt bovendien het meest waarschijnlijke mechanisme besproken van GST remming door tocoferolen en tocoferol denivaten. Onze hypothese is dat deze componenten een conformatie verandering van het enzym induceren ten gevolge van structurele modificaties van lipofiele regio's aanwezig in het raakvlak tussen de twee moniomeren van GST. Binding van een component in deze regio kan de activiteit van het enzym veranderen.

Hoofdstuk 6 beschrijft de remming van GST P1-1 door tocotrienolen. Tocotrienolen remmen de GST P1-1 activiteit met vergelijkbare potentie als tocoferolen. De remming is ook non-competitief ten opzichte van allebei de substraten CONB en GSH. De hypathese voor het remmingsmechanisme van GST door tocoferolen en tocotrienolen beschreven in hoofdstuk 5 wordt in hoofdstuk 6 geverifieerd. Driedimensionale evaluatie van de GST P1-1 eiwit structuur toont dat er verrassend weinig lipofiele aminozuren aanwezig zijn in de contact regio van de twee monomerem. Binding van tocoferol, tocotrienol of tocoferol derivaten in deze regio is zeer onwaarschijnlijk. Echter, onder de G-plek is een erg lipofiele put-achtige structuur aanwezig waar de lipofiele staart van tocoferolen en tocotrienolen in kan passen. Het is waarschijnlijk dat tocoferolen en tocotrienolen bij voorkeur binden aan deze regio en op deze manier de conformatie van het enzym veranderen. De activiteit van het enzym wordt waarschijnlijk op deze manier geremd. De locatie, voor binding van tocoferolen en tocotrienolen, die wordt beschreven in dit hoofdstuk is gedeeltelijk overlappend met een hydrofobe bindende regio zoals beschreven in eerdere studies.

GST is een superfamilie van meerdere isoenzymen. De drie meest belangrijke isoenzymen zijn alfa, mu en pi. De alfa en mu klasse isoenzymen worden voornamelijk tot expressie gebracht in de lever en de nier en het pi isoenzym in de huid en rode bloedcellen. In hoofdstuk 7 worden de effecten van RRR- $\alpha$-tocoferol op de activiteit van gezuiverde isoenzymen bediscussieerd. De effecten van RRR- $\alpha$-tocoferol op de GST activiteit in humaan lever cytosol en lysaat van humane rode bloedcellen worden eveneens besproken. Alle geteste gezuiverde enzymen (GST A1-1, A2-2, M1a-1a en P1-1) worden op een concentratie-afhankelijke manier geremd door RRR- $\alpha$-tocoferol. GST P1-1 wordt geremd met de grootste potentie. De IC $C_{50}$ waarden van GST A11 en GST M1a-1a zijn groter dan de IC ${ }_{50}$ waarde met GST P1-1. GST A2-2 vertoont de hoogste $\mathrm{IC}_{\text {sin }}$ van alle geteste isoenzymen voor $\mathrm{RRR}$ - $\alpha$-tocoferol.

De GST activiteit van humaan lever cytosol en humane rode bloedcellen, wordt ook gerend door RRR- $\alpha$-tocaferol. Deze remming door RRR- $\alpha$-tocoferol is eveneens concentratie-afhankelijk. De IC $\mathrm{C}_{59}$ waarde voor GST $\mathrm{P}$, aanwezig in lysaat van humane erytrocyten, is veel lager in vergelijking met de $\mathrm{IC}_{50}$ waarde voor het mengsel van GST $M$ en GST $A$, aanwezig in humaan lever cytosol. Deze resultaten zijn in overeenstemming met de resultaten van gezuiverde isoenzymen. De absolute $\mathrm{IC}_{50}$ waarden 
voor de isoenzymen aanwezig in lever cytosol en rode bloedcellen zijn echter hoger dan de waarden voor de gezuiverde enzymen. Een mogelijke verklaring voor deze verschillen in $\mathrm{IC}_{30}$ waarden is de aanwezigheid van eiwitten zoals albumine en hemoglobine, waardoor de effectiviteit van RRR- $\alpha$-tocoferol om GST te remmen drastisch wordt gereduceerd. Waarschijnlijk bindt RRR- $\alpha$-tocoferol met grotere affiniteit aan het eiwit dan aan GST.

Zoals al eerder opgemerkt, is GST P1-1 gevoelig voor oxidatieve schade. Het is bekend dat GST P1-1 in humane erytrocyten wordt geïnactiveerd door $\mathrm{H}_{2} \mathrm{O}_{2}$. Er zijn verscheidene reactieve zuurstofdeeltjes bekend die reactiever zijn dan het relatief stabiele $\mathrm{H}_{2} \mathrm{O}_{2}$. $\mathrm{HOCl}$ is een sterke oxidant die wordt gegenereerd uit $\mathrm{H}_{2} \mathrm{O}_{2}$ en chloride ionen door het enzym myeloperoxidase zoals dat voorkomt in neutrofielen. Het is zeer reactief tegen een aantal biologische substraten. In hoofdstuk 8 wordt het effect van deze sterke oxidant, $\mathrm{HOCl}$, op GST P1-1 activiteit weergegeven. De resultaten tonen dat GST P1-1 beter wordt geremd door $\mathrm{HOCl}$ dan door $\mathrm{H}_{2} \mathrm{O}_{2}$. De remming van GST P1-1 door HOCL is concentratie-afhankelijk, non-competitief en niet reversibel door GSH. Er is ook aangetoond dat de HOCl scavenger lipoïnezuur, GST P1-1 kan beschermen tegen inactivatie door HOCl. Humaan GST bevat vier cysteine groepen waarvan er twee, cys-47 en cys-101, essentieel zijm voor de activiteit. Waarschijnlijk remt $\mathrm{HOCl}$ de activiteit van het enzym door oxidatie van zo'n cysteine groep, aangezien het bekend is dat $\mathrm{HOCl}$ erg reactief is richting thiol groepen. $0 \mathrm{~m}$ GST in lysaat van humane erytrocyten (de belangrijkste vorm van GST in erytrocyten is GST P1-1) te remmen zijn hogere concentraties HOCl nodig in vergelijking met gezuiverd GST P1-1. Dit kan worden verklaard door de aanwezigheid van GSH en thiol bevattende eiwitten die ook kunnen reageren met $\mathrm{HOCl}$.

\section{Implicaties}

De effecten van de verschillende vormen van vitamine $\mathrm{E}$ op GSH-afhankelijke enzymen kunnen meerdere implicaties hebben.

Zoals beschreven in hoofdstuk $3, \operatorname{kan} \alpha$-tocoferol quinon werken als een pro-oxidant: in de GSH-afhankelijke bescherming tegen lipide peroxidatie, indien de $\alpha$-tocoferol concentratie laag is. Een ander nadelig effect van $\alpha$-tocoferol is de indirect carcinogene werking die kan optreden door remming van GST P1-1 activiteit (hoofdstuk 4). Naast het gebruik van vitamine $E$ als voedingsingrediënt of als supplement, bevatten verscheidene moderne cosmetische producten relatief hoge concentraties vitamine $E$. Bekend is dat GST $P_{1}-1$ aanwezig is in de huid. Met het oog op deze punten is het van belang op te merken dat muizen zonder GST P1-1 een verhoogd risico hebben op het ontwikkelen van huidkanker en dat er is aangetoond dat vita- 
mine $E$ een tumor promoter kan zijn in de huid varn de muis. De, in onze studie gevonden (hoofdstuk 4 ), potente GST P1-1 remming door $\alpha$-tocoferol suggereert dat dit promoter effect veroorzaakt kan zijh door GST P1-1 remming. De meeste cosmetische producten bevatten vitamine $E$ in de veresterde vorm van tocoferol. Deze veresterde producten zijn eveneens potente remmers van GST P1-1. 0ok tocotrienolen kunnen op deze manier indirect carcinogeen werken (hoofdstuk 6).

In hoofdstuk 5 wordt een risicoschatting beschreven voor dermale applicatie van vitamine E bevattende producten. Gebaseerd op de aannames, dat alle tocoferol de epidermis bereikt en dat de concentratie in de epidermis éen tiende deel is van de concentratie in het cosmetische product, kan er worden geconcludeerd dat een concentratie van $0,0005 \%$ tocoferol ester in het product, genoeg kan zijn om een concentratie van $10 \mu \mathrm{M}$ (remt GST P1-1 met meer dan 50\%) veresterd vitamine $\mathrm{E}$ in de epidermis te bereiken. In cosmetische producten kunnen concentraties tot $1 \%$ vitamine $\mathrm{E}$ worden gevonden. Dit indiceert dat applicatie van een vitamine $\mathrm{E}$ bevattend product op de huid waarschijnlijk kan resulteren in substantiële remming van GST P1-1, met mogelijk nadelige gevolgen.

In sommige gevallen kan echter de remming van GST ook woordelig zijn (hoofdstuk 7/8). Tumor cellen brengen bepaalde isoenzymen tot expressie, in het bijzonder GST P1-1. Dit leidt tot resistentie tegen cytostatica door GSH conjugatie met de actieve metabolieten. Remming van GST activiteit kan de effectiviteit van chemotherapeutica verhogen. Met dit doel worden stoffen ontwikkeld die GST remmen en gebruikt kunnen worden als toevoeging in kankertherapie.

Verder is bekend dat GST P1-1 kan werken als bewaker van c-Jun $\mathrm{NH}_{2}$-terminaal eiwit kinase (JNK) in normaal groeiende cellen. GST kan dienen als sensor voor intramoleculaire veranderingen in redox potentiaal die worden veroorzaakt door verschillende vormen van stress. Hoofdstuk 8 laat zien dat HOCl de GST P1-1 activiteit kan remmen. Hierdoor verandert waarschijnlijk de conformatie van GST P1-1 waardoor de fosforylatie van Jun door JNK wordt aangestuurd. Dit kan resulteren in veranderingen in cel cyclus, DNA herstel of apoptose. Overfosforylatie van Jun kan de cel proliferatie verhogen en uiteindelijk leiden tot apoptose (hoofdstuk 2/8).

Remming van GST P1-1 door vitamine $E$ vitameren geeft ook conformatie veranderingen in het GST molecuul (hoofdstuk 6), hoewel deze veranderingen anders zijn dan de veranderingen die worden geïnduceerd door HOCl. Waarschijnlijk kan vitamine E ook werken als bewaker van JNK. 


\section{Dankwoord}

De afgelopen vier jaar heb ik met veel plezier aan mijn promotieonderzoek gewerkt. Tijdens deze vier jaar is mij duidelijk geworden dat je promoveren niet alleen doet. Tot besluit wil ik daarom de mensen bedanken die direct of indirect hebben bijgedragen aan de totstandkoming van dit proefschrift.

Mijn promotor, Prof. dr. A. Bast, beste Aalt, allereerst wil ik je bedanken voor de kans die je me hebt gegeven om dit onderzoek uit te voeren. Verder wil ik je bedanken voor de inhoudelijke begeleiding en je enthousiasme dat je altijd weer op mij wist aver te brengen.

Mijn twee co-promotores, Dr. Ir. C.T.A. Evelo en Dr. G.R.M.M. Haenen. Beste Chris, tijdens mijn stage wees jij me op de magelijkheden van een AIO-plek binnen de afdeling Farmacologie en Toxicologie. Daarvoor allereerst hartelijk bedankt. Gedurende mijn AIO-periode heb je me op een zeer fijne manier begeleid. Het oprichten van je eigen afdeling halverwege mijn project weerhield je er zelfs niet van om actief bij mijn onderzoek betrokken te blijven. Bedankt dat je tijdens deze drukke periode tijd voor me hebt weten vrij te maken. Beste Guido, bedankt voor alle adviezen, discussies en hulp bij het uitvoeren van de experimenten. Tevens wil ik je bedanken voor de kritische, soms zeer gedetailleerde beoordeling van alle manuscripten. Uiteindelijk werden ze er wel beter van, wat ook blijkt uit het feit dat ze allemaal geaccepteerd werden.

De mensen van het lab waarmee ik gedurende de afgelopen jaren heb gewerkt. Mijn collega AIO's, Mariken, Gertjan, Chantal, Agnes, Gudrun en Bashir en de analisten Marc en Leo. Zonder jullie zou het vele labwerk vaak erg eentonig zijn geweest. Bedankt voor de gezelligheid in en rondom het laboratorium en voor de vaak nuttige (en soms zeer zinloze) tips. Zonder jullie zou deze AIO-periode voor mij veel meer stress hebben opgeleverd.

Ook de overige mensen van de capaciteitsgroep Farmacologie en Toxicologie wil ik bedanken voor de leuke en leerzame jaren. Een speciaal woord van dank gaat uit naar de secretaresses Els en Mia. Bedankt voor de vele administratieve activiteiten waarmee ik altijd bij jullie terecht kon.

Studenten, John en Miguel bedankt voor de vele proeven (beschreven in hoofdstuk 5) die jullie in korte tijd voor mij hebben uitgevoerd. 
De mensen van de capaciteitsgroep Gezondheidsrisico Analyse en Toxicologie wil ik bedanken voor het feit dat jullie me altijd hebben geholpen met de experimenten die ik heb uitgevoerd op jultie lab. Ook wil ik jullie bedanken voor de goede sfeer die altijd aanwezig was in onze Noordvleugel.

Mijn paranimfen, Manon en Chantal bedankt dat jullie voor de nodige ontspanning hebben gezorgd tijdens de afgelopen spannende periode en dat jullie achter me willen staan tijdens de verdediging van mijn proefschrift.

Harriet Kierkels, hartelijk bedankt voor de uiteindelijke vormgeving van het proefschrift en voor je hulp bij het ontwerpen van de omslag. Je hebt me heel wat werk uit handen genomen.

Mijn sponsoren, DSM Research, Technomed Europe, Dr. Ir. Van de Laar stichting en Ras Optiek, bedankt voor de financiële bijdrage voor het drukken van dit proefschrift.

De leden van de beoordelingscommissie, Prof. dr. F.J. van Schooten, Prof. dr. T.W.A. de Bruin, Prof. dr. M.P. van Dieijen-Visser, Prof. dr. D.C.M. Leysen en Prof. dr. G.J. Mulder wil ik bedanken voor het beoordelen van mijn proefschrift.

Last but not least, mijn ouders en Marc. Pap en mam, bedankt dat jullie altijd voor me klaar staan en dat jullie altijd in mij geloofd hebben. Marc, ook al wist je niet altijd waar ik me overdag mee bezig hield, je hebt me altijd gesteund en je wist me altijd weer gerust te stellen als ik het even niet meer zag zitten. Zeker niet vanzelfsprekend is de steun, het begrip en de liefde die ik altijd van jullie krijg.

Allemaal hartelijk bedankt!

Rachel 


\section{Curriculum Vitae}




\section{Curriculum vitae}

Rachel van Haaften werd geboren op 10 augustus 1976 in Geleen. In 1988 begon zij aan haar VW0-opleiding aan de Albert Schweitzer Scholengemeenschap in Geleen waar zij in 1994 haar diploma behaalde. In datzelfde jaar begon ze haar studie Gezondheidswetenschappen met als afstudeerrichting Biologische Gezondheidkunde aan de Rijksuniversiteit Limburg (tegenwoordig Universiteit Maastricht) te Maastricht. Tijdens haar studie rondde zij twee stages af. De eerste stage vond plaats binnen de capaciteitsgroep Gezondheidsrisico Analyse en Toxicologie aan de Universiteit Maastricht, onder begeleiding van Dr. G. Hageman en Prof. dr. F.J. van Schooten en de tweede stage vond plaats binnen de capaciteitsgroep Farmacologie en Toxicologie, sectie Humane Toxicologie aan de Universiteit Maastricht, onder begeleiding van Dr. Ir. C.T.A. Evelo en Prof. dr. A. Bast. In 1999 werd het doctoraaldiploma behaald. Vanaf 1 februari 1999 was zij werkzaam als assistent in opleiding bij de capaciteitsgroep Farmacologie en Toxicologie, sectie Humane Toxicologie, onder begeleiding van Dr. Ir. C.T.A. Evelo, Dr. G.R.M.M. Haenen en Prof. dr. A. Bast. Het onderzoek uitgevoerd tijdens deze periode is beschreven in dit proefschrift. Tijdens deze periode voltooide zij tevens de opleiding tot Toxicoloog. Vanaf 1 februari 2003 is Rachel werkzaam als Postdoc bij de afdeling BiGCaT Bioinformatica, Universiteit Maastricht en Techmische Universiteit Eindhoven. 
List of publications 


\section{List of Publications}

Articles:

R.I.M. van Haaften, C.T.A. Evelo, G.R.M.M. Haenen and A. Bast. No reduction of $\alpha$ tocopherol quinone by glutathione in rat liver microsomes. Biochemical Pharmacology, 61, p715-719, 2001.

R.I.M. van Haaften, C.T.A. Evelo, G.R.M.M. Haenen and A. Bast. $\alpha$-Tocopherol inhibits human glutathione S-transferase P. Biochemical and Biophysical Research Communications, 280, p631-633, 2001.

R.I.M. van Haaften, C.T.A. Evelo, J. Penders, M.P.F Eijnwachter, G.R.M.M. Haenen and A. Bast. Inhibition of human glutathione S-transferase P1-1 by tocopherols and $\alpha$-tocopherol derivatives. Biochimica et Biophysica Acta, 1548, p23-28, 2001.

R.I.M. van Haaften, G.J.M. den Hartog, C.T.A. Evelo, G.R.M.M. Haenen and A. Bast. Hypochlorous acid is a potent inhibitor of GST P1-1. Chemico-Biological Interactions, 138(1), p77-83, 2001.

R.I.M. van Haaften, G.R.M.M. Haenen, C.T.A. Evelo and A. Bast. Tocotrienols inhibit human glutathione S-transferase P1-1. IUBMB Life, 54, p1-4, 2002.

R.I.M. van Haaften, G.R.M.M. Haenen, P.J. van Bladeren, J.J.P. Bogaards, C.T.A. Evelo and A. Bast. Inhibition of various glutathione S-transferase isoenzymes by RRR- $\alpha$-tocopherol. Toxicology in Vitro, 2003.

R.I.M. van Haaften, G.R.M.M. Haenen, C.T.A. Evelo and A. Bast. Effect of vitamin E on glutathione-dependent enzymes. Submitted (Drug Metabolism Reviews).

\section{Abstracts}

R.I.M. van Haaften, C.T.A. Evelo, G.R.M.M. Haenen and A. Bast. No reduction of $\alpha-$ tocopherol quinone by glutathione in rat liver microsomes. A posisible prooxidant effect of $\alpha$-tocopherol quinone. In: Abstractbook of : A meeting of the Society for Free radical Research (Europe). Liverpool, July 2000.

R.I.M. van Haaften, C.T.A. Evelo, G.R.M.M. Haenen and A. Bast. Inhibition of glutathione S-transferase by $\alpha$-tocopherol. In: Proceedings of the scientific meeting of the Netherlands Society of Toxicology. Kerkrade, December 2000. 
R.I.M. van Haaften, C.T.A. Evelo, G.R.M.M. Haenen and A. Bast. $\alpha$-Tocopherol inhibits human glutathione S-transferase P. In: Abstractbook of: 2001 World Congress of the Oxygen Club of California. Santa Barbara, California, March 2001.

R.I.M. van Haaften, C.T.A. Evelo, G.R.M.M. Haenen and A. Bast. Vitamin E: Antioxidant or carcinogen. Vitamin E inhibits human glutathione S-transferase P1-1. In: Proceedings of the scientific meeting of the Netherlands Society of Toxicology. Nijmegen, November 2001.

R.I.M. van Haaften, C.T.A. Evelo, G.R.M.M. Haenen and A. Bast. Inhibition of glutathione S-transferase by vitamin E. In : Proceedings of the Jung Chemiker Forum. Aachen, 2002.

R.I.M. van Haaften, C.T.A. Evelo, G.R.M.M. Haenen and A. Bast. Inhibition of glutathione S-transferase by vitamin $\mathbb{E}$. Seminar of the European Graduate School. Maastricht, november, 2002. 